\title{
Knee immobilization : techniques and evaluation
}

Citation for published version (APA):

Veldhuizen, J. W. (1995). Knee immobilization : techniques and evaluation. [Doctoral Thesis, Maastricht University]. Datawyse / Universitaire Pers Maastricht. https://doi.org/10.26481/dis.19950609jv

Document status and date:

Published: 01/01/1995

DOI:

10.26481/dis.19950609jv

Document Version:

Publisher's PDF, also known as Version of record

\section{Please check the document version of this publication:}

- A submitted manuscript is the version of the article upon submission and before peer-review. There can be important differences between the submitted version and the official published version of record.

People interested in the research are advised to contact the author for the final version of the publication, or visit the DOI to the publisher's website.

- The final author version and the galley proof are versions of the publication after peer review.

- The final published version features the final layout of the paper including the volume, issue and page numbers.

Link to publication

\footnotetext{
General rights rights.

- You may freely distribute the URL identifying the publication in the public portal. please follow below link for the End User Agreement:

www.umlib.nl/taverne-license

Take down policy

If you believe that this document breaches copyright please contact us at:

repository@maastrichtuniversity.nl

providing details and we will investigate your claim.
}

Copyright and moral rights for the publications made accessible in the public portal are retained by the authors and/or other copyright owners and it is a condition of accessing publications that users recognise and abide by the legal requirements associated with these

- Users may download and print one copy of any publication from the public portal for the purpose of private study or research.

- You may not further distribute the material or use it for any profit-making activity or commercial gain

If the publication is distributed under the terms of Article $25 \mathrm{fa}$ of the Dutch Copyright Act, indicated by the "Taverne" license above, 
Knee Immobilization: Techniques and Evaluation 


\section{CIP-DATA KONINKLIJKE BIBLIOTHEEK, DEN HAAG}

\section{Veldhuizen, Jan Willem}

Knee immobilization : techniques and evaluation / Jan

Willem Veldhuizen. - Mastricin : Universitaire Pers

Matastricht - III.

Thesis Rijksuniversiteit Limburg Maastricht. - With ref. With summary in Dutch.

ISBN $90-5278-191-5$

Subject headings: knee immobilization / knees ; functional tests 


\section{KNEE IMMOBILIZATION Techniques and Evaluation}

\section{PROEFSCHRIFT}

ter verkrijging van de graad van doctor aan de Rijksuniversiteit Limburg te Maastricht, op gezag van de Rector Magnificus, Prof.mr. M.J. Cohen, volgens het besluit van het College van Dekanen, in het openbaar te verdedigen op vrijdag 9 juni 1995 om 14.00 uur

door

Jan Willem Veldhuizen

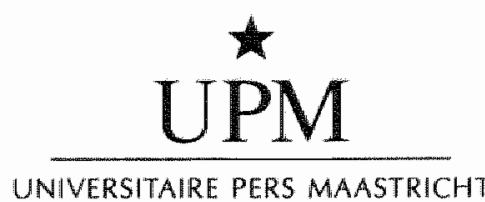




\section{Promotor}

Prof.dr. J.M. Greep

Co-promotor

Dr. F.T.J. Verstappen

Beoordelingscommissie

Prof.dr. A.J. van der Linden (voorzitter)

Prof.dr. H.J. Appel (German Sport University, Keulen)

Prof.dr. A. Huson

Prof.dr. H. Kuipers

Prof.dr. J.W.J.L. Stapert 
voor Joke, Vera en Inge 



\section{Contents}

1 Introduction.

2 Isokinetic aerobic power testing.

(submitted for publication Med Sci Sports Exerc)

3 The effects of a supportive knee brace on leg performance in healthy subjects.

(Int J Sports Med 1991, 12, 577-580)

4 Effects of cast-bracing of the knee on physical performance in healthy subjects.

(Int J sports Med 1994, 15, 520-524)

5 Functional and morphological adaptations following four weeks of knee immobilization.

(Int J Sports Med 1993, 14, 283-287)

6 Transposition of the semitendinosus tendon for early repair of medial and anteromedial laxity of the knee.

(Injury 1989, 20, 29-31)

7 General discussion.

8 Summary and conclusions.

9 Samenvatting en conclusies.

Dankwoord

Curriculum Vitae 



\section{Chapter 1}

\section{Introduction}

1.1 General introduction

1.2 Epidemiology of knee injuries

1.3 Instability

1.3.1 Mechanical instability

1.3.2 Testing mechanical instability of the knee

1.3.3 Functional anatomy

1.3.4 Functional instability

1.4 Treatment of instability

1.4.1 Treatment of mechanical instability

1.4.2 Treatment of functional instability

1.5 Atrophy of the quadriceps muscle after immobilization

1.5.1 Definition of muscle atrophy

1.5.2 Quantifying muscle atrophy

1.5.3 Histology and histochemistry of muscle atrophy

1.5.4 Functional testing of muscle atrophy

1.6 Immobilization techniques

1.6.1 Materials

1.6.2 Techniques

1.7 Aims of the study 


\subsection{General introduction}

The recovery after a knee injury follows the concept of tissue healing. The conditions for healing are: approximation of torn structures, sufficient healing time, clearance of debris and supply of nutrients. From a historical point of view' 'rest' of the injured extremity is generally advised. Immobilization provides this "rest'. Besides to the potentially beneficial effect of immobilization there is also a deleterious effect on the surrounding tissues resulting in atrophy and dystrophy. This tissue degeneration can be observed in cartilage $(49,52,137,214)$, tendons and ligaments $(2,3,23,66,138$, $169,202,239)$, bone-tendon and bone-ligament junctions $(125,169,214)$, and bone $(119,136,141)$. It also causes capsular and pericapsular contractures $(49,137,251)$. The speed and the extent of these unwanted adaptations are tissue specific. Muscular tissue reacts more quickly to inactivity than other tissues. Because of the large muscle mass and its reactivity thigh muscle atrophy is clearly observable, in contrast to the changes in ligaments and tendons. Especially the vasti muscles of the m. quadriceps are susceptible to the harmful effects of immobilization, more than other muscles around the knee joint $(91,142,242)$. This has serious implications for the patient with a knee injury. Coordination and strength of the thigh muscles play a major role in the stability of the knee during all leg activities in human life $(84,147,188,204)$. Especially sporting activities characterized by 'cutting-movements' confront the patient with a deficit in the thigh muscle function $(71,208)$. Thus immobilization of an extremity after trauma has serious side effects on healthy surrounding tissues caused by the imposed inactivity. Besides to the consequences for the injured individual, the surgeon also must consider the socio-economical effects such as costs of medical treatment and loss of labor (146). Therefore more attention is given to early active rehabilitation after a knee injury to prevent muscle atrophy $(51,210,222)$. This stresses the importance of research concerning the different current therapeutic immobilization techniques and the evaluation of measurement of the knee and quadriceps function. The next parts of the introduction will give an overview of the literature on the following subjects: (in-)stability (epidemiology, signs and symptoms, treatment), quadiceps atrophy and immobilization techniques. This will give a better understanding of the aims of the investigations in this thesis.

\subsection{Epidemiology of knee injuries}

Accidents in and around the house are the most frequent causes of injuries (26\%), followed by accidents at work (19\%) and in sports (17\%). In men $11 \%$ of all sports injuries are sprains of the knee. A knee injury is the most expensive type of injury $(145,146)$. Several sports are mentioned in literature as having a high incidence of knee injuries; American football, soccer, downhill skiing, and ice hockey. However, 
it is obviously difficult to compare the injury profiles of various sports because of differences in injury-reporting strategies $(174,240)$.

In the Dutch population $8.7 \%$ of all sports injuries involve the knee (223). Soccer is the most popular sport in the Netherlands. Swedish research shows that the injury risk from playing soccer in adults is 7.6 injuries per 1000 training hours and $16.9 \%$ in matches. Twenty percent of all soccer injuries involve the knee (48). In $S$ weden soccer is responsible for $58 \%$ of all knee injuries in men and of $27 \%$ of the knee injuries in women. The majority of serious soccer injuries in men consist of knee injuries (145).

The type of knee injury depends on the mechanism of injury and therefore to some extent on the type of sports, but also on age and gender (40). Of all knee injuries in skiing $60 \%$ involve the ACL (55), while the majority of knee injuries in American football involve the $\mathrm{MCL}(76,96,195,228)$. Isolated injuries of the $\mathrm{MCL}$ are seldom observed, most injuries are combined lesions. Meniscal pathology is found in 86-89\% of all patients presented with a chronic ACL lesion $(131,241)$. Recent MR imaging studies have shown that an ACL rupture is often associated $(80 \%)$ with subchondral lesions (bony bruises) (221). Injuries to the PCL have a much lower incidence rate. The most common causes are sports-related trauma and motor-vehicle accidents (115).

\subsection{Instability}

\subsubsection{Mechanical instability}

An injury to the passive stabilizers results in mechanical instability. Especially ruptures of the ACL and the combined injuries of the ACL lead to instability, since the ACL will not heal spontaneously $(4,16,18,116,171)$. Although the ACL plays only a limited role in the control of the passive stability of the knee (149), a complete rupture may result in early or late functional complaints and complications $(16,18,59$, 184). Noyes showed that a large number $(82 \%)$ of patients with an ACL rupture resumed their sports activities at first, but within two years $51 \%$ suffered a reinjury and five years after the initial injury only $35 \%$ still participated in strenuous sports (170). Also more optimistic results are reported (154). Isolated injuries of the PCL usually do well when treated nonoperatively $(61,182)$, while combined injuries do not (234). Injuries to the collateral ligaments do tend to heal, al though the quality of the scar may never reach normal ligament characteristics (63).

The active stabilizers can to some extent compensate for instability due to disfunction of the passive stabilizers. Extensive thigh muscle atrophy on the other hand will Jead to dynamic instability even in the presence of normal passive stability. Due to the abnormal motion in the chronically unstable knee, especially with concomitant 
meniscectomy, the remaining ligaments and active stabilizers are stressed more. This can be observed as muscle hypertrophy e.g. of the hamstrings. It can also result in a situation of wear and tear with pain, recurrent effusion, possible cartilage and meniscal damage and finally osteoarthritis $(16,41,59,155,166,170,171)$.

\subsubsection{Testing mechanical instability of the knee}

Testing the stability of the knee is limited to the examination of the passive stabilizers. The injured side is compared with the uninjured side. Most studies show consistent symmetry $(38,254)$, however, differences between the left and right knee for laxity and stiffness are reported in uninjured people (150). Various tests are used to show different types of instability (single ligament, combination of ligaments or combinations with capsular structures and iliotibial tract). The tests used are: valgus-varus testing in full extension and in $20^{\circ}$ flexion position, drawer sign in neutral position and endo- and exorotation, the posterior drawer test, the Lachman test and the pivot shift test $(58,105,129,213,233)$. Tests are combined to obtain a complete view of the injuries to the passive stabilizers (103). The specificity of these tests is limited $(122,175,176,241)$. The specificity is better in isolated lesions and poor in case of two or more lesions, as is seen in about $50 \%$ of all knee injuries (1.78). The sensitivity and specificity in diagnosing knee injuries is improved by examination of the patient under general anesthesia. The diagnostic process is preferably completed by arthroscopy $(6,36,43,109)$.

More objective tests, mainly applied for scientific investigations, are instrumental testing devices and radiographic examination of manually or instrumentally stressed knee joints (183). Instrumented testing is practically preferable because it requires no radiology. Some testing equipment is now commercially available (KT-1000/KT2000, Genucom, CALT, KLT). The reproducibility of the measurements and the sensitivity and specificity for ACL lesions are shown in several studies $(6,38,90$, $98,133,197$ ).

Magnetic resonance imaging of the knee can provide useful information after a knee injury. It makes it possible to identify and evaluate the cruciate ligaments, menisci, collateral ligaments, and the cartilage and the subchondral bone $(72,79,144,160)$.

\subsubsection{Functional anatomy}

The poor congruency of the tibiofemoral joint enables a fairly large freedom of motion in this joint. This motion is guided and limited by intra- and extra-articular structures (163). These structures are commonly referred to as active and passive stabilizers.

Muscles as the hamstrings, the quadriceps muscles and less importantly the popliteus muscle are the acrive stabilizers. The passive stabilizers are the joint capsule, the cruciate ligaments, the collateral ligaments, and the menisci, but the iliotibial tract 
can also be considered. This classical distinction between active and passive stabilizers is too simplistic since there are many connections between muscles and ligaments and between ligaments, capsular structures and menisci (224). The muscullature reinforces stability by tightening the contact between the joint surfaces and by the dynamisation of the passive stabilizers $(147,188)$. The interaction between the active and the passive stabilizers depends on intact proprioception.

The term instability referres to either mechanical instability or funcrional instability. Mechanical instability is the result of loosening of the joint due to disfunction of either the passive stabilisers or the active stabilizers. Functional instability is the feeling of instability as described by the patient.

\subsubsection{Functional instability}

In the acute knee injury symptoms of pain, haemarthros, joint effusion and inability to move predominate. In a chronic phase the patients primary complaint is instability, resulting in episodes of pain, joint effusion and disability $(59,148,155,170,184)$. The patient describes this instability as a feeling of giving-way. Falling or loss of body support is reported with various physical activities, because of an unexpected collapse of the affected knee, not precipitated by pain, locking, or weakness. Pain, joint effusion and soft tissue swelling will subside over 7-10 days. If pain and swelling last longer, or the symptoms are caused by a specific trauma, the accident is considered to be a reinjury. Giving-way is generally associated with chronic ACL-deficiency.

The degree of functional disability caused by a knee injury can be assessed by means of functional scoring scales. Such scoring scales are made up of subjective complaints (148), complaints in relation to the activity level (226), or complaints and tests of joint laxity at physical examination (151). Functional tests are also used to assess the function of the knee after an injury. Two-leg tests, figure-of-eight test, and the stairs-running test can provide information on daily function. One-leg tests, the triple jump test, and the new stairs hopple are correlated to knee instability (192). Posttraumatic functional instability has a variety of causes. Careful questioning about symptoms and examination of the knee can lead to one of the following underlying mechanisms of functional instability:

- mechanical instability

- disfunction of the passive stabilizers

- disfunction of the active stabilizers

- impaired proprioception

- pain

- locking

- psychogenic factors

Mechanical instability due to ACL-deficiency is often combined with disfunction of the active stabilizers. Muscle atrophy is especially seen in the quadriceps muscle. 
The hamstrings are generally less affected $(86,170,225,231)$. Muscle atrophy has serious effects on knee function as measured with functional scores. A training program to increase muscle strength in these patients can result in better functional scores $(12,208,225,227)$. There is, however some evidence that mechanoreceptor activity in the joint capsule in ACL-deficient knees results in reflex inhibition of the quadriceps (216).

Mechanoreceptors have been identified in the cruciate ligaments $(128,205,206)$, capsule, collateral ligaments (132), and menisci (256). With the muscle mechanoreceptors (muscle spindles) they account for the joint proprioception, defined as the extraction of any information regarding body position and movement (97). Proprioception was found to be impaired in the ACL-deficient knee $(17,20)$. The clinical relevance of this finding remains uncertain, but it is suggested that the impaired proprioceptive function contribute to the complaints of functional instability (132). Meniscal tears will also affect the motor control in submaximal activities (44). Many complaints of functional instability after knee injury are of patellofemoral origin. Acute pain inlhibits muscle function and subsequently results in loss of body support. Patellofemoral pain, often called Anterior Knee Pain, is thought to be caused by patellofemoral instability due to atrophy of the quadriceps muscle. Also (traumatic) chondromalacia and overuse are major causes for patella-femoral complaints $(65,104)$.

Locking can also cause functional instability. Locking is the result of impingement of remnants of a ruptured ACL, a lose body or a meniscal tear. Locking often results in joint effusion.

Next to the physical causes of functional instability psychogenic factors may play a role. Many patients are anxious to use their knee after injury. In the past surgeons stimulated this fear prescribing long-lasting immobilization for the healing of the ligamentous repair. Functional treatment regimens overcome immobilization and overprotection of ligamentous repairs. On the other hand the patient may suffer more pain during early mobilization. This may interfere with effective early mobilization (13). In a patient, who is mentally sensitive to pain, a cascade of pain, immobility, muscle atrophy, functional instability and as a result more pain will occur (51).

\subsection{Treatment of instability}

\subsubsection{Treatment of mechanical instability}

The aim of treatment of knee ligament injuries is to restore the stability. For most surgeons this means restoration of the passive stabilizers. This is best achieved through anatomical reconstruction of the injured structures (179). However, various tissue structures like the cruciate liganents cannot be reconstructed easily. Healing 
of collateral ligaments can last a long time. Moreover, surgical exploration of the injured structures may lead to substantial damage. Next to ligamentous reconstruction thigh muscle rehabilitation and restoration of coordination are important parts of the treatment of knee ligament injuries.

\section{Cruciate ligaments}

The natural course of ACL lesions is unfavorable, and an ACL lesion is called 'the beginning of the end of the knee'. This clinical observation has led to the development of reconstructive surgical procedures. It is thought that operative reconstruction of the ACL can reduce the complaints and increase the level of activity, and can also reduce the risk for secondary osteoarthritis (59). Several extra-articular repairs for the treatment of cruciate ligament ruptures have been advocated in the past $(62,93$, 213) next to simple suturing or reinsertion (179). Both good (152) and poor results of these procedures $(54,64)$ are reported. Nowadays it is accepted that primary repair of an intrasubstance tear of a cruciate ligament is inferior to reconstruction. By the introduction of arthroscopic reconstructive surgery, it is possible to reduce the surgical damage and achieve better anatomical reconstruction under direct vision $(26,31,110,173,189)$. The major problem still to solve is to find the optimal material for replacement of the cruciate ligament. Some prostheses are not able to withstand the forces applied to the ligament eventually $(19,70,78,173,245)$. Rejection phenomena are also reported (8). Patellar bone-tendon-bone autografts, allografts and augmented prosthetic replacements are the most promising so far $(1,30,37,112$, $117,140,158,172,193,194,199,211)$.

\section{Collateral ligaments}

An injury to the collateral ligaments can heal spontaneously. The conditions for healing seem to be adequate approximation, limited stress on the ligament and sufficient time to heal. In theory healing requires longstanding immobilization. Animal experiments in MCL-healing show that the biomechanical properties of the healing ligament are inferior even after 40 weeks (63). Exposure of the ligament to limited stretching and movement (74) and surgical approximation (32) improve the quality of healing, with better organized collagen structure. Similar findings were reported for the LCL (180). Therefore, there are three possibilities of treatment for collateral ligament ruptures:

1) cast-immobilization $(112,198)$

2) partial immobilization to restrict unwanted range of motion, but permitting beneficial tissue stress through motion $(107,118,161,207,227)$

3) surgical treatment through an anatomical or extra-anatomical reconstruction $(57,102,198)$ 
All treatment regimens will eventually result in an almost complete restoration of function.

\section{Muscle rehabilitation}

Thigh muscles play an important role in knee joint stability. Quadriceps activity reduces the strain produced on the $\mathrm{MCL}$ and reduces the anterior-posterior translation when the knee is stressed $(73,235,243)$. Hamstring activity reduces strain on the ACI (191). It is also stated that the gastrocnemius muscle is also a primary stabilizer of the knee in case of ACL-deficiency $(139,249)$. Disfunction of the passive stabilizers can partially, or even completely, be compensated for by well-balanced support of the active stabilizers $(12,71,171,225,227,238)$. An ACL-deficient knee can be asymptomatic.

There is discussion concerning the method of muscle rehabilitation after cruciate ligament injury or surgery. Especially the isokinetic training programs prove to be efficient and effective (232). Such exercises will induce strain on the ACL, but the clinical relevance of this phenomenon seems limited (101). Axial loading, on the other hand, will limit anterior tibial displacement. Therefore, squat exercises are the safest way to train the thigh muscles after an $\mathrm{ACL}$ injury $(162,252)$. Based on theoretical, biomechanical considerations some authors stress the importance of training the hamstrings, since they work synergistically with the ACL to prevent anterior displacement of the tibia on the femur $(7,71,124,162,191,218,219,231,238)$.

\subsubsection{Treatment of functional instability}

The treatment of functional instability does not consist of a ligamentous reconstruction alone. Not all patients with ligamentous instability suffer from giving-way. Good $(71,154,184,198)$ and poor $(4,18,59,170)$ results of functional treatment are reported in studies comparing operative and nonoperative treatment of ACL ruptures. Therefore, the treatment of ACL ruptures is still discussed among surgeons (116). The outcome of treatment can be improved by ruling out and treating the other causes of functional instability: locking or clenching, muscular atrophy, Anterior Knee Pain Syndrome, impaired proprioception, and psychogenic factors. This means that after initial diagnosis and treatment an adequate effort is put in muscular rehabilitation. A training program of 6-12 weeks is usually effective to improve the muscle condition. Quadriceps strengthening is also recommended for all patients with Anterior Knee Pain, leading to recovery in most cases (126).

The value of specific proprioceptive training in case of ligamentous lesions of the knee has not been well established so far, although its popularity is growing and satisfying results have been reported in some patients even after ACL reconstruction $(33,255)$. Closed Kinetic Chain Functional Training is a method that allows for 
task-specific application, speed/intensity manipulation, and incorporation of these motor learning concepts (177).

Patients trapped in the spiral of pain, fear and muscular arrophy should be given an intensive, supervised rehabilitation schedule. In these patients operative treatment of ligamentous lesions is not the first choise of treatment.

The problems described above lead to the following treatment schedule in patients suffering from complaints of functional instability of the knee after a ligamentous lesion. The patient should undergo an arthroscopy with stability testing under anaesthesia. Locking as a cause of functional instability can be delt with at athroscopy. Additionally isokinetic muscle strength testing is recommended. Next a treatment schedule should be instituted with emphasis on regaining the strength and coordination of the thigh muscles. The patient should learn to deal with mechanical instability (135). Bracing a knee for a given period or for certain stressfull events (eg. sports) is a useful part of the nonoperative treatment $(185,212)$. Operative treatment is considered when this rehabilitation fails and the patient is significantly impaired $(26,170,171)$.

\subsection{Atrophy of the quadriceps muscle after immobilization}

\subsubsection{Definition of muscle atrophy}

Muscular function depends on intact innervation, mechanical loading, mobility of the joints, and adequate blood supply for nutrients and oxygen. Deterioration of any of these factors will result in an adaptation of muscle tissue known as muscle atrophy. Muscle atrophy is defined as shrinking of muscle fibers because of diminished intracellulair substance. The term atrophy should be used descriptively to denote a decrease in size and not, like degeneration to denote dynamic mechanisms responsible for adverse cellular reactions (34). Atrophy is commonly seen as a physiological reaction to sub-optimal conditions, or changes in conditions such as denervation, inactivity or malnutrition.

\subsubsection{Quantifying muscle atrophy}

The most informative way to evaluate muscle atrophy in vivo in humans is the microscopical analysis of biopsy specimens. This enables the measurement of the fiber diameter, and permits histological and histochemical evaluation of atrophy in different muscle fiber types. Measurement of fiber cross sectional area, however, is not free of errors. These errors include muscle cuts not made perpendicularly to the muscle fibers as well as alterations in fiber size caused by fixation and staining procedures. 
The macroscopical evaluation of muscle atrophy includes techniques such as Computer Tomography (CT), Ultrasound, and Magnetic Resonance Imaging (MRI). These techniques allow differentiation between large muscle groups (e.g. hamstrings and quadriceps), bone, and subcutaneous fat $(108,253)$. They cannot discriminate between different muscle fiber types, nor between the relative changes in intramuscular substance as the connective tissue fraction and fat tissue. This includes an error in the evaluation of true muscle atrophy considering that intramuscular connective tissue increases with immobilization $(34,92,120,247)$.

The thigh circumference is generally used in medical practice as a measure for muscle atrophy. Next to the shortcomings as mentioned for the other macroscopical evaluation techniques, it cannot differentiate between quadriceps and hamstrings, and muscle tissue and subcutaneous fat. Since subcutaneous fat increases with immobilization (86), and considering that the measurement of thigh circumference is not very reliable and reproducible, this method is obviously only a rough estimate (11).

\subsubsection{Histology and histochemistry}

Muscle tissue has a high metabolic rate and adjusts specifically to different functional demands. In case of immobilization this results in atrophy. The fiber diameter decreases, and there is an increase of intramuscular connective tissue, both endomysially and perimysially (120,121). Capillary blood supply is impaired due to the increased intramuscular connective tissue, but also due to a decreased capillary density $(34,120)$. In animal experiments also more dramatic effects are observed such as fiber disruption and fiber splitting (34), and fiber necrosis (9). Also fiber regeneration takes place, most likely from satellite cells $(9,10)$. The number and size of mitochondria decrease and mitochondrial damage is observed $(9,34,130)$. Nuclei become irregularly shaped and some are no longer located in the periphery, but in central parts of the fiber (9). There is also an increase in autophagic activity and an increased number of phagocytes $(9,34,120)$. This is not reported in human studies after immobilization.

Biochemical analysis of muscle tissue after immobilization reveals a rapid decrease in protein synthesis $(25,203)$. Muscles with predominantly type I fibers (slow-twitch, oxidative) show a more rapid decrease in protein turnover than muscles with more type Il fibers (fast-twitch, glycolitic) $(120,203)$. Myofibrillar protein mass and concentration decrease (95). Signs of catabolism can be shown after immobilization by a negative nitrogen ballance. Also, the skeletal muscles become diabetic-like with a decreased ability of insulin to stimulate glucose uptake and glycogen synthesis (167). The oxydative enzymatic activity remains the same or decreases. The glycolytic enzyme activity is essentially unchanged. The findings in literature are not completely unanimous concerning changes in energy stores or enzymatic activities (table 1). This is probably due to different measurement techniques, studies in 
Table 1: Effect of immobilization on energy stores and enzymatic activity as reported in different studies (= unchanged values, $\downarrow$ decreased values).

\begin{tabular}{llll}
\hline & Effect & References \\
\hline Energy stores & & & \\
Creatine & $=$ & 77 \\
CP & $\downarrow$ & 24,156 \\
ADP & $=$ & 156 \\
ATP & $=$ & 77,156 \\
& $\downarrow$ & 24 \\
Glycogen & $=$ & 47 \\
& $\downarrow$ & 24,156 \\
Oxidative enzymes & & \\
SDH & $=$ & $45,47,80,82$ \\
Citrate synthetase & $\downarrow$ & $35,88,100$ \\
Glycolytic enzymes & & $14,111,244$ \\
Phosphofructokinase & $=$ & $80,82,88,111$ \\
Phosphorylase & $=$ & 45,47 \\
Lactodehydrogenase & $=$ & $45,77,111$ \\
& $\downarrow$ & 100 \\
\hline
\end{tabular}

different species, different muscles, limited numbers, and inadequate establishment of reference values in studies concerning patients.

A shift in muscle fiber typing toward more type II fibers is reported in some studies $(45,83,87,95,106)$, but these findings are still controversial $(11,106)$. When comparing the results of studies concerning the topics of muscle atrophy, enzymatic activity, and shift in muscle fiber typing, one has to consider the different mechanisms of muscle atrophy and degeneration induced by different methods as immobilization, suspension, tenotomy, and denervation.

The development of muscle atrophy is influenced by different factors:

- duration of immobilization

The rate of atrophy is more pronounced during the first week of immobilization and less after that (9). It is not known if there is a maximum to this decrease. A variety in the degree of muscle atrophy is reported (Figure 1).

- method of immobilization

Immobilization of a leg can be either weight bearing or non-weight bearing. Non-weight bearing immobilization has some resemblance to suspension, and several studies have shown that suspension will allso result in muscle atrophy, but some differences to immobilization are noted (56,91). Immobilization of a leg results in complete or partial immobilization of the individual muscles, i.c. monoversus bi-articular muscles in knee immobilization (142). 


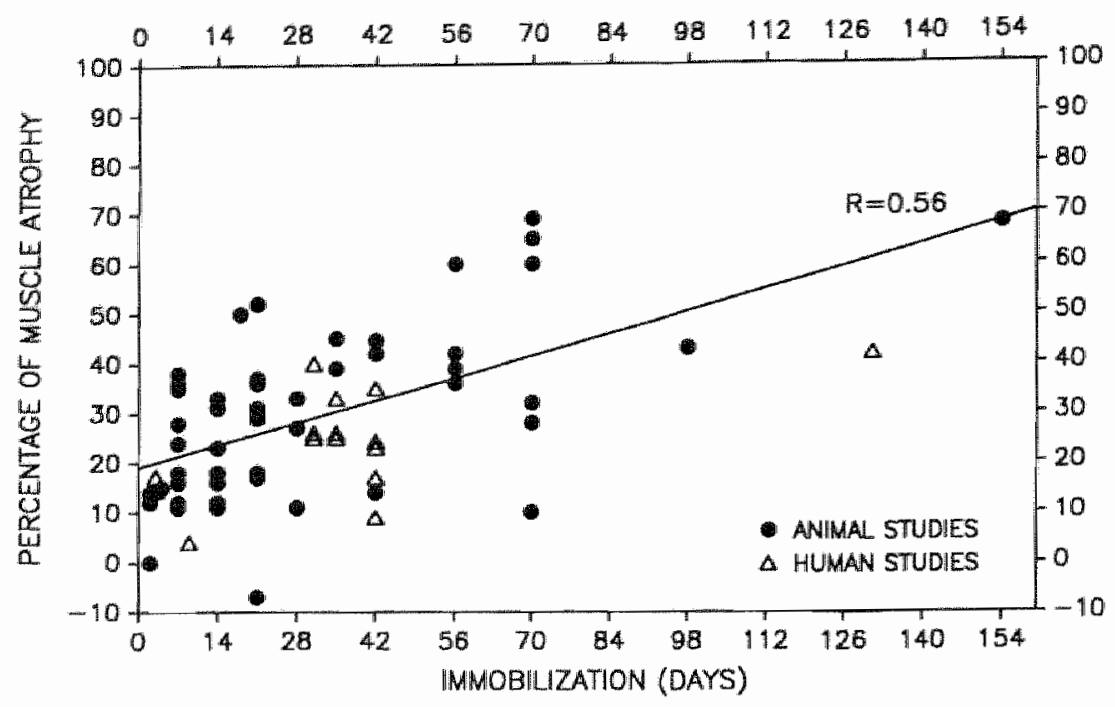

Fig. 1: Immobilization induced muscle atrophy as reported in different studies. (References in figure: $9,14,21,27,28,34,69,77,80,81,82,87,94,95,106,108,142,143,157,159$, $168,186,203,217,244,247)$

- denervation

Denervation results in impressive muscle atrophy, which is different from atrophy induced by immobilization $(34,202)$.

- muscle fiber typing

Muscles with predominantly type I fibers are more sensitive to immobilization $(9,80,81,82,186,201)$. On the other hand, a greater atrophy in type II fibers after immobilization is also reported (47).

- muscle length at immobilization

Immobilization in a shortened position will result in a more pronounced atrophy than immobilization in a lengthened position $(94,203)$.

- preimmobilization state

Well-trained muscles show a lower rate of atrophy (9).

The development of muscle atrophy induced by immobilization can be opposed in different ways:

- isometric contractions (196)

- electrical muscle stimulation $(14,50,69,75,215,244)$.

- adminstration of growth hormone (28).

- administration of calcium entry blocking drugs (217). 
In case of a knee trauma or surgery the following measures can be taken to restrict muscle atrophy:

- partial immobilization techniques (80).

- preimmobilization training $(9,127)$.

- reduction of surgical damage (173).

- limitation of tourniquet application $(68,181)$.

- prevention of joint effusion $(39,53,220)$.

- pain relief by NSAID's (15) or Transcutaneous Neural Stimulation (TNS) (113), although the effectiveness is subject to discussion $(5,165)$.

- Continuous Passive Motion (CPM) $(42,67,209)$.

- Exercise with the contralateral leg (123).

It was shown that muscle atrophy caused by immobilization is fully or nearly fully restored by training. Even fiber regeneration can be observed, probably from satellite cells $(9,10)$. It was also shown that muscles with predominantly type I fibers regenerate quicker than type II muscles (24). The functional recovery after immobilization seems to take about the same period as the immobilization phase itself or longer $(24,60)$. Recovery after trauma or surgery with subsequent immobilization is hindered or delayed by:

- mechanical instability (218)

- joint effusion (53)

- reflex inhibition (216)

- fear resulting in disuse through relative immobility pain.

\subsubsection{Functional testing of muscle atrophy}

Based on its unique contractile properties muscle tissue can develop tension between its origin and insertion. A contraction can be concentric, eccentric, or isometric. The ability to contract gives rise to some measurable parameters of its function, namely strength and endurance. Current research concerning muscle atrophy has focused mainly on concentric muscle strength, being the most obvious ability.

\section{Muscle strength}

Physiological considerations: The contractile behavior of the muscle is best characterized by the force-velocity relation. The highest force can be achieved at lower velocities, and force and maximal work decline with inclining velocity $(99,246)$. The force-velocity relation of a muscle depends on the muscle fiber typing. Muscles with predominantly FT motorunits and muscle fibers can develop a higher torque at high angular velocities, than ST muscles. At lower angular velocities there is no relation between muscle fiber composition and force development (229). Under eccentric loading the muscle is considerably stronger than in concentric or isometric contrac- 
tions. With increasing stretching velocity the eccentric force-velocity relation becomes steeper (46). A muscle can counteract an external force exceeding its isometric maximum force by $40 \%-50 \%$ without considerable lengthening. This enables active shock-absorption under conditions of fast cyclic motion.

Isokinetic dynamometry. With the development of isokinetic dynamometers it is possible to measure torque as a function of angular velocity. Another advantage of the isokinetic dynamometer over isotonic measuring devices is that it allows for optimal loading over the full range of motion. The peak torque (PT; $N m$ ) is the highest torque during a Maximal Voluntary Contraction (MVC). The measurement of PT is thus dependent on the cooperation of the subject, which clearly limits its value. However, a surprisingly high reproducibility of PT is reported $(114,153,230)$.

The Cybex II (Lumex, N.Y.) is a commonly used isokinetic dynamometer. It allows for measurements of the torque at isometric and concentric contractions of muscles around major joints at angular velocities up to $300 \mathrm{deg.} \mathrm{s}^{-1}$. The standard configuration is meant for torque measurements of knee flexion and extension with the subject in sitting position. Applications for measurements of movement in other major joints are available. Isokinetic dynamometry has many pitfalls, which can be divided in subject, protocol, and device errors.

- Subject related problems are due to the fact that PT measurement requires a maximal contraction, which depends on skill and motivation. Sensations of pain can also interfere with PT measurements especially at low angular velocities in patients with anterior knee pain.

- The protocol of PT measurement must give the subject the opportunity to get used to the isokinetic movement before starting the actual measurements. The test protocol must also provide sufficient rest between different tests in the same leg.

- The Cybex II dynamometer does not correct its measurements for the effect of gravity acting on the lever arm and limb. This results in a considerable error in measturements done in the vertical plane, e.g., knee flexion and extension. It is suggested to correct this error by calculating the gravitational torque of the limb-llever arm system based on an actual measurement during passive knee flexion (164), or placement of an accelerometer (248). Another source of error results from overshoot in torque recordings (200).

The test protocol for PT measurement should consist of sufficient training before the actual measurements. It is recommended to perform two preceding training sessions. The subject must be optimally motivated. PT is recorded at different angular velocities because of individual differences in torque-angular velocity curves due to muscle fiber typing, and to evaluate the motivation of the subject. Working with the Cybex II means accepting the overshoot in speed and torque, and either adequate correction for gravity with the use of an accelerometer, or no correction. Without correction for gravitational forces the results of the tests are still valuable for 
left-right, and test-retest comparisons, but useless for intersubject comparisons and hamstring-quadriceps ratio determinations.

Muscle strength in muscular atrophy: Muscle strength decreases significantly after immobilization. The decline in muscle strength is greater than the observed muscle atrophy $(89,157,159)$. However, the number of studies that allow this comparison is limited. The greater decrease in muscle strength than in muscle or fiber diameter is thought to be the result of deterioration in the neural activity of the muscle. This decline in the electrical activity of the muscle at MCV after detraining has been observed in EMG studies $(85,250)$.

\section{Muscular endurance}

Physiological considerations: Endurance is the ability to maintain an isometric contraction, or to continue repeated dynamic contractions, and thus to resist fatigue. There is no consensus to what the parameters of endurance are. The term endurance must therefore be defined carefully within the context of the specific movement patterns and the metabolic and physiological requirements of an activity. Endurance testing refers to the capacities of the various energy transfer systems. The immediate energy system (ATP-CP) is tested by means of very intense exercise of short duration, e.g., the stair-stepping power test. The short-term energy system (anaerobic system) is tested through all-out-exercise with a duration up to three minutes, e.g., Wingate test and Katch test. The isokinetic fatigue tests measuring the decline of PT after a given number of MCV's, or the time in which PT of repeated MCV"s declines to $50 \%$ must also be considered as tests of the anaerobic energy system. Important information about the capacity of the long-term energy system (aerobic system) is provided by the maximall oxygen uptake capacity ( $\mathrm{VO}_{2} \max$ ). This has become the fundamental measurement in exercise physiology. $\mathrm{VO}_{2}$ max can be measured by exercise that activates large muscle groups with sufficient intensity for longer periods. The $\mathrm{VO}_{2}$ max test usually consists of graded exercise untill exhaustion. No such tests for the aerobic energy system of single muscles or muscle groups have been reported.

Endurance testing and muscular atrophy: Traditionally rehabilitation is focused on muscular strength, and the training programs have only little emphasis on endurance (35). This is surprising because it is known that the oxidative enzyme activities decrease after immobilization (see Table 1), but so far no research on the subject of functional effects of immobilization on the aerobic energy system has been reported. Some research is done on the effects of immobilization or injury on the anaerobic energy system showing no effect of shortterm voluntary immobilization (159), and no effect of surgery and subsequent immobilization (89) on fatigue. The dynamic endurance as tested on an one-legged bicycle is reported to be decreased by $27 \%$ in 
operated patients, but not in non-operatively treated patients being immobilized ( 89 ). If can be concluded that the sparse data concerning the effects of immobilization on the anaerobic energy system are not conclusive. The negative effect of immobilization and atrophy on the aerobic energy system is known from changes observed in the oxidative enzymes, but is not yet confirmed by functional measurements.

\subsection{Immobilization techniques}

\subsubsection{Materials}

Originally cotton wrappings sprinkled with plaster were used for the immobilization of limbs. Nowadays, Plaster of Paris is still the most commonly used casting material, but more and more new casting materials are introduced. These are based on polyesters or glassfibers impregnated with polyurethane. Also thermoplastic materials are applied. These new materials are lighter, often waterproof, less vulnerable, and have better X-ray translucency. Disadvantages are the less easy application, and the higher costs. In case of immobilization for longer periods and for special indications, these 'plasterless' casting materials are favoured. Next to the casting materials as mentioned above there are also prefabricated splints for immobilization.

\subsubsection{Techniques}

There are different techniques for immobilization and stabilization of the knee, each with its own indications and rigidity c.q. level of stability:

a) external fixation crossing the joint

b) long leg cast

c) walking or cylinder cast

d) hinged cast-brace

e) knee brace

- rehabilitation

- functional

ad. a) The external fixation crossing the knee joint is solely applied in cases of serious injuries or infections, requiring rigid immobilization and optimal access to the joint.

ad. b) The long leg cast is applied from the toes to the groin, resulting in a nearly rigid immobilization of the knee. Flexion and extension are virtually impossible, but valgus-varus, rotational, and anterior-posterior movements are still possible to a considerable degree (134). Isometric muscle contractions are of course possible, and it must be kept in mind that the bi-articular thigh muscles are also not immobilized. The cast can be made suitable for weight-bearing with a minor application under the foot. 
ad.c) The walking or cylinder cast is a circular cast applied from the malleoli to the groin. The ankle joint remains free. This results in a less rigid immobilization of the knee due to increased activity of the gastrocnemius muscle, a slightly increased flexion and extension movement, but more important increased freedom of rotatory movements.

ad.d) A hinged cast-brace consists of two circular casts, one around the lower leg from the malleoli to the tuberositas tibiae, and one around the upper leg from just above the patella to the groin. Both parts are connected with two hinges, one mediall and one lateral with their axes of movement as close as possible around the center of the joint. Rotation and sliding down are opposed by means of a heel support connected to the lower leg cast with two hinges, allowing movement in the ankle joint. A hinged cast-brace is used in full or partial weight-bearing conditions, according to the indication. Motion in the knee is possible from full extension to about $100^{\circ}$ flexion, but it can be limited by stops in the hinges.

ad. e) A Rehabilitation knee brace is a prefabricated hinged cast-brace. The brace has bars and shells on the upper and lower leg fixed with velcro strips or straps. This allows the patient or the physician to remove the brace when needed. The rehabilitation brace has the same indications as the cast-brace, but the immobilization is less rigid. These braces significantly reduce translations and rotations (29).

Functional knee braces are made of shells for upper and lower leg, fixed with straps, or of bars and straps. The upper and lower leg parts are connected with one or two hinges. The braces allow the ful $\|$ range of motion in the knee joint, but limitation of both flexion and extension is adjustable. The functional knee braces are not used for immobilization, but for stabilization of the knee. Biomechanical testing reveals that shell type braces provide more mechanical stability than bar-strap type braces $(22,236)$. Functional knee braces are applied in cases of mechanical instability with functional instability and in (secondary) prevention of knee joint injuries. On prescribing a functional knee brace on has to consider the activities at which the brace is worn, the build of the patient, the patient's ability to place and remove the brace properly, and the weight of the brace (especially in top athletes) (187). Level and type of stabilization depends on factors like fit and type of brace, length and material of the shells or bars-straps, and the hinges $(29,190,236)$.

\subsection{Aims of the study}

Immobilization of the knee joint is a hot topic in (sports) traumatology. A ligamentous knee injury gives rise to symptoms (pain, joint effusion, giving-way) forcing the patient to spare the leg, resulting in immobility. This results in disuse atrophy 
and disfunction of the stabilizing muscles. The complaints of pain and joint effusion will subside gradually during the process of healing. During the recovery the effect of muscle atrophy, especially of the quadriceps muscle, can become more prominent, giving rise to symptoms of instability.

The treatment of knee ligament injury is successful when the rehabilitation process results in complete functional recovery. Often recovery is incomplete and the patient is left with complaints of functional instability. In these cases muscular atrophy is frequently observed, and difficult to treat. It is therefore important to prevent or to limit the muscle atrophy in the treatment of knee injuries. There are many factors contributing to the development of posttraumatic muscle atrophy. Immobility (disuse) is the key factor. Therapeutic immobilization causes the extreme form of immobility. Thus, abolition of immobilization seems to be the answer to the problem of muscle atrophy. However, it is unknown to what extent the posttraumatic muscle atrophy is due to immobilization. It is also unknown whether and to what extent the alternatives of treatment with partial immobilization will lead to muscle atrophy. The effect of immobilization cannot be distinguished from all the other atrophy inducing factors, that are present in patients with a knee injury. These interfering factors can only be ruled out in healthy subjects. Therefore we used healthy subjects to examine the effects of some immobilization techniques. This also allows the evaluation of the effects of the immobilization techniques on thigh muscles by functional testing. These functional tests apply to the major abilities of the thigh musculature: strength and endurance. Strength is tested by means of an isokinetic dynamometer, which is a safe and reliable method. Endurance, however, is not clearly defined, and so far no tests for the aerobic endurance capacity of an isolated muscle or muscle group have been described. To develop a meaningful parameter of endurance a new test procedure for the maximal aerobic capacity of the quadriceps is described in chapter 2 . We studied the effects on the thigh muscles of cast-immobilization and two of the most commonly applied partial immobilization techniques: hinged cast-bracing and a functional knee brace. A functional knee brace may be a helpful tool in the rehabilitation phase after a knee injury or surgery, and in cases of chronic instability. Sportsmen, however, are reluctant to use these knee braces since it is thought that they 'weaken the knee'. To evaluate the effects on thigh muscle performance the brace is worn by healthy subjects for four weeks (chapter 3). Hinged cast-bracing may be an alternative to cast-immobilization in the treatment of knee joint injuries, or in the post-operative phase. It is felt that this will lead to less muscular atrophy. The quantitative effects of hinged cast-bracing and cast-immobilization on the thigh muscle performance are not yet known. Therefore we studied the effects of their application during a clinically relevant period of four weeks (chapter 4 and 5 , respectively). In chapter 6 the results are discussed of a functional treatment regimen with shortterm cast-immobilization and hinged cast-bracing in patients with a grade III lesion of the MCL. 


\section{References}

1 Aglietti P, Buzzi R, Zaccherotti G, De Biase P: Patellar tendon versus doubled semitendinosus and gracilis tendons for anterior cruciate ligament reconstruction.

Am IS Sports Med 1994, 22, 211-218

2 Amiel D, Woo SL-Y, Harwood FL, Akesen WH: The effect of immobilization on collagen turnover in connective tissues: a biochemical-biomechanical correlation.

Acta Orthop Scand 1982, 53, 325-332

3 Amiel D, Akeson WH, Harwood FL, Frank CB: Stress deprivation effect on metabolic tumover of the medial collateral ligament collagen.

Clin Orthop 1983, 172, 265-270

4 Anderson AC: Knee laxity and function after conservative treatment of anterior cruciate ligament injuries: A prospective study.

Int J Sports Med 1993, 14, 150 153

5 Anderson AF, Limscomb AB: Analysis of rehabilitation techniques after anterior cruciate ligament reconstruction.

Am J Sports Med 1989, 17, 154-160

6 Anderson $\mathrm{AF}$, Lipscomb $\mathrm{AB}$ : Preoperative instrumented testing of anterior and posterior knee laxity.

Am J Sports Med $1989,17,387-392$

7 Antich TJ, Brewster $\mathrm{CE}$ : Relhabilitation of the nonreconstructed anterior cruciate liganent-defi cient knee.

Clin Sports Med 1988, 7,813-826

8 Apel $\mathrm{R}$, Mommsen U, Wening V, Jongbluth KH, Arps $\mathrm{H}$, Delling $\mathrm{G}$ : Alloplastischer Ersatz des vorderen Kreuzbandes durch Polytetrafluoräthylenband. Tierexperimentelle Studic.

Unfallheilkunde $1986,12,291-294$

9 Appell H-J: Morphology of immobilized skeletal muscle and the effects of a pre- and postimmobilization training program.

Int J Sports Med 1986,7,6m12

10 Appell H-J, Forsberg S, Hollmann W: Satellite cell activation in human muscle after training: Ewidence for muscle fiber neotormation.

Int J Sports Med 1988, 9, 297-299

II Appell H-ll: Muscular atrophy following immobillization. A review.

Sports Med 1990, 10, 42-58

12 Arvidsson I, Erijsson E, Johnson RJ: Isokinetic thigh muscle strength after ligament reconstruction in the knee joint: results from a 5-10 year follow-up after reconstruction of the anterior cruciate ligament in the knee joint.

Int I Sports Med $1981,1,7-11$

13 Arvidsson I, Eriksson E, Knutsson E, Arner S: Reduction of patin inhibition on voluntary muscle activation by epidural analgesia.

Orthopedics $1986,9,1415-1419$ 
14. Arvidsson I, Arvidsson $H$, Eriksson E, Jansson E: Prevention of quadriceps wasting after immobilization: An evaluation of the effect of electrical stimulation.

Orthopedies $1986,9,1519-1528$

15 Arwidsson I. Eriksson E: A double blind trial of NSAD versus placebo during rehabilitation. Orthopedics $1987,10,1007 \% 10 \sharp 4$

16 Balkfors $\mathbb{B}$ : The course of knee-ligament injuries. Acts: Orthop Scand 1982, 53 Suppl 198

17 Barrack RL, Skinner HB, Buckley SL: Proprioception in the anterior cruciate deficient knee. Am J Sports Med 1989, 17,1-6

18. Barrack RL, Bruckner JD, Kneisl J, Inman WS, Alexander AH: The outcome of nonoperatively treated complete tears of the anterior cruciate ligament in active young adults.

Clin Orthop 1990,259, 192-199

19 Barrett GR, Line LL, Shelton WR. Manning JO, Phelps R: The Dacron prosthesis in anterior cruciate ligament reconstructions. A four-year rewiew.

Am J Sports Med 1993, 21, 367-373

20 Beard DJ, Kyberd DJ, O'Connor JJ, Fergusson CM, Dodd CAF: Reflex hamstring contraction latency in anterior cruciate ligament deficiency.

J Orthop Res $1994,12,219-228$

21 Bebout DE, Hogan MC, Hempelman SC, Wagner PD: Effects of training and immobilization on $\mathrm{VO}_{2}$ and $\mathrm{DO}_{2}$ in dog gastrocnemius muscle in sitt.

J Appil Physiol 1993, 74, 1697-1703

22 Beck C. Drez, D, Young J, Cannon WD, Stone ML: Instrumented testing of functional knee braces. Am J Sports Med $1986,14,253-256$

23 Binkley JM, Peat M: The effects of immobilization on the ultrastructure and mechanical properties of the medial collateral ligament of rats.

Clin Orthop 1986, 203, 301-308

24 Booth FW, Seider MI: Recovery of skeletal muscle after 3 mo of hindlimb immobilization in rats. I Appl Physiol $1979,47,435,439$

25 Booth FW, Seider MJ: Early change in skeletal muscle in protein synthesis after limb immobilization of rats.

I App Physiol $1979,47,974-977$

26 Buss DD, Warten RF, Wickiewica TL, Galinat BJ, Panariello R: Arthroscopically assisted reconstruction of the anterior crucaite ligament with use of autogenous patellar-ligament grafts. Results after twenty-four to forty-two months.

J Bone Joint Surg 1993, 75A, 1346-1355

27 Cardenis. DD, Stolov WC. Hardy R: Muscle fiber number in immobilization atrophy. Arch Phys Med Rehabil 1977, 58, 423-426

28 Carmeli E, Hochberg Z, Livne E, Lichtenstein I, Kestelboim C, Silbermenn M, Reznick AZ: Effect of growth hormone on gastrocnemius muscle of aged rats after immobilization: Biochemistry and morphology.

Appl Physiol 1993, 75, 1529 1535 
29 Cawley PW, France EP, Paulos LE: Comparison of rehabilitative knee braces. A biomechanical investigation.

Am J Sports Med 1989, 17, 141-146

30 Clancy WG, Shelbourne KD, Zoelner GB, Keene JS, Reider B, Rosenberg TD: Treatment of knee joint instability secondary to rupture of the posterior cruciate ligament. Repont of a new procedure.

J Bone Joint Surg 1983, 65A, 310-322

31 Clancy $W G$, Smith $L:$ Arthroscopic anterior and posterior cruciate ligament reconstruction technique.

Ann Chir Gynaecol1991, 80, 141-148

32 Clayton ML, Miles JS, Abdulla M: Experimental investigations of ligamentous healing. Clin Orthop $1968,61,146-153$

$33 \mathrm{Co} F H$, Skinner HB, Canmon WD: Effect of reconstruction of the anterior cruciate ligament on proprioception of the knee and heel strike transient.

J Orthop Res 1993, 11, 696-704

34. Cooper RR: Alterations during immobilization and regeneration of skeletal muscle in cats.

J Bone Joint Surg 1972, 54A, 919-953

35 Costill DL, Fink WJ, Habanski AJ: Muscle rehabilitation after knee surgery.

Physician Sportsmed 1977, 5, 71-74

36 Dahlstedt LJ, Dalén N: Knee laxity in cruciate ligament injury. Value of examination under anesthesia.

Acta Orthop Scand 1989,60, 181-184

37 Dahlstedt L, Dalên N, Jonsson U, Adolphson P: Cruciate ligament prosthesis vs. augmentation. A randomized, prospective 5-year follow-up of 41 cases.

Acta Orthop Scand $1993,64,431-433$

38 Daniel DM, Malcom LL, Losse G, Stone ML, Sachs R, Burks R: Instrumented measurement of anterior laxity of the knee.

J Bone Joint Surg 1985, 67A, 720-726

39 deAndrade JR, Grant C, Dixon ASJ: Joint distension and reflex muscle inhibition in the knee. $\checkmark$ Bone Joint Surg 1965, 47A, 313-322

40 DeHaven KE, Lintner DM: Athletic injuries: Comparison by age, sport and gender. Am J Sports Med 1986, 14, 218-224

41 Dejour $H$, Walsh G, Peyrot J, Eberhard $\mathrm{P}$ : The natural history of rupture of the posterior cruciate ligament.

Orthop Trans $1987,11,146$

42 Dhert WJA, O'Driscoll SW, wan Royen BJ, Salter RB: Effects of immobilization and continuous passive motion on postoperative muscle atrophy in mature rabbits.

Can J Surg 1988, 31, 185-188

43 Donaldson WF, Warten RF, Wickiewicz T: A comparison of acute cruciate liganent examinations. Initial versus examination under anesthesia.

Am J Sports Med 1985, 13, 5-10 
44 Durand A, Richards $\mathrm{CL}$. Malouin F, Bravo G: Motor recovery after anhroscopic partial meniscactony. Analyses of gait and the ascent and descent of stairs.

$J$ Bone Joint Surg 1993, 75A, 202-214.

45 Edgerton VR, Bamard RJ, Peter JB, Mater A, Simpson DR: Properties of the immobilized hind-limb muscles of the Galago senegalensis.

Exp Neurol 1975, 46, 115-131

46 Edman KAP: Double-hyperbolic force-velocity relation in frog muscle fibres.

IPhysiol 1988, 404, 301-321

47 Edstrom L: Selective atrophy of red muscle fibres in the quadriceps in long-standing knee-joint dysfunction. Injuries to the anterior cruciate ligament.

J Neurol Sciences 1970, 11,551,-558

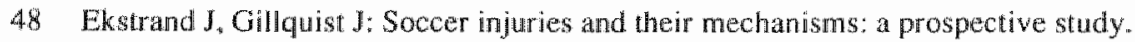

Med Sci Sports Exerc 1983, 15, 267-270

49 Enneking WF, Horrowitz M: The intra-articular effects of immobilization on the human knee. J Bone Joint Surg 1972, 54A, 973-985

50 Eriksson $\mathbb{E}$. Häggmark $\mathrm{T}$ : Comparison of isometric muscle training and electrical stimulation supplementing isometric muscle training in the recovery after major knee ligament surgery. A preliminary report.

Am J Sports Med 1979, 7, 169-171

51 Eriksson E: Rehabilitation of muscle function after sport injury- Major problem in sports medicine.

Int I Sports Med 1981, 2, 1-6

52 Evans EB, Eggers GVN, Butler JK, Blumel J: Experimental immobilization and remobilization of rat knee joints.

J Bone Joint Surg 1960, 42A, 737-758

53 Fahrer H, Rentsch HU, Gerber N., Beyeler C, Hess CW, Grinig B: Knee effusion and reflex inhibition of the quadriceps. A bar to effective retraining.

J Bone Joint Surg 1988, 708, 635-638

54 Feagin IA. Curl WW: Isolated teat of the anterior cruciate ligament. 5-year follow-up study. Am J Sports Med 1976, 4, 95-100

55. Feagin JA, Lamben KL, Cunningham RR, Anderson LM, Riegel J, King PH, VanGenderen L: Considertition of the anterior cruciate ligament injury in sking.

Clin Orthop $1987,216,13-18$

S6 Fell RD, Steffen IM, Musacchia XI: Effect of hypokinesia-hypodynamia on rat muscle oxidative capacity and glucose uptake.

Am J Physiol 1985, 249, R308-R312

57 Fetio JF. Marshall JL: Medial collateral injuries of the knee.

Clin Orthop 1978, 132, 206-218

58 Fetto JF, Marshall $\Lambda_{L}$ : Injury to the anterior cruciate ligament producing the pivot-shift sign. An experimental study on cadaver specimens.

J Bone Joint Surg $1979,61 \mathrm{~A}, 710-714$ 
59 Fent JF, Marshall IL: The natural history and diagnosis of anterior cruciate ligament insufficiency. Clin Orthop 1980, 147, 29.38

60 Fits RH, Brimmer CJ: Recovery in skeletal muscle contractile function after prolonged hindlimb immobilization.

J Appl Physiol 1985, 59, 916-923

61 Fowler PJ, Messieh SS: Isolated posterior cnuciate ligament injuries in ahletes.

Am J Sports Med 1987, 15, 553-557

62 Fox JM. Blazina ME, Del Pizzo W, Ivey FM, Broukhim B: Extra-articular stabilization of the knee joint for anterior instability.

Clin Orthop $1980,147,56-61$

63 Frank C, Woo SL Y, Amiel D, Harwood F, Gomez M, Akeson W: Medial collateral ligament healing. A multidisciptinary assesment in rabbits.

Am I Sports Med $1983,11,379-389$

64 Fruensgaard S, Kroner K, Riis J: Suture of the torn anterior cruciate ligament. 5 -Year follow-up of 60 cases using an instrumental stability test.

Acta Orthop Scand 1992, 63, 323-325

65 Fulkerson JP, Hungerford DS: Disorders of the patellofemonal joint.

Second edition. Baltimore, Williams and Wilkins, 1990

66. Gamble JG, Edwards CC, Max SR: Enzymatic adaptation in ligaments during immobilization. Am J Sports Med 1984, 12, 221-228

67 Gebhard IS, Kabo M, Meals RA: Passive motion: the dose effects on joint stilfness, muscle mass. bone density, and regional swelling.

J Bone Joint Surg 1993, 75A, 1636-1647

68. Gersoff WK, Ruwe P, Jokl P, Panjabi M: The effect of tourniquet pressure on muscle function. Am J Sports Med 1989, 17, 123-127

69 Gibson JNA, Smith K, Rennie MJ: Prevention of disuse muscle atrophy by means of electrical stimulation: Maintenance of protein synthesis.

The Lancel 1988, 767-769

70 Gillquist J, Odensten M: Reconstruction of old anterior cruciate ligament tears with at Dacron prosthesis. A prospective study.

Am I Sports Med 1993,21, 358-366

71 Giove TP, Miller SJ, Kent BE, Sanfort TL, Garrick JG: Non operative treatment of the torn anterior cruciat liggament.

J Bone Joint Surg 1983, 65 A, 184-192

72 Glashow $\mathrm{L}$, Katz $\mathrm{R}$, Schneider M, Scott WN: Double-blind assessment of the value of magnetic resonance imaging in the diagnosis of anterior cruciate and meniscal lesions.

J Bone Joint Surg 1989, 71 A, 113-119

73 Goldfuss AJ, Morehouse CA, LeVeau BF: Effect of muscular tension on knee stability. Med Sici Sports 1973, 5, 267-271 
74 Gomez MA. Woo L-Y, Inoue M, Amiel D. Harwood FL. Kitabayashi L: Medial collateral ligament healing subsequent to different treament regimens.

J Appl Physiol 1989, 66, 245-252

75 Gould N, Donnermeyer D, Gammon GG, Pope M, Ashikaga T: Transcutaneous muscle stimulafion to retard disuse atrophy after open meniscectomy.

Clin Orthop 1983,178, 190-197

76. Grace TG, Skipper BJ, Newberry JC, Nelson MA, Sweetser ER, Rothman ML: Prophylactic knee braces and injury to the lower extremity.

I Bane Joint Surg 1988, 70A, 422-427

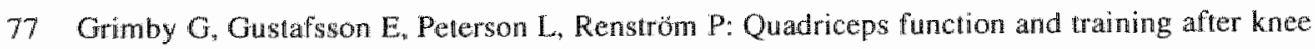
ligatnent surgery.

Med Sci Sports Exere 1980, 12, 70-75

78 Grood ES, Noyes FR: Cruciate irgament prosthesis: Strength, creep and fatigue properties.

J Bone Joint Surg 1976, 58, $1083 \mathrm{ew}$

79 Grower JS, Bassett LW, Gross ML, Seeger LL, Fineman GAM: Posterior cruciate ligament: MR imaging.

Radiology 1990, 174, 527.530

80 Haggmark T, Eriksson E: Cylinder or mobile cast brace after knee ligament surgery. A clinical analysis and morphologic and enzymatic studies of changes in the quadriceps muscle. Am J Sports Med 1979, 7, 48-56

S1 Haggmark T, Eriksson E: Hypotrophy of the soleus muscle in man after Achilles tendon rupture. Am J Sports Med 1979,7, 121-126

82 Haggmark T, Jansson E, Eriksson E: Fiber type area and metabolic potential of the thigh muscle in man after surgery and immobilization.

Int J Sports Med 1981, 2, 12-17

83 Häggmark T, Eriksson E, Jansson E: Muscle fiber type changes in human skeletal muscle after injuries and immobilization.

Orthopedies $1986,9,181-185$

84 Hagood S, Solomonow M, Baratta R, Zhou BH, D'Ambriosia R: The effect of joint velocity on the contribution of the antagonist musculature to knee stiffness and laxity.

Am J Sports Med 1990, 18, 182 187

85 Hakkinen $\mathbb{K}$, Komi PV: Electromyographic changes during strength training and detraining. Med Sci Sports Exerc 1983, 15, 455-460

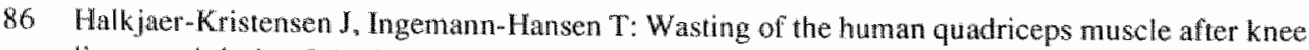
ligament injuries. I Anthropometrical consequences.

Scand J Rehabil Med 1985, Suppl 13, 5-11

87 Halkjwer-Kristensen $J$, Ingemann-Hansen T: Wasting of the human quadriceps muscle after knee ligament injuries. II Muscle fibre morphology.

Scand I Rehab Med 1985, Suppl 13, 12-20 
88 Halkjaer-Kristensem J. Ingemann-Hansen. T: Wasting of human quadriceps muscle after knee ligament injuries. III Oxidative and glycolytic enzyme activities.

Scand J Rehabil Med 1985. Suppl 13.21-28

89 Haljaer*Kristensen J, Ingemann-Hansen T: Wasting of the human quadriceps muscle after knee ligament injuries. IV Dynamic and static muscle functions.

Scand J Rehabil Med 1985, Suppl 13, 29-37

90 Hanten WP, Pace MB: Reliability of measuring anterior laxity of the knee joint using a knee ligament arthrometer.

Phys Ther $1987,67,357-359$

91 Hather BH, Adans GR, Tesch PA. Dudley GA: Skeletal muscle responses to lower limb suspension in humans.

J Appl Physiol 1992, 72, 1493-1498

92 Hauschka EO, Roy RR, Edgerton RV: Size and metabolic properties of single muscle fibers in rat solets after hindlimb suspension.

J Appl Physiol 1987, 62, 2338-2347

93 Hauser EDW: Extra-articular repair for ruptured collateral and cruciate ligaments.

Surg Gynaecol Obstet 1947, 84, 339-345

94 Herbert RD, Balnave RJ: The effect of position of immobilisation on resting length, resting stiffiness, and weight of the soleus muscle of the rabbit.

J Orthop Res 1993, 11, 358-366

95. Herbison GJ, Jaweed MM, Ditunno JF: Muscle fiber atrophy after cast immobilization in the rat. Arch Phys Med Rehabil 1978, 59, 301-305

96 Hewson GF, Mendini $\mathbb{R A}$, Wang JB: Prophylactic knee bracing in college football.

Am J Sports Med 1986, 14, 262-266

97 Higgins S: Motor control acquisition.

Phys Ther 1991, 71, 123-139

98 Highgenboten CL, Jackson A. Meske NB: Genucom, KT-1000, and Stryker knee laxity measuring device comparisons. Device reproducibility and interdevice comparison in asymptomatic sub. jects.

An I Sportis Med 1989, 17, 743-746

99. Hill AV: The maximum work and mechanical efficiency of human muscles, and their most economical speed.

J Physiol 1922, 56, 19-41

100 Houston ME, Bentzen H, Larsen H: Interrelationships between sikeletal muscle adaptations and performance as studied by detraining and retraining.

Acta Physiol Scand 1979, 105, 163-170

101 Howell SM: Anterior tibiall translation during a maximum quadriceps contraction: Is it clinically significant?

Am J Sports Med 1990, 18, 573-578 
102 Hughston JC. Eilers AE: The role of the posterior oblique ligament in repairs of acute medial (collateral) ligament tears of the knee.

I B Bone Joint Surg 1973,55A.923-940

103 Hughton JC. Andrews JR, Cross MO, Moschi A: Classification of knee ligament instabilities. Part 1. The medial compartment and cruciate ligaments.

J Bone Joint Surg $1976,58 \mathrm{~A}, 159-172$

104 Hughston $\mathrm{IC}$, Walsh WM, Puddu G: Patellar subluxation and dislocation. Philadelphia, WB Saunders Company 1984

105 Hughston JC: The absent posterior drawer test in some acute posterior cruciate ligament tears of the kried.

An I Sports Med 1988, 16.39-43

106 Hurme T, Lehto M, Kal imo $H$, Kannus $P$. Jarvinen M: Sequence of changes in fibre size and type in muscle immobilized at various lengths.

I Sports Tratimatol $1990,12,77-85$

107 Indelicato PA: Non-operative treatment of complete tears of the medial collateral ligament of the knee.

J Bone Joint Surg 1983, 65, 323-329

108 Ingemanm-Hansen T, Halkjaer-Kristensen $\mathbf{J}$ : Computerized tomographic determination of human thigh components. The effects of immobilization in plaster and subsequent physical training.

Scand J Rehab Med 1980, 12, 27-311

109 Ivey FM, Blazina ME, Fox JM, Del Pizzo W: Arthroscopy of the knee under general anesthesia: an atid to the determination of ligamentous instability.

Am J Sports Med 1980, 8, 235-238

110 Jackson $\mathbb{D W}$, Jennings LD: Arthroscopically assisted reconstruction of the anterior cruciate ligament using a patella tendon bone autograft.

Clinics in Sports Med 1988, 7, 785-800

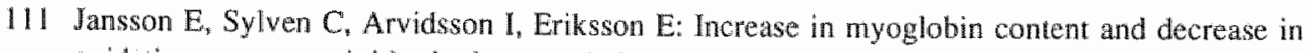
oxidative enzyme activities by leg muscle immobilization in man.

Acta Physiol Scand 1988, 132, 515-51.7

112 Jairvinen M, Kannus $\mathrm{P}$, Johnson RI: How to treat knee ligament injuries.

Ann Chir Gynaed 1991, 80, 134-140

II Jensen JE, Conn RR. Hazelrigg G, Hewett JE: The use of transcutaneous neural stimulation and isokinetic testing in arthroscopic knee surgery.

Am J Sports Med $1985,13,27-33$

114 Johnson J, Siegel D: Reliability of an isokinetic movement of the knee extensors.

Res Q 1978, 49,88,90

115 Johnson JC. Back BR: Current concepts rev lew. Posterior cruciate ligament. Am I Knee Surg $\llbracket 990,3,143-153$

116 Johnson RJ: The anterior cruciate ligament problem.

Clin Orthop 1983,172,14-18 
117 Jones KG: Reconstruction of the amterior cruciate liganent. A lechrique using the central one-third of the patellar ligament.

J Bone Joint Surg 1963, 45A, $925-932$

118 Jones RE, Henley MB, Francis P: Nonoperative management of isolated grade III colateral ligament injury in high school football players.

Clin Orthop 1986.213.137-140

119 Jozsa L, Jarvinen M, Kamus P, Letho M. Kvist M: Cortical and irabecular osteopenia afier immobilization.

Int Orthop 1988, 12, 169-172

120 Jozsa L, Thöring J, Järvinen M. Kannus $P$. Letho $M$. Kvist M: Quantintive anterations in intramuscular connective tissue following immobilization. An experimentall study in tho rat calf muscles.

Exp Molec Pathol 1988, 49, 267-278

121 Jozsa $L$, Kannus $P$, Thöring $J$, Reffy A, Järwinen $M$, Kvist M: The effect of tenotony and immobilization on intramuscular connective tissue.

I Bone Joint Surg 1 990, 72B, 293-297

122 Kalenak A, Morehouse CA: Knee stability and ligament injuries. JAMA $1975,234,1143-1145$

123 Kannus P, Alosa D, Cook L, Johnson RJ, Pope M, Beynnon B, Yasuda K. Kaplan M: Effect of one-legged exercise on the strength, power and endurance of the contrallaterall leg. A randomized, controlled study using isometric and concentric isokinetic trating.

Eur J Appl Ptaysiol 1992, 64, 117-126

124 Kannus $P$, Järvinen $M$, Johnson $R$, Rensiröm P, Pope $M$, Beynnon B, Nichols $C$, Kaptan M: Function of the quadriceps and hamstrings muscles in knees with chronic partial deficiency of the anterior cruciate ligament. Isometric and isokinetic evaluation.

Am J sports Med 1992, 20, 162-168

125 Kannus P, Jozsa L, Kvist M, Letho M., Järvinen M: The effect of immobilization on myotendinous junction: an ultrastructural, histochemical and immunohistochemicat study. Acta Physiol Scand 1992, 144, 387-394

126 Kannus $\mathrm{P}$, Nittymaki $\mathrm{S}$ : Which factors predict outcome in the nonoperaliwe treatment of patellofemoral pain syndrome? A prospecive follow-lip study.

Med Sci Sports Exerc 1994, 26, 289-296

127 Karpakka J, Väanänen K. Orava S. Takala TES: The effects of preimmobilization trainimg and immobilization on collagen synthesis in rat skeletal muscle.

Int J Sports Med 1990, 11,484-488

128. Katonis PG, Assimakopoulos AP. Agapitos MV, Exarchou EI: Mechanoreceptors in the posterior cruciate ligament. Histologï study on cadaver knees.

Acta Orthop Scand $1991,62,276-278$

$129 \mathrm{Katz}$ JW, Fingeroth RJ: The diagnostic accuracy of ruptures of the anterior cruciate ligament comparing the Lachman test, the anterior drawer sign, and the piwot shift test in acule and chronic knee injuries.

Am J Sports Med 1986, 14,88-91 
130 Kananen S. Leivo I, Michelssor J-E: Early muscle changes after immobilization. An experimenlal sudy on musclie damage.

Clin Orthop 1993, 297, 44-50

131 Keene GCR. Bickerstaff D, Rae PJ, Paterson RS: The natural history of meniscal tears in anterior cruciate ligament insufficiency.

Am J sports Med 1993, 21,672-679

132 Kennedy $\mathrm{JC}_{\mathrm{C}}$, Alexander IJ, Hayes $\mathrm{KC}$ : Nerve supply of the human knee and its functional inportance.

Arn J Sports Med 1982, 10, 329-335

133 Kowalk DL, Wojtys EM, Disher J, Loubert P: Quantitative analysis of the measuring capabilities of the KT-1000 knee ligament arthrometer.

Am J Sporis Med 1993, 21, 744-747

134 Krackow KA, Vetter WL: Knee motion in a long leg cast. An J Sports Med 1981, 9, 233-239

135 Kramer $J$, Nusca D, Fowler $\mathbb{P}$, Webster-Bogaeri 5 : Knee flexor and extensor strength during concentric and eccontric muscle actions after anterior cruciate ligament reconstruction using the semitendinosus tendon and ligament augmentation device.

Arn J Sports Med 1993, 21, 285-291

$136 \mathbb{K u h r}$ J: Der Einfluss der immobilisation auf Zahl und Funktion der Osteoblasten.

Chirurg 1982,53,160-164

137 Langenskiold $A$, Michelsson J-E, Videman T: Osteoarthritis of the knee in the rabbit produced by immobilization.

Acta Orthop Scand 1979, 50, 1-14

138 Larsen NP, Forwood MR, Parker AW: Immobilization and retraining of cruciate ligaments in the rat.

Acta Orthop Scand 1987, 58, 260-264

139 Lass P, Kaalund S, leFevre S. Arendt-Nielsen L, Sinkjaer T, Simonsen O: Muscle coordination following rupture of the anterior cruciate ligament. Electromyographic studies of 14 patients.

Acta Orthop Seand 1991, 62, 9-14

140 Lephart SM, Kocher MS, Harner CD, Fu FH: Quadriceps strength and functional capacity after anterior cruciate ligament reconstruction. Patellar tendon autograft versus allograft.

An J Sports Med 1993, 21,738 743

14) Lepola $V$, Vatananen $K$, Jalovaara $P$ : The effect of immobilization on the torsional strength of the făt tibia.

Clin Orthop $1993,297,55-61$

142 Lieber RL, Fridén JO, Hargens AR, Danzig LA, Gershuni DH: Differential response of the dog quadriceps muscle to external skeletal fixation of the knee.

Muscle Nerve 1988, 11, 193-210

143 Lindboe CF, Platou CS: Effect of immobilization of short duration in the muscle fibre size. Clin Physiol 1984, 4, 183-188 
144 Liu SH, Osti L, Dorey F, Yao L: Anterior cruciate ligament tear. A New diagnostic index on magnetic resonance imaging.

Clin Orthop 1994, 302, 147-150

145 de Loes M, Goldie I: Incidence rate of injuries during sport activity and physical exencise in a rural Swedish municipality: Incidence rates in 17 sports.

Int J Sports Med 1988, 9, 461-467

146 de Loës M: Medical treatment and costs of sports-related injuries in a total population. Int J Sports Med 1990, 11, 66-72

147 Louie JK, Mote Jr CD: Contribution of the musculature to notatory laxity and torsionall stifness at the knee.

J Biomech $1987,20,281-300$

148 Lysholm J, Gillquist J: Evaluation of knee ligament surgery results with spectal emphasis on use of a scoring scale.

Am J Sports Med 1982, 10, 150-154

149 Markolf KL, Mensch IS, Amstutz HC: Stiffness and laxity of the knee- The contributions of the supporting structures.

J Bone Joint Surg 1976,58A, 583-593

150 Markolf KL, Graff-Radford A, Annstutz HC: In wiwo knee stability a quantitative assessment using a clinical testing apparatus.

I Bone Joint Surg 1978, 60A, 664-674

151 Marshall JL, Fetto JF, Botero PM: Knee ligament injuries. A standardized evaluation method. Clin Orthop 1977, 123, 115-129

152 Marshall JL, Warren RF, Wickiewicz TL: Primary surgical treatment of anterior cruciate ligament lesions.

Am J Sports Med 1982, 10, 103-107

153 Mawdsley RH, Croft BJ: The effects of submaximal contractions on an isolated test session. J Orthop Sports Phys Ther 1982, 4, 74-77

154 McDaniel WJ, Dameron TB: Untreated ruptures of the anterior cruciate ligament. A follow-up study.

J Bone Joint Surg 1980,62A, 696-705

155 McDaniel WJ, Dameron TB: The untreated anterior cruciate ligament rupture.

Clin Orthop 1983, 172, 158-163

i56 McDougall JD, Ward GR, Sale DG, Sutton JR: Biochemical adaptation of human skeletal muscle to heavy resistance training and immobilization.

J Appl Physiol 1977, 43,700-703

157 McDougall JD, Elder GCB, Sale DG, Moroz JR, Sutton JR: Effects of strength training and immobilization on human muscle fibres.

Eur J Appl Physiol 1980, 43, 25-34 
158 McPherson GK, Mendentall HV, Gibbons DF, Plenk $H_{*}$ Rotmann W. Sanford JB, Kennedy IC, Roth $\mathrm{HH}$ : Experimental mechanical and histologic evaluation of the Kennedy Ligament Augmentation Device.

Cin Orthop 1985, 196, 186-195

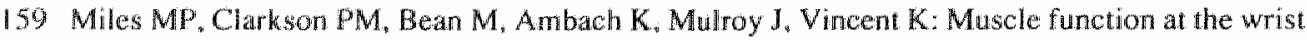
following 9 a of immobilization and suspension.

Med Sci Sports Exerc 1994, 26, 615-623

160 Mink JH, Deutsch AL: Occull cartilage and bone injuries of the knee: Detection, classification, and assessment with MR imaging.

Radiology 1989, 170,823-829

161 Mok DWH, Good C: Non-operative management of acute grade III medial collateral ligament injury of the knee: a prospective study.

Injury $1989.20,277-280$

162 More RC. Karras BT, Neiman R. Fritschy D, Woo SL-Y. Daniel DM: Hamstrings- an anterior cruciate ligament protagonist. An in vitro study.

Am I Sports Med 1993,21, 23 I-237

163 Müller W: Das Knie. Form, Funktion und ligamentäre Wiederstellungschirurgie. Springer. Berlin, Heidelberg, New York, 1982

164 Nelson SG, Duncan PW: Correction of isokinetic torque recordings for the effects of gravity. A clinical report.

Phys Ther 1983, 63, 674-676

165 Nelson WE, Henderson RC. Almekinders LC. DeMasi RA, Taft TN: An evaluation of pre- and postoperative nonsteroidal antinflammatory drugs in patients undergoing knee arthroscopy. $\mathrm{A}$ prospective, randomized, double-blinded study.

Am I Sports Med 1993, 21,510-516

166 Neyret P, Donell ST, Dejour D, Dejour H: Partial meniscectomy and anterior cruciate ligament. rupture in soccer players. A study with a minimum 20-year followup.

Am J Sports Med $1993,21,455-460$

167 Nicholson WF. Watson PA. Booth FW: Gucose uptake and glycogen synthesis in muscles from immobillized limbs.

Appl Physiol $1984,56,431-435$

168 Nicks DK, Beneke WM, Key RM, Timson BF: Muscle fibre size and number following immobilization atrophy.

J Anat $1989,163,1-5$

169 Noyes FR: Functional properties of knee ligaments and alterations induced by immobilization. Clin Orthop 1977, 123,210-242

170 Noyes FR, Mooar PA, Matthews DS, Butler DL: The symptomatic anterior cruciate-deficient knee. Part $\mathrm{I}$ : The long-term functional disability in athletically active individualls,

J Bone Joint Surg 1983, 65A, 154-162 
171 Noyes FR, Mathews DS, Mooar PA, Grood ES: The symptomatic anterior cruciate-deficient knee. Part II: The results of rehabilitation, activity modification, and counseling on functional disabillity.

J Bone Joint Surg 1983, 65A, 163-174

172 Noyes FR, Butler DL, Grood ES, Zernicke RF, Hef zy MS: Biomechanical analysis of human ligament grafts used in knee-ligament repairs and reconsmbtions.

J Bone Joint Surg 1984, 66A, 344-352

173 Noyes FR, Mangine RE, Barber S: Early knee motion after open and arthroscopic anterior cruciate ligament reconstruction.

Am J Sports Med 1987, 15, 149-160

174 Noyes FR, Albright JP: Sports injury research; foreword. I Sports Med 1988, 16, Suppl 1, VI-XV

175 Noyes FR, Cummings JF, Grood ES, Walz-Hassalfeld KA, Wroble RR: The diagnosis of knee motion limits, subluxations, and ligament injury.

AmI Sports Med 1991, 19, 163-171

176 Noyes FR, Grood ES, Cummings JF, Wroble RR: An anallysis of the pivot shift phenomenon. The knee motions and subluxations induced by different examiners.

Am J Sports Med 1991, 19, 148-155

177 Nyland J, Brosky T, Currier D, Nitz A, Cabon D: Review of the afferent neural system of the knee and its contribution to molor learning.

J Orthop Sports Phys Ther 1994, 19, 2-11

178 Oberlander MA, Shalvoy RM, Hughston JC. The accuracy of the clinical knee examination documented by arthroscopy. A prospective study.

Am I Sports Med 1993, 21, 773-778

179 O'Donoghue DH: Surgical treatment of fresh injuries to the major ligaments of the knee.

J Bone Joint Surg 1950, 32A, 721. 738

180 O'Donoghue DH, Rockwood CA, Zaricznyj B, Kenyon R: Repair of knee ligaments in dogs. I The laterat collateral ligament.

J Bone Joint Surg 1961, 43A, 1167-1178

181 Ong SC, Caiozzo VJ, Starr KL: Ischemia induced atrophy in skeletal muscle fibers. Int I Sports Med 1989, 10,373

182 Parolie JM, Bergfeld JA: Long-term results of nonoperative treatment of isolated posterior cruciate ligament injuries in the athlete.

Am J Sports Med 1986, 14, 35-38

183 Pässler HH, Mäz S: Der radiologische Lachman Test-eine einfache und sichere Methode zum Nachweis won Kreizbandschäden.

Unfallchirurgie 1986, 12, 295-300

184 Pattee GA, Fox JM, Del Pizzo W, Friedman MJ: Four lio ten year followup of unreconstructed anterior cruciate ligament tears.

Ant I Sports Med 1989, 17, 430-435 
185 Paulos L, Noyes FR, Grood E, Butler DL: Knee rehabilitation after anterior cruciate ligament reconstruction and repair.

Am J Spors Med 1981, 9, 140-149

186 Petit $J$, Gioux M: Properties of motor units after immobilization of cat peroneus longus muscle. J Appl Physiol 1993, 74, 1131. 1139

187 Podesta L, Sherman MF: Knee bracing.

Orthop Clin North Am 1988, 19, 737-745

188 Pope MH, Johnson RJ, Brown DW, Tighe C: The role of the musculature in injuries to the medial collateral ligament.

J Bone Joint Surg 1979,61A, 398-402

189 Raab DJ, Fisher DA, Smith JP, Markman AW, Steubs JA: Comparison of arthroscopic and open reconstruction of the anterior cruciate ligament. Early results.

Am J Sports Med 1993, 21,680-684

190 Regabuto MA. Rowick JS, Walker PS: The forces in a knee brace as a function of hinge design and placement.

Am J Sports Med 1989, 17,535.543

191 Renstrom P. Arms SW, Stanwyck TS, Johnson RJ, Pope MH: Strain within the anterior cruciate ligament during hamstring and quadriceps activity.

Am J Sports Med 1986, 14,83-87

192 Risberg MA, Ekeland A: Assessment of functional tests after anterior cruciate ligament surgery. J Orthop Sports Phys Ther 1994, 19,212-217

193 Roth JH, Kennedy JC, Lockstadt H, McCallum CL, Cunning LA: Polypropylene braid augmented and nonaugmented intraarticular anterior cruciate ligament reconstruction.

Am J Sports Med 1985, 13, 321 - 336

194 Rougraff B, Shelbourne D, Gerth PK. Warner I: Arthroscopic and histologic analysis of human patellar tendon autografts used for anterior cruciate ligament reconstructions.

A.m J Sports Med 1993,21, 277-284

195 Rovere GD, Haupt HA, Yates CS: Prophylactic knee bracing in college football. An I Sports Med 1987, 15, 111-116

196 Rozier CK. Elder ID, Arown M: Prevention of atrophy by isonetric exercise of a casted leg. ISports Med 1979, 19, 191-195

197 Rijke AM, Perrin DH, Goitz HT, McCue FC: Instrumented arthrometry for diagnosing partial versus complete cruciate ligament tears.

An I Sports Med 1994, 22, 294-298

198 Sandberg R, Balkfors B, Nilsson B, Westlin N: Operative versus non-operative treatment of recent injuries to the ligaments of the knee. A prospective randomized study.

J Bone Joint Surg 1987,69A, 1120-1126

199 Sandberg R, Balkfors B: Reconstruction of the anterior cruciate ligament. A 5 year follow-up of 89 patients.

Acta Orthop Scand $1988,59,288-293$ 
200 Sapega AA, Nicholas JA, Sokolow D, Saranit P: The nature of torque "overshoot" in Cybex isokinetic dynamometry.

Med Sci Sports Exere 1982, 14, 368-375

201 Sargeant AJ, Davies CTM, Edwards RHT, Mander C. Young A: Functional and structural changes after disuse of human muscle.

Clin Sci Molec Med 1977, 52, 337-342

202 Savolainen J, Myllylä V, Myllylä A, Vihko V, Vaanänen K, Takala "TES: Effects of denervation and immobilization on collagen synthesis in rat skeletal muscle snd tendon.

Am J Physiol 1988, 254, $897-902$

203 Savolainen J, Väänảnen K, Puranen J, Takala TES, Komulainen J, Vihko V: Collager synthesis and proteolytic activities in rat skeletal muscles: Effect of cast-immobilization in the lengthened and shortened positions.

Arch Phys Med Rehabi $1988,69,964-969$

204 Schipplein OD, Andriacchi TP: Interaction between active and passive knee stabilizers during levell walking.

J Orthop Res 1991, 9, 113-119

205 Schultz RA, Miller DC, Kert CS, Micheli L: Mechanoreceptors in human cruciate ligaments. A histological study.

J Bone Joint Surg 1984, 66A, 1072-1076

206 Schutte MJ, Dabezies EJ, Zimny ML, Happel LT: Neural anatomy of the human anterior cruciate ligament.

J Bone Joint Surg 1987, 69A, 243-247

207 Seiler H, Niemeyer H, Kayser M, Bïhren V: Ist die operative Behandlung bei der kompletten Innenbandruptur des Kniegelenkes notwendig?

Unfallchirurg 1987, 90, 180-185

208 Seto JL, Orofino AS, Morrissey MC, Medeiros JM, Mason WJ: Assesment of quadriceps/hamstring strength, knee ligament stability, functional and sports activity levels five years after anterior cruciate ligament reconstruction.

Am Sports Med 1988, 16, 170-180

209. Shelbourne KD, Nitz P: Accelerated rehabilitation after anterior cruciate ligament reconst tuction. Am J Sports Med 1.990, 18, 292-299

210 Sherman WM, Pearson DR, Plyley MJ, Costill DL, Habanski AJ, Vogelgesang DA: Isokinetic rehabilitation after surgery. A review of factors which are important for developing physiotherapeutic techniques after knee surgery.

Am J Sports Med 1982, 10, 155-161

211 Shino K, Nakata K, Horibe S, Inoue M, Nakagawa S: Quantitative evaluation after arthroscopic anterior cruciate ligament reconstruction. Allograft versus autograft.

Am I Sports Med 1993, 21, 609-616

212 Silfwerskiold JP, Steadman JR, Higgins RW, Hagerman T, Atkins JA: Rehabilitation of the anterior cruciate ligament in the athlete.

Sports Med 1988, 6, 308-319 
213 Slocumb DB, James SL, Larson RL: Rotatory instability of the knee. Its pathogenes is and a clinical test to demonstrate its presence.

I Bone Joint Surg 1968,50A, 211.225

214 Smith LR, Thomas KD, Schurman DJ, Carter DR, Wong M, van der Meulen MC: Rabbit knee immobilization: Bone remodeling precedes cartilage degeneration.

J Orthop Reseach 1992, 10, 88-95

215 Snyder Mackler $L_{*}$ Ladin $Z_{\text {; }}$ Schepsis AA, Young JC: Electrical stimulation of the thigh muscles after reconstruction of the anterior cruciate ligament.

I Bone Joint Surg 1991, 73A, 1025-1036

216 Snyder-Mackler L* De Luca PF, Whllams PR, Eastlack ME, Bartolozzi AR: Reflex inhibition of the quadriceps femoris muscle after injury or reconstruction of the anterior cruciate ligament.

J Bone Joint Surg 1994, 76A, 555-560

217 Soares IMC, Duarte JAR, Carvalho J, AppelI H-J: The possible role of intracellular Ca ${ }^{2+}$ accumulation for the development of immobilization atrophy.

Int J Sports Med 1993, 14, 437-439

218 Solomonow M, Baratta R, Zhou BH, Shoji H, Bose W, Beck C, D'Ambrosia R: The synergistic action of the anterior cruciate ligament and thigh muscles in maintaining joint stability.

Am J Sports Med 1987, 15, 207-213

219 Solomonow M, Baratta R, D'Ambrosia R: The role of the hamstrings in the rehabilitation of the anterior cruciate ligament-deficiert knee in athletes.

Sports Med 1989, 7, 42-48

220 Spencer JD, Hayes KC. Alexander IJ: Knee joint effusion and quadriceps reflex inhibition in man. Arch Phys Med Rehabil 1984, 65, 171-177

221 Spindler KP, Schils JP, Bergfeld JA, Andrish JT, Weiker GG, Anderson TE, Piraino DW, Richmond BJ, Medendorp SV: Prospective study of osseous, articular, and meniscal lesions in recent anterior cruciate ligament tears by magnetic resonance imaging and arthroscopy.

Am J sports Med 1993, 21, 551-557

222 Staniski CL: Rehabilitation following knee injury.

Clinics in Sports Med 1985, 4.495-511

223 Stichting Consument en Veiligheid: Prive ongevallen registratiesysteem. Jaaroverzicht 1984. The Neiherlands, Amsterdam 1985

224 Strobel M, Stedtfeld H-W: Diagnostik des verletzten Kniegelenkes.

Marseille Verlag, Munchen, 1988

225 Tegner $Y$, Lysholm J Gillquist J, Öberg B: Two-year follow-up of conserwatiwe treatment of knee ligament injuries.

Acta Orthop Scand 1984, 55, 176-180

226 Tegner $\mathrm{Y}, \mathrm{Lysholm} \mathrm{J}$ : Rating systems in the evaluation of knee ligament injuries.

Clin Orthop 1985, 198, 43-49

227 Tegner Y, Lysholm J, Lysholm M. Gillquist J: Strengthening exercises for old cruciate ligament tears.

Acta Orthop Scand 1986,57, 130-134 
228 Teitz CC, Hermanson BK. Kronmal RA, Diehr PH: Evaluation of the use of braces to prevent injury to the knee in collegiate football players.

IBone Joint Surg 1987,69A, 2-9

229 Thorstensson A: Muscle strength, fibre types and enzyme activities in man. Acta Physiol Scand 1976, suppl 443

230 Thorstensson A, Grimby $\mathrm{G}, \mathrm{Karlsson} J$ : Force-velociry relations and fiber composition in human knee extensor muscles.

J Appl Physiol 1975, 40, 12-16

231 Tibone JE, Antich TJ, Fanton GS, Moynes DR, Perry J: Functional analysis of anterior cruciate ligament instability.

Am J Sports Med 1986, 14, 276-284

232 Timm KE: Postsurgical knee rehabilitation. A five year study of four methods and 5,381 patients. Am J Sports Med 1988, 16, 463-468

233 Torg JS, Conrad W, Kalen A, Kalen V: Clinical diagnosis of anterior cruciate ligament instability in the athlete.

Am J Sports Med 1976, 4,84-91

234 Torg JS, Barton TM, Paviov H, Stine R: Natural history of the posterior cruciate ligament-deficient knee.

Clin Orthop $1989,246,208-216$

235 Torzilli PA, Deng X, Warren RF: The effect of joint-compressive load and quadriceps muscle force on knee motion in the intact and anterior cruciate ligament-sectioned knee.

Am J Sports Med 1994, 22, 105-112

236 Vailas JC, Pink M: Biomechanical effects of functional knee bracing. Practical implications. Sports Med 1993, 15, 210-218

227 Wagner UA, Gotzen L, Buhr Th: Behandlung isolierter Bandlitsionen des Kniegelenkes. Orthopäde $1989,18,315-320$

238 Walla DJ, Albright JP, McAuley E et al: Hamstring control and the unstable anterior cruciate liganent deficient knee.

A.m J Sports Med 1985,13,34-39

239 Walsh S, Frank C, Strive N, Hart D: Knee immobilization inhibits biomechanical maturation of the rabbit medial collateral ligament.

Clin Orthop 1993, 297, 253-261

240 Walter SD, Sutton J, McIntosh JM et al: The atiology of sports injuries: A review of methodologies.

Sports Med 1985, 2, 47-58

241 Warren RF, Marshall JL: Injuries of the anterior cruciate and medial collateral ligaments of the knee. A retrospective analysis of clinical records - Part 1.

Clin Orthop $1978,136,191-197$

242 West SP, Roy RR, Alford EK, Edgerton VR: Fiber type and fiber size of cal ankle, knee, and hip extensors and flexors following low thoracic spinal cord transection at an sarly age.

Exp Neural $1986,91,174,182$ 
243 White AA, Raphael IG: The effect of quadriceps loads and knee position on strain measurements of the tibial collateral ligament. An experimental study on human amputation specimens. Acta Orthop Scand 1972,43,176-187

244 Wigerstad-Lossing 1, Grimby G, Jansson T, Morelli Bi, Peterson L, Renström P: Effects of electricall muscle stimulation combined with voluntary contractions after knee ligament surgery. Med Sci Sports Exerc 1988, 20,93-98

245 Wilk RM, Richmond JC: Dacron ligament reconstruction for chronic anterior cruciate ligament insufficiency.

An J Sports Med 1993, 21, 374-380

246 Wilkie DR: The relation between force and velocity in human muscle.

J Physiol 1950, 110,249-280

247 Williams PE, Goldspink $\mathrm{O}$ : Connective tissue changes in immobilized muscle. J Anal 1984, 138, 343-350

248 Winter DA, Wells RP, Or GW: Errors in the use of isokinetlic dynamometers. Eur J Appl Physiol 1981, 46, 397-408

249 Wojtys EM, Huston LJ; Neuromuscular performance in normal and anterior cruciate ligamentdeficient lower extremities.

Am J Sports Med 1994, 22, 89-104

250 Wolf E, Magora A, Gonen B: Disuse atrophy of the quadriceps muscle.

Electromyography 1971, 11,479-490

251 Woo SL-Y, Mathews IV, Akeson WH. Amiel D, Convery FR: Connective tissue response to immobility.

Arthritis and Reumatism 1975, 18, 257-264

252 Yack HJ, Collins CE, Whieldon TJ: Comparison of closed and open kinetic chain exercise in the anterior cruciate ligament-deficient knee.

Am J Sports Med 1993, 21, 49-54.

253 Young $A$, Hughes I, Russel P, Parker MX, Nichols PJR: Measurement of quadriceps muscle wasting by ultrasonography.

Rheumatology and Rehabilitation 1980,19,141-148

254 Zarins B, Rowe CR, Harris BA, Watkins MP: Rotational motion of the knee.

An J Sports Med 1983, 11, 152-156

255 Zatterström R, Friden T, Lindstrand A, Moritz U: Muscle training in chronic anterior cruciate ligament insufficiency - a comparative study.

Scand I Rehab Med 1992, 24,91-97

256 Zimny ML, Albright DJ "Dabezies E: Mechanoreceptors in the human medial meniscus. Acta Anat 1988, 133, 35-40 


\title{
Chapter 2
}

\section{Isokinetic aerobic power testing of the quadriceps muscle}

\author{
J.W. Veldhuizen \\ F.T.J. Verstappen \\ M. Twellaar \\ M.R. Drost \\ J.M. Greep
}

Departments of Surgery and Movement Sciences, University of Limburg, Maastricht, The Netherlands 


\section{Summary}

A stepwise increasing exercise protocol to measure the maximal aerobic power of the quadriceps muscle is introduced. Sixteen healthy volunteers perfomed isokinetic knee extensionlflexion exercises at an angular velocity of $180^{\circ} .5^{-1}$. The protocal consisted of stages of 200 knee movements from $100^{\circ}$ flexion to full extension, starting at $10 \%$ peak torque (PT) and increasing by $10 \%$ PT each following stage until exhaustion. Quadriceps work, oxygen uptake, heart rate, plasma lactate cancentration and surface electromyography were monitored. Quadriceps power (Pext) was highty related $(r=0.95)$ with the extension torque at which the subjects were instructed to exercise. The test-retest $(r=0.82)$ and left to night $(r=0.94)$ correlations of maximum quadriceps power (Pmax) were good. Both sexes (males $43 \pm 9 \mathrm{~W}$, females $36 \pm 8 \mathrm{~W}$ ) achieved their Pmax at $47 \%$ PT. Oxygen uptake $(r=0.85)$ and EMG-amplitude $(r=0.88)$ were linearly related to Pext. Mechanical efficiency and plasma lactate concentration showed a large variabilty between work stages and between subjects. In conclusion: Pmax as assessed by the proposed test is an useful measure of muscular endurance capacity.

\section{Introduction}

Rehabilitation after a knee injury is a major problem in (sports)medicine. Muscular performance in particular of the knee extensor muscles deteriorates significantly after knee injury, surgery, and/or immobilization $(6,16)$, and recovery can be difficult. Rehabilitation programs are all focussed on regaining muscular strength of the thigh muscles. Consequently, strength testing of the thigh muscles is nearly common practice in rehabilitation after eg. knee injuries, but endurance with emphasis on aerobic metabolism is generally forgotten. There is, however a demand for endurance testing both in sports medicine and in rehabilitation since endurance is an important factor for physical activity as well.

Endurance is somewhat unclear defined as the ability to resist fatigue, while fatigue is defined as a failure to maintain force or power output, the cause and characteristics of which vary according to the nature of the activity performed (3). Endurance performance depends on adequate supply of oxygen and essential nutrients to the active muscle cell on the one hand, and on eliminating heat and waste products on the other. There are no general accepted parameters for endurance of isolated muscles, and therefore endurance is not easily tested. Some studies on isokinetic muscle fatigue testing have been published. In general, two methods are used: the decline in strength of a series of Maximal Voluntary Contractions (MVC) in a given period of time (12), or the number of MCV's $(8,11,15)$ (Fatigue Index, FI) until the 
torque has declined to a certain percentage of the previously established maximum (usually 50\%)(2,7). However, repeated MCV's are associated with anaerobic metabolism and will therefore result in local accumulation of lactate, and in fatigue. This will quickly impede muscular function, resulting in poor judgment of the aerobic muscular endurance capacity. In this view it is not surprising, that not all subjects are able to perform the above described isokinetic fatigue tests $(7,11)$. So there is a need for tests which evaluate the maximal aerobic power of local muscles or certain muscle groups. The aim of the present study is to develop a graded exercise protocol for the use in sport- and rehabilitation settings to measure the maximum aerobic power of the quadriceps muscle. The proposed test procedure is validated by testretest and left-right comparisons, and correlations of power output and physiologic and electromyographic parameters. Finally, suggestions are made for its application in general practice.

\section{Subjects and Methods}

Subjects

Sixteen healthy volunteers, eight males and eight females, participated in this study after giving their written informed consent. None of the subjects suffered from complaints of the knee, nor had a history of knee injury. They were all sedentary and not accustomed to isokinetic testing. The physical characteristics of the subjects are presented in Table 1.

Table 1: Characteristics of the subjects (means \pm S.D.)

\begin{tabular}{lrr}
\hline sex & males $(\mathrm{n}=8)$ & fermales $(\mathrm{n}=8)$ \\
\hline age & $22.4 \pm 1.7$ & $21.4 \pm 1.3$ \\
height & $178.9 \pm 5.8$ & $167.5 \pm 5.4$ \\
weight & $72.6 \pm 7.4$ & $63.0 \pm 7.4$ \\
\hline
\end{tabular}

\section{Test procedure}

In two practice sessions prior to the tests the subjects were accustomed to exercising on the isokinetic dynamometer (Cybex II, Lumex, N.Y.), and to the testing procedure. The subjects were placed on the chair of the isokinetic device, and the thigh, pelvis and upper body were fixed. They were allowed to support the arms. Prior to the test sessions a venous catheter was inserted into an antecubital vein. Next the peak torque $(\mathrm{PT} ; \mathrm{Nm})$ was determined at an angular velocity of $180^{\circ} . \mathrm{s}^{-1}$, being the highest value 
in two bouts of five knee extensions with maximal effort. PT was not corrected for gravity.

The range of motion on the dynamometer was set from full extension to $100^{\circ}$ flexion, and was checked with an audio-visual feedback system. The demanded as well as the delivered torque were shown on a monitor placed in front of the subject. The speed of the dynamometer was set at $180^{\circ} . \mathrm{s}^{-1}$. The subjects were instructed to perform 200 knee extensions with a demanded torque (Tdem; Nm) of $10 \% \mathrm{PT}$. The instruction was also to alternate the knee extensions with passive knee flexions. After completing the first stage Tdem was increased by $10 \% \mathrm{PT}$ each stage, until exhaustion. The test ended when the subject could no longer produce Tdem, or as soon as the quadriceps power of the last completed stage turned out to be lower than the previous one. The time (s) for completion of each stage was recorded. Both legs were tested with a two hours recovery period between the tests for allowing complete recovery of plasma lactate and heart rate. Four weeks later a retest was performed to assess the test reliability.

\section{Data gathering}

The torque of knee flexion and extension was registered by means of an Apple II computer with an $\mathrm{AD}$-chart sampling at $50 \mathrm{~Hz}$. Custom made software calculated the work of the knee extensions for each stage of 200 movements ( $\mathrm{J}$ ext; J). The work of the knee flexions, due to gravity acting on the mass of the leg plus unintended active flexion activity, was also calculated ( $\Sigma J f l e x$ ). Finally the delivered power of the knee extension movement and the power of the complete knee movement were calculated $\left(\right.$ Pext $=\Sigma$ Jext. $s^{-1}, P$ tot $=(\Sigma$ Jflex $+\Sigma$ Jext $\left.) . s^{-1}\right)$.

Oxygen uptake $\left(\mathrm{VO}_{2} ; 1 . \mathrm{min}^{-1}\right)$ was measured continuously by means of a pulmonary metabolic apparatus, the EOS Sprint (Jaeger, Würzburg, Germany). Heart rate (HR) was recorded by means of an ECG recorder (Hellige, Freiburg, Germany). Plasma lactate values were determined from a blood sample obtained at the end of each stage (PLa; mmol. $\mathrm{I}^{-1}$, Lactate Analyzer 640, Kontron, Zürich, Switzerland). Mechanical efficiency (ME; $\%)$ was calculated according to the following equation: $\mathrm{ME}=(60 \mathrm{x}$ Ptot) $/\left(20934 \times \mathrm{VO}_{2}\right) \cdot 100 \%$.

\section{Electronyography}

At each exercise stage, starting at the $100^{\text {th }}$ movement, raw surface electromyography signals (EMG) were obtained from the vastus medialis during $10 \mathrm{~s}$ using Beckmann $\mathrm{Ag} / \mathrm{AgCl}$ surface electrodes. The data were digitalized at a sample frequency of $1000 \mathrm{~Hz}$ (Labmaster ADC), and were stored on computer hard disc for further analysis.

The electromyographic bursts were selected manually from the raw signal (1024 points). The data were filtered (Blackman window) and Fourier transformed. The 
amplitude $(\mathrm{mV})$ of the 512 frequency components were summed. The amplitude of the interbust interval was determined in the same way and subtracted from the burst amplitude. The data were normalized per subject by setting the average of the amplitudes of the completed stages in each test at $50 \%$, and recalculating the amplitudes of the separate stages accordingly. Computerized analyses were made using the Asystant ${ }^{+}$software package.

\section{Statistical analysis}

Data for left to right and test- retest comparisons of quadriceps power were statistically analysed using the Student-t-test for paired data. The Pearson correlation coefficient was used to compute the relationship between power and physiologic and electromyographic parameters. The data were analysed by means of the SPSS/PC ${ }^{+}$ statistical package, and are presented as means $\pm \mathrm{SD}$. The level of significance was set at $\mathrm{p}<0.05$.

\section{Results}

Technical aspects of the test

All subjects completed four or five exercise stages. Pext showed a linear increase with Tdem ( $\mathrm{r}=0.95$, Figure 1). EJflex was not constant over all exercise stages. It

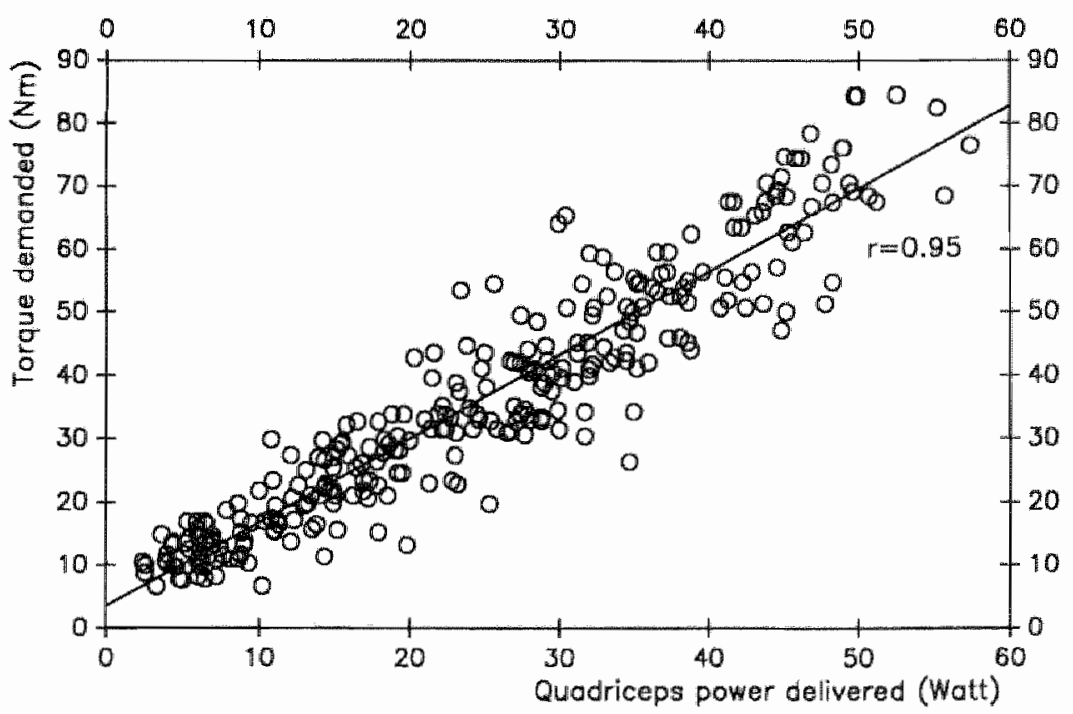

Fig.1: Quadriceps power as delivered in relation to the torque levell ats demanded $(r=0.95)$ 
increased from $1.8 \pm 1.0 \mathrm{~kJ}$ at stage $1(10 \% \mathrm{PT})$ to $3.5 \pm 1.6 \mathrm{~kJ}$ at stage $4(40 \% \mathrm{PT})$ $(\mathrm{p}<0.001)$. The contribution of flexion to the total work produced decreased from $48 \%$ at stage 1 to $21 \%$ at stage 4 . The duration of exercise stages declined from 285 $\pm 22 \mathrm{~s}$ for stage 1 to $260 \pm 20 \mathrm{~s}$ for stage 4 . The myoelectric bursts of knee extension also lasted shorter ( $767 \pm 103 \mathrm{~ms}$ in stage 1 to $593 \pm 81 \mathrm{~ms}$ in stage 5). The two hours of rest between testing of both legs was sufficient as was judged by measurements of $\mathrm{HR}_{4} \mathrm{PLa}$ and $\mathrm{VO}_{2}$ at rest.

\section{Reliability of the test}

The peak power of knee extension (Pmax; W) showed no significant differences between the test- and retest situation $(39.2 \pm 10.1 \mathrm{~W}$ and $39.6 \pm 8.3 \mathrm{~W}, \mathrm{r}=0.82)$. The mean variability of Pmax was $12 \%$. Pmax of the right leg $(39.1 \pm 9.5 \mathrm{~W})$ did not differ significantly from the left leg $(39.6 \pm 9.0 \mathrm{~W})$. The comparison between males and females as another indication for the test reliability showed, that Pmax was reached at the same exercise stages between $40 \% \mathrm{PT}$ and $50 \% \mathrm{PT}$ in both sexes (average males $46.7 \pm 7.6 \% \mathrm{PT}$, females $46.9 \pm 7.8 \% \mathrm{PT}$ ).

\section{Test performance and physiologic correlates}

Males reached a significantly higher PT $(\mathrm{p}<0.001)$ and $\mathrm{Pmax}(\mathrm{p}<0.001)$ than females (PT; males 138.6 $24.1 \mathrm{Nm}$, females 11.0.0 $29.9 \mathrm{Nm}$, Pmax; males $43.4 \pm 9.2 \mathrm{~W}$, fenales $35.6 \pm 7.6 \mathrm{~W}$ ). The difference between both sexes in peak oxygen consumption $\left(\mathrm{VO}_{2}\right.$; males $1.50 \pm 0.381 . \mathrm{min}^{-1}$, females $1.26 \pm 0.381 . \mathrm{min}^{-1}$ ) was correlated to the difference in Ptot. The peak heart rate in females ( $156 \pm 21$ beats. min $^{-1}$ ) was significantly $(p<0.05)$ higher than in males $\left(142 \pm 20\right.$ beats. min $\left.^{-1}\right)$. Peak plasma lactate concentrations were lower than commonly found in $\mathrm{VO}_{2}$ max testing on treadmill or bicycle ergometer $\left(8-10 \mathrm{mmol}^{-1} \mathrm{I}^{-1}\right)$, and there were no statistically significant differences between males $\left(6.9 \pm 3.7 \mathrm{mmol}^{-\mathrm{I}^{-1}}\right)$ and females $(5.8 \pm 2.2$ mmol. $\left.1^{-1}\right)$.

$\mathrm{VO}_{2}$ at each stage was plotted against Pext (Figure 2). The relationship appeared to be linear in the submaximal stages $(r=0.85)$ with a tendency to incline at the maximal stage. When the calculated mechanical efficiency was plotted against the relative work delivered (Figure 3), the best fit of the relationship was a curve with its optimum around $60 \%$ peak power, and a correlation coefficient of $\mathrm{r}=0.54$. The relative oxygen consumption was linearly related $(r=0.74)$ to $\mathrm{HR}$. Plasma lactate concentration showed a curvilinear relation with $\mathrm{VO}_{2}$ with a correlation of 0.71 (Figure 4). PLa remained at resting levels until $50-60 \%$ of the peak oxygen consumption, then it increased exponentionally, with peak values ranging from $2.1 \mathrm{mmol}^{-1}$ to 15.6 mmol. $\mathrm{I}^{-1}$.

Surface electromyography from the vastus lateralis was applied to identify the relationship between the electrical activity of the quadriceps and the work performed 


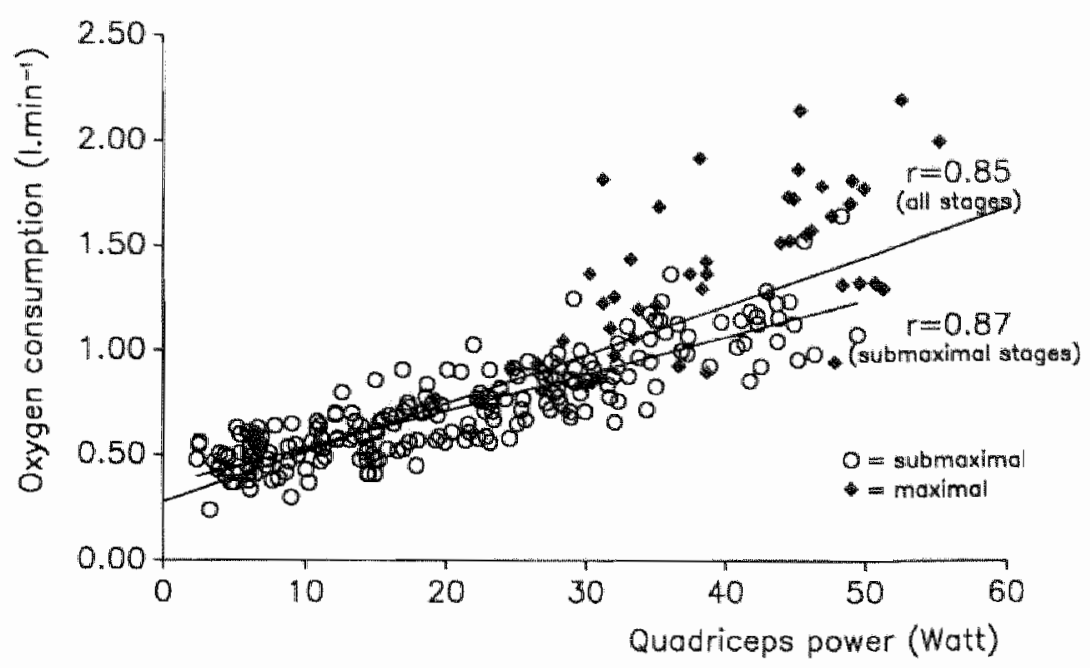

Fig. 2: Oxygen consumption (l.min ${ }^{-1}$ ) for quadriceps power as delivered (Wati). Overall correlation is 0.85 ; correlation for submaximal stages only is 0.87 .

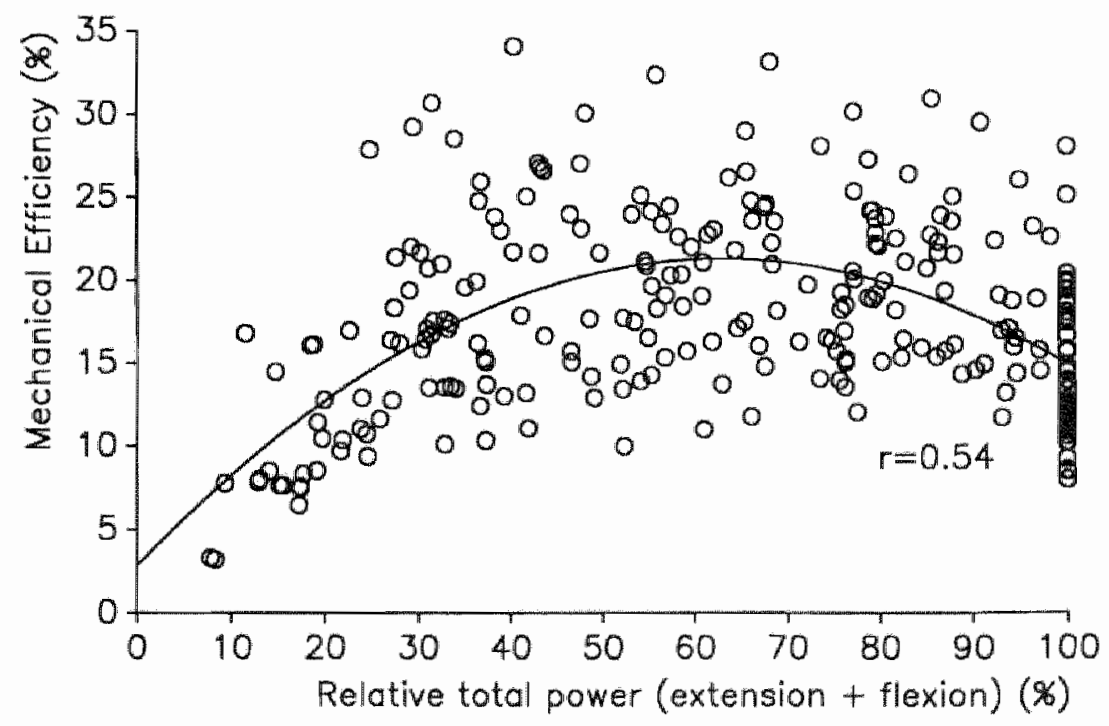

Fig. 3: Mechanical efficiency (\%) for relative power delivered in both flexion and extension movements $(\%)$. Maximal power level is set at $100 \%$ 


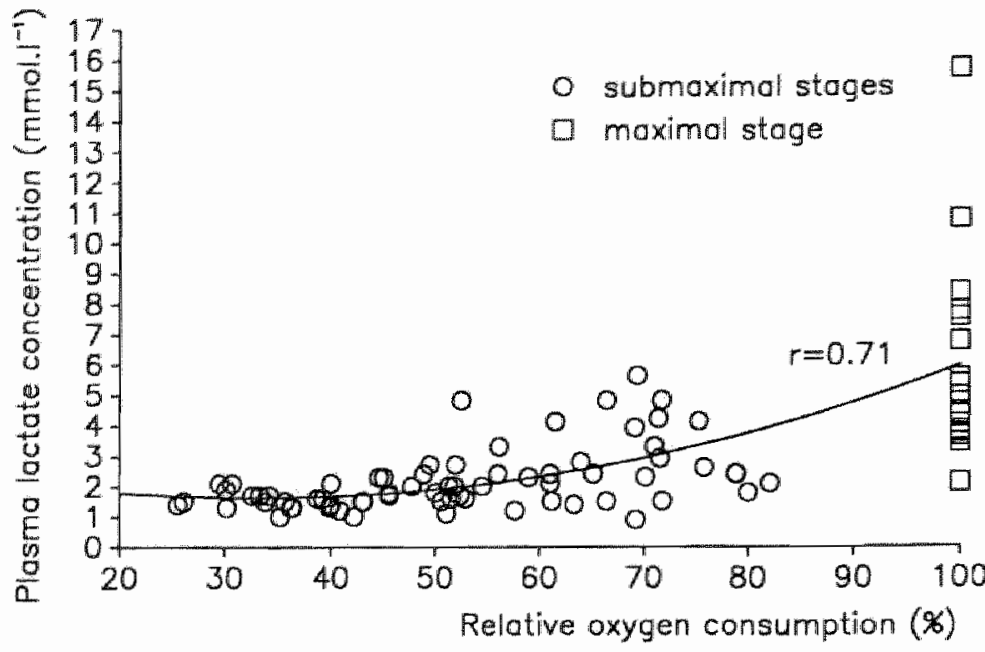

Fig. 4: Plasma lactate concentration (mmol. $I^{-1}$ ) in relation to the relative oxygen consumption. Peak oxygen consumption at the isokinetic endurance test is set at $100 \%$.

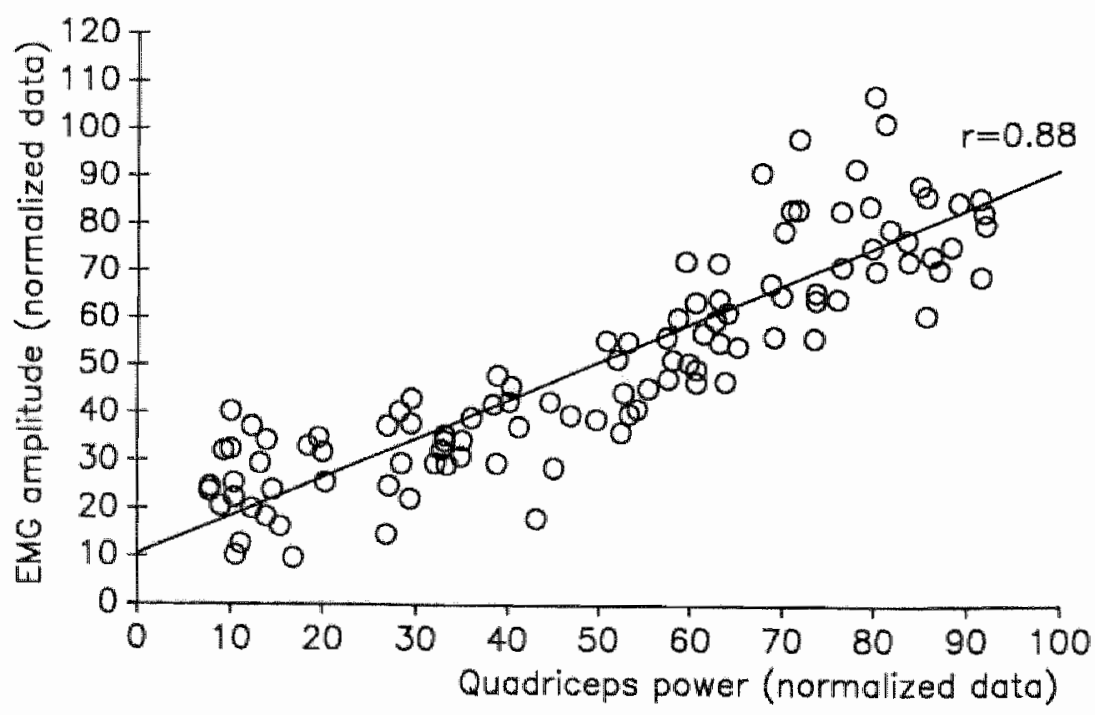

Fig. 5: EMG amplitude in relation to quadriceps power. Both variables are normalized at $50 \%$ for each test of consecutive stages 10 compensate for differences in electrode placement. 
by the quadriceps. The relationship between EMG amplitude after normalization, and quadriceps power appeared to be linear $(\mathrm{r}=0.88)$ with a tendency to increase at peak power (Figure 5).

\section{Discussion}

The present study evaluates a stepwise increasing isokinetic loading protocol to measure maximal aerobic power of the quadriceps muscle.

\section{Technical aspects}

A significant, but constant error in the measurements is included because no correction for gravity has been applied. However, because gravity, mass of the leg, and movement cycle remain the same during the test, the error in measurement of $\Sigma$. lext and $\Sigma$ Jflex is constant within each subject. This means that extension strength and work are underestimated due to gravity acting on the mass of the leg and lever arm, while flexion strength and work are overestimated to the same extent. Because the mass of the leg is a variable in this measurement of extension power, the results of the test can only be used for intra-subject comparisons with intact limbs.

In the ideal situation the work recorded in passive knee flexions is constant over all exercise stages. However, unintended muscular activity may cause an increase of the power of flexion with increased quadriceps loading. This increase is relatively small, from $6.3 \pm 3.5 \mathrm{~W}$ at $10 \% \mathrm{PT}$ to $13.5 \pm 6.2 \mathrm{~W}$ at $40 \% \mathrm{PT}$, but differences between the subjects are noted. The increased flexion activity never interferes with the extension exercise as can be judged from the limited power that is obtained. In addition the subjects stated that exhaustion was always the result of quadriceps fatigue.

A remarkable finding was that the time needed for completing each stage decreased with increased quadriceps loading. Since the speed of the dynamometer is fairly constant during movement, as well as the range of motion, this means that the alternation of movement is swifter. This might be the result of changes in motor control. These changes are observed with surface EMG as a decreased duration of the myoelectric bursts with increased loading. The decrease in time needed for completing each stage can to some extent also be attributed to technical shortcomings of the Cybex II dynamometer, since the preset limit of the angular velocity can be exceeded at the impact of the leg and lever arm (14). Due to this technical shortcoming the absolute values of torque and power measurements are device specific.

Angular velocity was set at $180 \mathrm{deg} \cdot \mathrm{s}^{-1}$. This velocity was chosen because it is well tolerated by the subjects and it is usually applied in other studies examining fatiguability $(2,7,8,15)$. It is, however, shown that fatigue is velocity dependent (12). This means that the results of this test are velocity specific as well. 
The Cybex II isokinetic dynamometer does not have the feature of an adjustable external loading, the apparatus merely accommodates to forces applied to it and makes them measurable. In order to allow stepwise increased quadriceps loading the subjects are therefore instructed to deliver a given torque at each stage. In doing this they are aided with wisual feedback to keep the variation in torque output within range. However, fluctuations in torque during each stage are inevitable, and the expected increase in the delivered work can only be assessed retrospectively since the actual work delivered is only calculated after completing the exercise stage. The high correlation between Tdem and Pext at each stage $(r=0.95)$ demonstrates that even though fluctuations in torque output occur, this does not influence the work produced over the entire stage.

\section{Reliability}

The test- retest correlation for maximal performance is fairly good ( $r=0.82$ with a mean variability of $12 \%$ ). This is in accordance with a test- retest correlation of 0.85 found in an isokinetic anaerobic power test at $180 \mathrm{deg} . \mathrm{s}^{-1}$ (2). Nevertheless, the testretest correlation is less than in aerobic power testing on the treadmill $(\mathrm{r}=0.96)(17)$ and the variability is higher than in bicycle ergometer exercise (4.79\%) (9). Poor muscular coordination with this unaccustomed movement, and the poor training status of our sedentary subjects may be responsible for this lower correlation and higher variability.

Test-performances and physiological correlates (Pmax, VO2, HR, PLa, EMG)

The average Pmax is $39.2 \pm 10.1 \mathrm{Watt}$, and is delivered at an average of $47 \% \mathrm{PT}$. This is in accordance with findings of Komi et al. (8), who reported a maximal torque output of $44 \%$ after 100 Maximal Voluntary Contractions (MCV): $51 \%$ in subjects with predominantly ST fibers and $38 \%$ in those with predominantly FT fibers.

As expected, males have a higher Pmax than females. In both sexes Pmax is linearly related to PT. No left to right differences are noted for PT or Pmax. This is in accordance with the findings of Gilliam (5). This natural equality between both legs makes the test suitable for use in rehabilitation settings, comparing the injured leg with the healthy leg.

At submaximal exercise stages oxygen uptake is linearly related to Pext $(r=0.85)$ and to Ptot $(r=0.89)$, but it inclined at the maximal performance stage. This extra oxygen consumption may be the result of coactivity of various muscle groups (e.g. arms, back, neck, abdomen), at peak performance, which are likely present during the test. The maximal capacity of the heart is not fully exploited in this test as shown in the submaximal peak heart rates. This is due to the limited active muscle mass during one leg knee extension/passive knee flexion exercise. During the progressive exercise protocol the maximal blood flow capacity of the active muscles is most probably 
approached and anaerobic energy sources contribute progressingly to the energy delivery demanded. This process is reflected in the increase of the plasma lactate concentration at the final stages.

In the present study, the amplitude of the EMG is well related to Pext $(r=0.88)$. It is shown both in submaximal isometric contractions (13), as in submaximal bicycle ergometer exercise (1), that iEMG is linearly related to strength. The same linear relationship between contractional work and EMG activity is demonstrated in isokinetic exercise of the human triceps surae by Fugl-Meyer (4). The present isokinetic quadriceps loading protocol reveals a linear relationship between muscle power and amplitude of EMG up to about $75 \%$ Pmax. At higher power levels the amplitude increases more exponentially. This exponential rise in EMG activity in maximal exercise is also reported by Kuroda in isometric quadriceps contractions (10).

\section{Applications}

Pmax can be a valuable measure in the evaluation of local muscular endurance capacity in sports medical practice and in rehabilitation settings. A simple and reliable test procedure is important. We feel that the test procedure described above can be simplified. At first, a reliable assessment of Pmax can be done without measurement of $\Sigma$ Jext with the additional computer and software due to the strong correlation between Tdem and Pext. Secondly, the protocol can be shortened by starting at 20\%PT since all subjects were able to complete at least the $30 \%$ PT stage. The suggested simplified protocol to assess Pmax consists of stepwise loading of the knee extensors at $180 \mathrm{deg} . \mathrm{s}^{-1}$, starting at $20 \% \mathrm{PT}$ and increasing with $10 \% \mathrm{PT}$ each consecutive stage, until exhaustion. 


\section{References}

I Bigland-Ritchie B, Woods JJ: Integrated EMG and oxygen uptake during dynamic contractions of human muscles.

I Appl Physiol 1974, 36, 475 479

2 Burdett RG, van Swearingen J: Reliability of isokinetic endurance tests.

J Orthop Sports Phys Ther $1987,8,484-488$

3 Edwards RHT: Human Muscle Fatigue: Physiological Mechanisms, London. Pitman Medical, $1981,1-18$

4 Fugl-Meyer AR, Gerdle B, Eriksson B-E, Jonsson B: Isokinetic plantar flexion endurance.

Seand J Rehabil Med 1985, 17, 47-52

5 Gillam TB, Sady SP, Freedson PS, Villanacci J: Isokinetic torque levels for high school football players.

Arch Phys Med Rehabil 1979, 60. 110-114

6 Halkjaer-Kristensen I, Ingemann-Hansen T: Wasting of the human quadriceps muscle after knee ligament injuries.

Scand J Rehab Med 1985, 13 Suppl

7 Jenseth JE, Conn RR, Hazelrigg G, Hewett JE. The use of transcutaneus neural stimulation and isokinetic testing in arthroscopic knee surgery.

An J Sports Med 1985, 13, 27-33

8 Komi PV, Tesch P: EMG frequency spectrum, muscle structure, and fatigue during dynamic contractions in man.

Eur J Appl Physiol 1979, 42, 41-50

9 Kuipers $H$ : Variability of physiologic responses to exercise.

Thesis, State University of Limburg, Maastricht, The Netherlands, 1983

10 Kuroda E, Klissouras V, Milsum JHE: Electrical and metabolic activities and fatigue in human isometric contraction.

JAppl Physiol 1970, 29, 358-367

11 Lorentzon R. Johansson C, Sjöström M, Fagerlund M, Fugl-Meyer AR: Fatigue during dynamic muscle contractions in male sprinters and marathon runners: relationships between performance, eletromyographic activity, muscle cross-sectional area and morphology.

Actu Physion Scand 1988, 132,531-536

12 Mathiassen SE: Influence of angular velocity and movement frequency on development of fatigue in reparted isokinetic knee extensions.

Eur I Appl Physiol 1989, 59.80-88

13 Moritani $\mathrm{T}$, de Vries HE: Rewexamination of the relationship between the surface integrated electromyogram (IEMG) and force of isometric contraction.

Am J Phys Med 1978, 57, 263-277

14 Sapega AA, Nicholas JA, Sokolow D, Saraniti A: The nature of torque "overshoot" in Cybex isokinetic dynamometry.

Med Sci Sports Exerc 1982, 14, 368-375 
15. Thorstensson A, Karlsson I: Fat guability and fibre composition of human skeletal muscle. Acta Physiol Scand 1976, 98, 318-322

16 Veldhuizen JW, Verstappen FTJ, Vroemen JPAM, Kuipers H, Greep JM: Functional and morphological adaptations following four weeks of knee immobilization. Int J Sports Med 1993, 14, 283-287

17 Weltman A, Snead D, Seip R, Schurrer R, Rutt R, Weltman J: Reliability and validity of a increamental treadmill protocol for the determination of lactate threshold, fixed blood lactate concentrations, and $\mathrm{VO}_{2} \mathrm{max}$.

Int J Sports Med 1990, 11, 26-32 


$$
"
$$




\section{Chapter 3}

\section{The effects of a supportive knee brace on leg performance in healthy subjects}

I.W. Veldhuizen

F.M.M. Koene

H.J.M. Oostwogel

Th.P.H. v. Thiel

F.T.J. Verstappen

Departments of Surgery and Movement Sciences, University of Limburg,

Maastricht, The Netherlands 


\section{Summary}

Eight healthy volunteers were fitted with a supportive knee brace (Push Brace ${ }^{\circledR}$ 'Heavy') to one knee for the duration of four weeks wherein they were tested before, during and after the application to establish the effect of bracing on performance. The tests consisted of isokinetic strength measurement of knee flexion and extension, 60 meter dash, vertical jump height and a progressive horizontal treadmill test until exhaustion ( $V m a x$ ) with determination of oxygen uptake, heart rate and plasma lactate concentration. Wearing the brace for one day, the performance indicators showed a decline compared with the tests before application (base values). Sprint time was $4 \%$ longer $(p<0.01)$, and $V$ max $6 \%$ slower $(p<0.05)$. Peak torque of knee flexion at 60 and 240 deg.sec $^{-1}$ was $6 \%(p<0.01)$ respectively $9 \%(p<0.05)$ less. Peak extension torque at 60 deg.sec ${ }^{-1}$ was $9 \%$ less $(p<0.05)$. While wearing the brace for four weeks, the test performances were practically identical to their base values. After removal of the brace, all test parameters were statistically similar to the base values. Heart rate at submaximal exercise levels was even lower $(p<0.05)$. In conclusion, performance in sports with testlike exercise patterns is not affected by the knee brace tested. Bracing does not 'weaken the knee' as it is widely believed in sports practice.

\section{Introduction}

The main reasons for a sportsman to wear a supportive knee brace are symptomatic knee joint instability and secundary prophylaxis after a previously encountered knee ligament lesion. Particularly, athletes make high demands upon supportive braces. On the one hand, the brace must compensate for joint instability and must lower the risk of re-injury, but on the other hand, it should not interfere with performance. A number of studies demonstrate that in laboratory settings knee braces are capable of reducing undesired valgus/varus, rotational and anterior/posterior movements to a certain extent $(1,2,6,9,12,14)$. Functional evaluation of bracing in case of instability shows that bracing only reduces the occurence of swelling, pain and giving-way $(3,4,11)$.

Recent publications concerning the prophylactic use of knee braces give rise to serious doubt regarding their injury-preventive effect $(5,7,8,13,15)$. In addition, in sports practice it is generally assumed that when a brace is worn for preventive purposes, the joint stability relies less on muscular function. This will lead to muscular atrophy and consequently decreased performance. Supportive for this view are the findings of Houston et al. (10) and Zetterlund et al. (17), who concluded that a knee brace affects muscle strength and aerobic capacity. Thus the gain in passive 
stability may be counterbalanced by decreased muscular stability and lower leg performance. However, it is not known to what extent preventive bracing does induce muscular atrophy and decrease performance. Especially for use in sports, a supportive knee brace (Push Brace 'Heavy') has been developed. The use of this brace is indicated in patients with complaints of chronic medial or lateral instability and is assumed to increase stability and not to decrease performance or muscle strength. The aim of the present study is to evaluate the direct and long-run effects of this knee brace on leg performance.

\section{Materials and Methods}

\section{Subjects}

In order to eliminate all injury-related bias, the study was performed in healthy subjects. Eight healthy volunteers participated in this study after giving their informed consent (Table 1). The participants did not have a history of knee injury and were all active in sports.

\section{Brace}

In all subjects the Push Brace ${ }^{\circledR}$ 'Heavy', a supportive knee brace, weighing 300 grams, was used. This brace has elastic strappings and a series of lateral and medial built-in hinges preventing valgus and varus movement (Figs. $1 \mathrm{a}$ and $1 \mathrm{~b}$ ). Knee flexion and extension are possible over the full range of motion. The brace was randomly assigned to the right or the left leg. The subjects were instructed how to tie the brace to the previously selected knee during daytime hours for a period of four weeks. Application of the brace was regularly checked during the period of this study and before testing.

Table 1: Characteristics of the subjects

\begin{tabular}{llllllll}
\hline Subject & $\begin{array}{l}\text { Sex } \\
\text { M/F }\end{array}$ & $\begin{array}{l}\text { Age } \\
\text { yrs }\end{array}$ & $\begin{array}{l}\text { Height } \\
\mathrm{cm}\end{array}$ & $\begin{array}{l}\text { Weight } \\
\mathrm{kg}\end{array}$ & $\begin{array}{l}\text { Braced knee } \\
\mathrm{R} / \mathrm{L}\end{array}$ & $\begin{array}{l}\mathrm{VO}_{2} \mathrm{max} \\
1 . \mathrm{min}^{-1}\end{array}$ & Sports \\
\hline 1 & $\mathrm{~F}$ & 23 & 180 & 56 & $\mathrm{R}$ & 2.58 & finess \\
2 & $\mathrm{M}$ & 26 & 180 & 75 & $\mathrm{~L}$ & 5.08 & triathlon \\
3 & $\mathrm{M}$ & 39 & 176 & 75 & $\mathrm{~L}$ & 3.64 & soccer \\
4 & $\mathrm{~F}$ & 19 & 168 & 64 & $\mathrm{R}$ & 2.67 & jogging \\
5 & $\mathrm{M}$ & 19 & 185 & 81 & $\mathrm{~L}$ & 4.41 & jogging \\
6 & $\mathrm{M}$ & 21 & 188 & 82 & $\mathrm{R}$ & 4.05 & soccer \\
7 & $\mathrm{M}$ & 25 & 185 & 73 & $\mathrm{~L}$ & 3.74 & soccer \\
8 & $\mathrm{M}$ & 22 & 183 & 75 & $\mathrm{R}$ & 4.23 & jogging \\
mean & & 24 & 181 & 75 & & 3.80 & \\
S.D. & & 6 & 6 & 9 & & 0.85 & \\
\hline
\end{tabular}



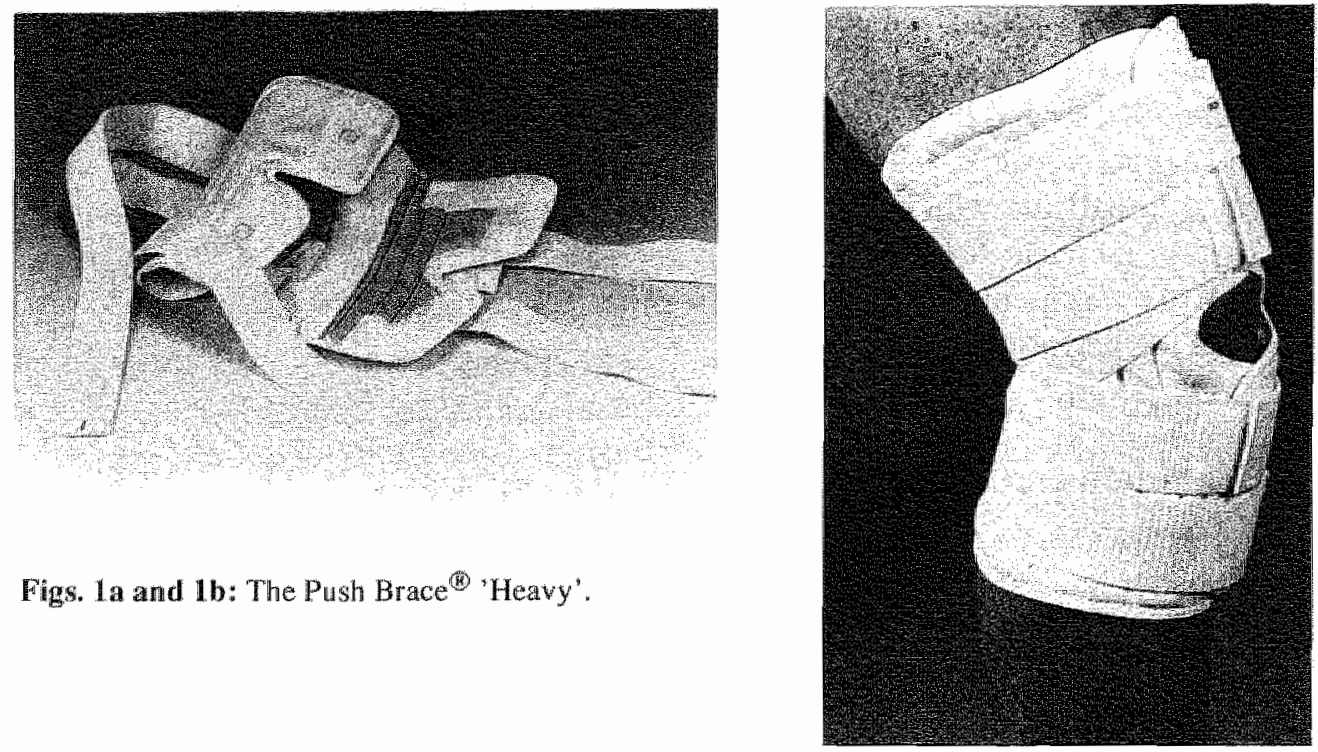

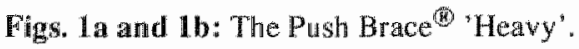

\section{Testing protocol}

The tests series examining changes in leg performance were taken three days before application of the brace, at day one and at day 28 during the bracing period, and again one day after removall. The results of the test before application were considered as base values. In both test series at day one and and at day 28 during the bracing period, the subjects were wearing the brace. The test series included isokinetic muscle strength measurements, 60 meter dash, vertical jump height testing and treadmill. running. Prior to the study, the subjects were familiarized with the dynamometer and treadmill. Strength of knee flexion and extension was measured as maximal torque output using a Cybex II isokinetic dynamometer (Lumex, N.Y.). Maximal torque was registered for both knees at an angular velocity of 60,120,180,240 and 300 deg. $\mathrm{sec}^{-1}$ from a series of five movements with maximal effort. Dynamometry was followed by a vertical jump height testing and manually clocked 60 meter dash. After a 30-minute rest period the subjects performed a horizontal treadmill test which consisted of a warm-up at a speed of $10 \mathrm{~km} \cdot \mathrm{h}^{-1}$. Every three minutes the speed was increased two $\mathrm{km} . \mathrm{h}^{-1}$ until volitional exhaustion (Vmax; $\left.\mathrm{km} \cdot \mathrm{h}^{-1}\right)$. Oxygen uptake $\left(\mathrm{VO}_{2} ; 1 . \mathrm{min}^{-1}\right)$ and heart rate $\left(\mathrm{HR} ; \mathrm{b}, \mathrm{min}^{-1}\right)$ were continuously monitored by means of an automatic pulmonary metabolic apparatus (EOS Sprint ${ }^{\circledR}$, Jaeger, Würzburg, Germany) and E.C.G. recorder (Hellige, Freiburg, Germany). At the end of each workload a blood sample was drawn from a catheter in an antecubital vein for plasma lactate analysis (PLa; mmol. $\mathrm{H}^{-1}$ : Lactate Analyzer $640^{(B)}$, Kontron, Zürich, Switzerland). 


\section{Statistics}

The data during submaximal exercise at 10,12 and $14 \mathrm{~km} . \mathrm{h}^{-1}$ were statistically analysed by two-way analysis of variance with repeated measures using the four test situations (16). For statistical analysis of the results of the 60 meter dash, high-jump and $V \max$, the Wilcoxon test was used. The level of significance was set at 0.05 .

\section{Results}

During the first three days of wearing, some of the subjects complained about pinching of the knee. After this initial habituation period the complaints ceased. The physical activities of the subjects in terms of duration and level of performance in sports were not affected by the brace.

\section{Strength measurements}

Peak torque values for knee extension and flexion at $60 \mathrm{deg} \cdot \mathrm{sec}^{-1}$ and of flexion at 240 deg. $\sec ^{-11}$ were $9 \%(p<0.05)$, respectively $6 \%(p<0.05)$ and $9 \%(p<0.05)$ lower on the first day of the application period (Figs, 2 and 3 ). Four weeks later the outcome of the strength measurements were again equal to the base values.

\section{Sprinting, high jump and Vmax}

The results of vertical jump height tests, 60 meter dash and Vmax are shown in Table 2 . The results of the vertical jump height tests showed a large variation over all test trials and therefore no significant differences. The running time of the 60 meter dash was $4 \%$ longer $4 \%(p<0.01)$ on the first day of application of the brace (test 2$)$. After four weeks there were no significant differences compared with the base values. Testing $V \max$, while wearing the brace on day one and day 28 , resulted in a decrease of $6 \%(\mathrm{p}<0.05)$ and $4 \%(\mathrm{p}<0.05)$, respectively.

Table 2* Results of 60 meter dash, vertical jump height test, and maximal speed on the treadmill in the successive test trials. Values are means \pm S.D. (* p $<0.05$ as compared with base values).

\begin{tabular}{llll}
\hline & $\begin{array}{l}\text { Sprinting } \\
(\mathrm{s})\end{array}$ & $\begin{array}{l}\text { Jump height } \\
(\mathrm{cm})\end{array}$ & $\begin{array}{l}\mathrm{Vmax} \\
\left(\mathrm{km} \cdot \mathrm{h}^{-1}\right)\end{array}$ \\
\hline Before application & $8.74 \pm 0.35$ & $47.1 \pm 7.2$ & $16.6 \pm 2.6$ \\
Day 1 of application & $9.05 \pm 0.44^{*}$ & $45.1 \pm 8.2$ & $15.6 \pm 1.8^{*}$ \\
Day 28 of application & $8.91 \pm 0.55$ & $47.4 \pm 7.0$ & $16.0 \pm 2.7^{*}$ \\
After removal & $8.86 \pm 0.56$ & $45.8 \pm 6.7$ & $16.8 \pm 2.7$ \\
\hline
\end{tabular}




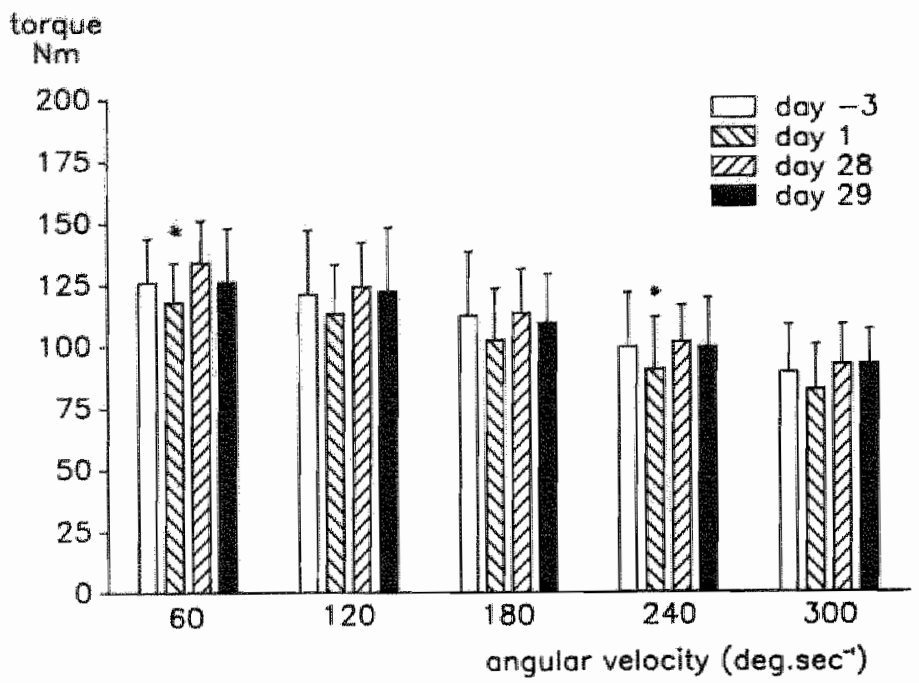

Fig. 2: Knee flexion

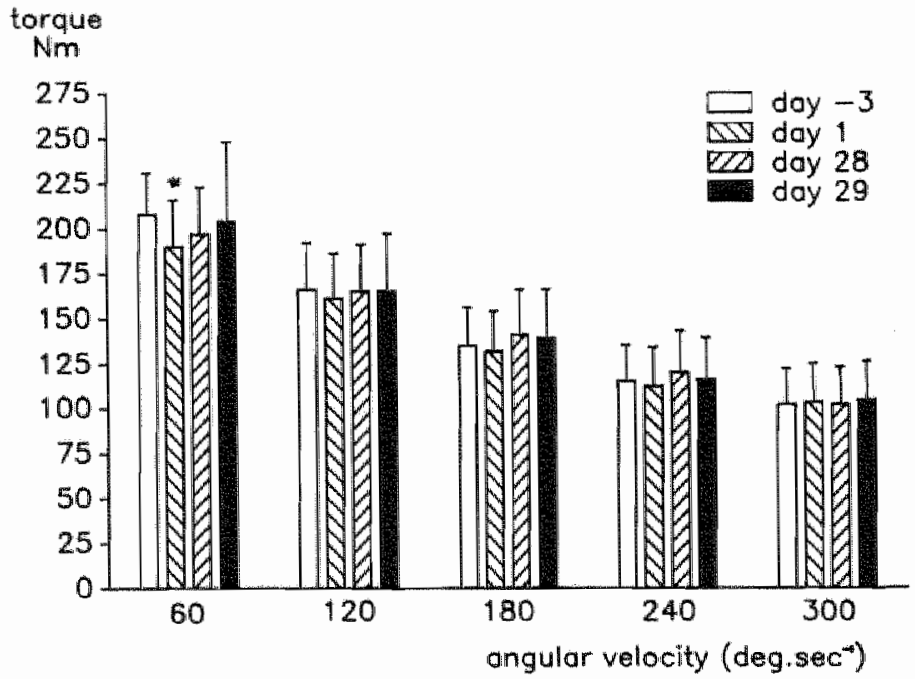

Fig. 3: Knee axtension

Figs. 2 and 3: Mear values of isokinetic strength of knee flexion and extension in the eight subjects at angular velocities of $60,120,180,240$ and 300 deg $\sec ^{-1}$.

Test 1 raken 3 days before application of the brace, test 2 the first day of application. test 3 the $28^{\text {th }}$ day after application, and test 4 the day after removal of the brace. (" $p<0.05$ as compared with base values.) 
Table 3: HR, VO2, and PLa at 10, 12 and $14 \mathrm{~km}^{-1}$ on the treadmill at the four successive test trials. Values are means $\pm S . D$. Lewel of significance is set at 0.05 , "denotes a significant difference as compared to test $1,{ }^{b}$ as compared to tesit 2 , and as compared to test 3 .

\begin{tabular}{|c|c|c|c|c|c|}
\hline & $\begin{array}{l}\text { Speed } \\
\mathrm{km} \cdot \mathrm{h}^{-1}\end{array}$ & $\begin{array}{l}\text { Test } 1 \\
\text { before }\end{array}$ & $\begin{array}{l}\text { Test } 2 \\
\text { day } 1\end{array}$ & $\begin{array}{l}\text { Test } 3 \\
\text { day } 28\end{array}$ & $\begin{array}{l}\text { Test } 4 \\
\text { removed }\end{array}$ \\
\hline $\begin{array}{l}\text { HR } \\
\text { b.min'l }\end{array}$ & $\begin{array}{l}10 \\
12 \\
14\end{array}$ & $\begin{array}{l}166 \pm 19 \\
175 \pm 18 \\
180 \pm 15\end{array}$ & $\begin{array}{l}160 \pm 20^{3} \\
173 \pm 18 \\
178 \pm 13\end{array}$ & $\begin{array}{l}161 \pm 21 \\
173 \pm 19 \\
180 \pm 17\end{array}$ & $\begin{array}{l}156 \pm 18^{\mathrm{a} . \mathrm{b}_{n} \mathrm{c}} \\
169 \pm 19^{\mathrm{ab} \mathrm{b}_{0} \mathrm{c}} \\
175 \pm 17^{\mathrm{ah}}\end{array}$ \\
\hline $\begin{array}{l}\mathrm{VO}_{2} \\
\text { l.min-1 }\end{array}$ & $\begin{array}{l}10 \\
12 \\
14\end{array}$ & $\begin{array}{l}2.67 \pm 0.40 \\
3.02 \pm 0.44 \\
3.43 \pm 0.47\end{array}$ & $\begin{array}{l}2.72 \pm 0.40 \\
3.12 \pm 0.54 \\
3.54 \pm 0.67\end{array}$ & $\begin{array}{l}2.67 \pm 0.40 \\
3.09 \pm 0.47 \\
3.53 \pm 0.58\end{array}$ & $\begin{array}{l}2.54 \pm 0.39 \mathrm{~b} b c \\
2.92 \pm 0.42^{b, c} \\
3.40 \pm 0.49\end{array}$ \\
\hline $\begin{array}{l}\text { PLa } \\
\text { mmol.. }\left.\right|^{-1}\end{array}$ & $\begin{array}{l}10 \\
12 \\
14\end{array}$ & $\begin{array}{l}3.1 \pm 1.1 \\
4.1 \pm 2.0 \\
5.0 \pm 2.2\end{array}$ & $\begin{array}{l}3.3 \pm 1.6 \\
4.6 \pm 2.9 \\
5.7 \pm 2.8\end{array}$ & $\begin{array}{l}3.2 \pm 0.8 \\
4.4 \pm 2.1 \\
5.5 \quad 2.3\end{array}$ & $\begin{array}{l}2.9 \pm 1.0 \\
3.7 \pm 1.8^{\circ} \\
4.5 \pm 1.7\end{array}$ \\
\hline
\end{tabular}

\section{Treadmill tests}

$\mathrm{HR}, \mathrm{VO}_{2}$ and PLa at submaximal exercise on the treadmill are shown in Table 3 . HR showed only slight variation between the test trials, except for the test one day after removal. HR at 10,12 and $14 \mathrm{~km} \cdot \mathrm{h}^{-1}$ was then $6 \%(\mathrm{p}<0.05)$ respectively $3 \%(\mathrm{p}<0.05)$ and $3 \%(\mathrm{p}<0.05)$ lower in respect to base values. $\mathrm{VO}_{2}$ was slightly, but not significantly increased while wearing the brace at submaximal treadmill running. Alter removal of the brace $\mathrm{VO}_{2}$ at 10,12 and $14 \mathrm{~km} \cdot \mathrm{h}^{-1}$ declined below base values. PLa at submaximal exercise showed the same pattern as $\mathrm{VO}_{2}$, i.e. slightly elevated levels during brace application (n.s.) and $6 \%$ to $10 \%$ reduction after removal (n.s.) as compared with the test results before brace application.

\section{Discussion}

When comparing the results of the four test trials, performance appears to be impaired. on the first day of application of the brace. Isokinetic strength of knee flexion and extension declined, sprinting was slower, and exhaustion at the progressive treadmill test was achieved at a lower velocity. After wearing the braces for four weeks, the test results were again similar to the base values. However, both $\mathrm{VO}_{2}$ and PLa at submaximal exercise remained elevated. These findings indicate some mecthanical. impediment of knee movement due to the brace. One day after removal of the brace, $\mathrm{VO}_{2}$, PLa and $\mathrm{HR}$ at submaximal treadmill exercise appeared to be declined below 
base values. This might indicate a slight training effect, probably induced by the mild hindrance of the brace mimicking resistance training.

Both Houston et al. (10) and Zetterlund et al. (17) investigated the effects of wearing a supportive knee brace on performance in patients accustomed to wearing a brace. In order to compare their results to those of the present study, the "brace-condition" in their tests is considered similar to the test at day 28 of brace application. The 'non-brace condition' is compared with the test the day after removal of the brace. Houston et al. found that wearing a brace gave rise to a $41 \%$ increase in PLa after a fifteen-minute ride on a bicycle ergometer at a load established to ellict a heart rate of $170 \mathrm{~b} \cdot \mathrm{min}^{-1}$. PLa in our subjects rose $11.9 \%$ at $10 \mathrm{~km} \cdot \mathrm{h}^{-1}$ (n.s.), $18.9 \%$ at $12 \mathrm{~km} \cdot \mathrm{h}^{-1}$ (p<0.05), and $22.3 \%$ at $14 \mathrm{~km} . \mathrm{h}^{-1}$ (n.s.) when comparing brace condition with the test results after removal. Houston et al. also found isokinetic strength to be $12 \%$ to $30 \%$ lower, compared to a maximum of $6 \%$ in our subjects. Zetterlund et al. revealed that patients wearing a Lennox Hill ${ }^{\oplus}$ brace had $4.6 \%$ higher $\mathrm{VO}_{2}$ and $5.1 \%$ higher $\mathrm{HR}$ at a treadmill test at $9.7 \mathrm{~km} \cdot \mathrm{h}^{-1}$. In our subjects treadmill running at $10 \mathrm{~km} \cdot \mathrm{h}^{-1}$ whilst wearing the brace resulted in a $5 \%$ higher $\mathrm{VO}_{2}(\mathrm{p}<0.05)$ and a $3 \%$ higher $\mathrm{HR}$ $(\mathrm{p}<0.05)$ as compared with the test after removal.

In order to understand the effects of a supportive knee brace on leg performance itself, without interference of a traumatic lesion, we used healthy subjects in our tests. Testing in patients can give rise to false findings in 'non-brace-conditions' caused by reticence, resulting in an underestimation of the impediment caused by bracing. Tegner et al. (14) reported, that wearing certain types of supportive knee braces will interfere with the results of functional tests. Our protocol enables us to reveal both direct and structural effects on leg performance of wearing the brace. Muscular strength is tested by isokinetic strength measurements, vertical jump height testing and 60 meter dash; muscular endurance and the aerobic capacity by the treadmill tests. A follow-up period of four weeks during which time the brace was constantly worn, was considered to be sufficient in comparison with medical practice, where bracing is adviced for a limited period, or during sports, where a brace is worn intermittently.

In conclusion we can say that the knee brace tested does impair performance slightly but significantly during the first day of application. After familiarization only a slight mechanical hindrance remains, with little or no effect on performance, but which gives rise to some resistance training effects. For optimal performance in sports, it is important to get accustomed to bracing in training sessions. After removal of the brace, signs of muscular atrophy were not demonstrated. The present study does not give any indications to support the believe that bracing 'weakens the knee". In the case of athletes with symptomatic knee instability, the effect of an appropriate supportive brace on performance might well be positive, when mechanical hindrance is outweighed by functional improvement. More effort should be considered in functional testing of braces used by sportsmen. 


\section{References}

1 Baker BE, VanHanswyk E, Bogosian IV S, Wemer FW. Eng MM, Murphy D: A biomechanical study of the static stabilizing effect of knee braces on medial stability.

Am J Sports Med 1987, 15.566-570

2 Beck $C_{*}$ Drez D, Young J, Cannon WD. Stone ML. Instrumented testing of functional knee braces. Am J Sports Med 1986, 14, 253-256

3 Colville MR, Lee DL, Cuillo JV: The Lemox Hill Brace - an evaluation of ef fectiveness in trating knee instability.

Am J Sports Med 1986, 14, 257-266

4 Coughlin $\mathbb{L}$, Oliver J, Berretta $G$ : Knee bracing and anterolateral rotatory instability. Am J Sports Med $1987,15,161-163$

5 Cowell HR: College football: To brace or not to brace (editorial).

J Bone Joint Surg 1987,69A, I

6 France EP, Paulos LE, Jayaraman $G_{4}$ Rosenberg TD: "The biomechanics of lateral knee bracing. Part II: Impact response of the braced knee.

Am J Sports Med 1987, 15,430-438

7 Garrick JG, Requa RK: Prophylactic knee bracing. Am J Sports Med 1987, 15, 471-476

8 Grace TG, Skipper BJ, Newberry JC, Melson MA, Sweetser ER. Rothman ML: Prophylactic knee braces and injury to the lower extremity.

J Bone Joint Surg 1988, 70A, 422-427

9 Hofmann AA, Wyatt RW, Bourne MH, Daniels AU: Knee stability in orthotic knee braces. Am J Sports Med 1984, 12, 37\%-374

10 Houston ME, Goemans PH: Leg muscle performance of athletes with and without knee support braces.

Arch Phys Med Rehabil 1981,63, 431-432

11 Noyes FR, Matthews DS, Mooar PA, Grood ES: The symplomatic anterior cruciatedeficient knee; part II: The results of rehabilitation, activity modification, and counseling on functional disability.

J Bone Joint Surg 1983, 65 A, 163-174

12 Paulos LE, France EP, Rosenberg TD, Jayaraman G, Abbott PJ, Jaen J: The biomecanics of fateral knee bracing. Part I: Response of the valgus resitraints to loading.

Am J Sports Med 1987, 15, 419-429

13 Rovere GD, Haupt HA, Yates CS: Prophylactic knee bracing in college football. Am. J Sports Med 1987, 15,111-116

14 Tegner $Y$, Pettersson $G, L y$ sholm J, Gillquist J: The effect of derotation braces on knee motion. Acta Orthop Scand $1988,59,284-287$ 
681 CHAPTER 3

15 Teitz CC, Hermanson BK, Kronmal RA, Deihr PH: Evaluation of the use of braces to prevent injury to the knee in collegiate football players.

I Bone Joint Surg 1987.69A, 2-9

16 Zerbe $\mathrm{CO}$ : Randomisation analy sis of randomized blocks design extended to growth and response curves.

Commun Stat Ther Meth 1979, A8, 191-205

17 Zetterlund AE, Serfass RC, Hunter RE: The effect of wearing the complete Lennox Hill Derotation Brace on energy expenditure during horizontal treadmill running at 161 meters per minute.

Am J Sports Med 1986, 14, 73-76 


\section{Chapter 4}

\section{Effects of cast-bracing of the knee on physical performance in healthy subjects}

J.W. Veldhuizen

F.T.J. Verstappen

F.M.M. Koene

J.M. Greep

Departments of Surgery and Movement Sciences, University of Limburg,

Maastricht, The Netherlands 


\section{Summary}

Effects of application of a hinged cast-brace on thigh muscle strength and physical performance tests were studied in eight healthy volunteers. The castbrace was applied to one leg for four weeks. The subjects were free to move around. The extra loading by the cast-brace was determined in a progressive uphill walk test on a treadmill with measurements of oxygen uptake, heart rate and plasma lactate concentration. Submaximal oxygen uptake in the uphill walk test was raised significantly (average 9\%) on the day after application. After four weeks of cast-brace wearing the submaximal oxygen uptake in the uphill walk test had decreased, but remained elevated (average $4 \%$ ) even one day after removal. Heart rate was significantly higher (average $7 \%$ ) during cast application and after removal. Plasma lactate concentration, however, was not influenced. To investigate the effect of four weeks cast-bracing various performance tests to judge the thigh muscle function were taken before application and after removal. No significant changes in peak torque of knee flexion and extension, in physiologic variables at submaximal running pace during treadmill exercise, maximal running speed, $60 \mathrm{~m}$ dash, or in jump height were found. In conclusion, cast-bracing of a healthy knee for four weeks has no significant effecis on physical performance after removal.

\section{Introduction}

Immobilization of the knee joint is indicated in a number of traumatic disorders such as knee ligament lesions, tibial shaft fractures and fractures of the tibial condyle. However, it is known that immobilization of the knee is associated with degeneration of cartilage and ligaments, thigh muscle atrophy and osteodystrophy $(3,4,6,8,13,14$, 15,19 ). The indication to immobilize the knee joint should be carefully balanced against these adverse effects. Cast-bracing, whenever possible has been advocated to avoid long lasting complete immobilization. The use of a hinged cast-brace is indicated in primary non-operative treatment of knee ligament lesions and postoperative protection after surgically treated knee ligament lesions $(1,2,11,16)$. The range of motion can be adjusted, depending on the lesion. By allowing movement and weight-bearing less degeneration of ligaments is seen (6). Thigh muscle atrophy is also less severe as compared with complete immobilization, but it is still evident. Muscle atrophy observed in patients wearing a cast-brace after knee ligament surgery might be attributed to the partial immobilization or other factors causing a relative immobilization. Such immobilizing factors are pain, discomfort, joint effusion, surgical and/or traumatic damage to joint or muscle-tendon complex, or fear to move the injured leg. Thus the relative immobility may not exclusively be due to the 
cast-bracing itself, but can also be influenced by the other mentioned immobilizing factors. The aim of the present study was to assess the effects of cast-bracing alone on physical performance during application of a hinged cast-brace for four weeks and after its removal in healthy subjects.

\section{Materials and Methods}

Subjects

Eight healthy volunteers participated in this study after giving their informed consent. Their physical characteristics are given in Table 1. The participants did not have a history of prior knee injury and were all active in sports.

Table 1: Physical characteristics of the subjects.

\begin{tabular}{llllll}
\hline Subject & $\begin{array}{l}\text { Sex } \\
\text { M/F }\end{array}$ & $\begin{array}{l}\text { Age } \\
\text { yr }\end{array}$ & $\begin{array}{l}\text { Height } \\
\mathrm{cm}\end{array}$ & $\begin{array}{l}\text { Weight } \\
\mathrm{kg}\end{array}$ & $\begin{array}{l}\mathrm{VO}_{2} \mathrm{max}_{\mathrm{kg}}{ }^{-1} \\
\mathrm{mi}^{-1} \mathrm{~min}^{-1}\end{array}$ \\
\hline 1 & $\mathrm{M}$ & 21 & 184 & 80 & 49 \\
2 & $\mathrm{M}$ & 21 & 198 & 90 & 55 \\
3 & $\mathrm{M}$ & 22 & 174 & 59 & 52 \\
4 & $\mathrm{~F}$ & 20 & 174 & 59 & 42 \\
5 & $\mathrm{M}$ & 19 & 191 & 72 & 58 \\
6 & $\mathrm{M}$ & 39 & 176 & 73 & 60 \\
7 & $\mathrm{M}$ & 21 & 179 & 67 & 55 \\
8 & $\mathrm{~F}$ & 21 & 178 & 62 & 46 \\
median & 21 & 178.5 & 69.5 & 55 \\
\hline
\end{tabular}

Cast-brace

A hinged cast-brace (Delta Cast Light ${ }^{(B)}$ ) was applied to one randomly selected leg by an experienced castroom technician for a period of four weeks (Fig. 1). The cast-braces weighed 905 to 1260 gram (median 1011 g). Full weight-bearing was allowed. The hinges were set free, enabling normal knee extension and 90-100 degrees of flexion.

\section{Exercise protocol}

Test series examining leg performance were executed three days before application of the cast-brace (base values), the day after application (test 2), four weeks after application (test 3), and the day after removal of the cast-brace (test 4). Test 1 and test 4 included isokinetic strength measurements, vertical jump height, 60 meter 


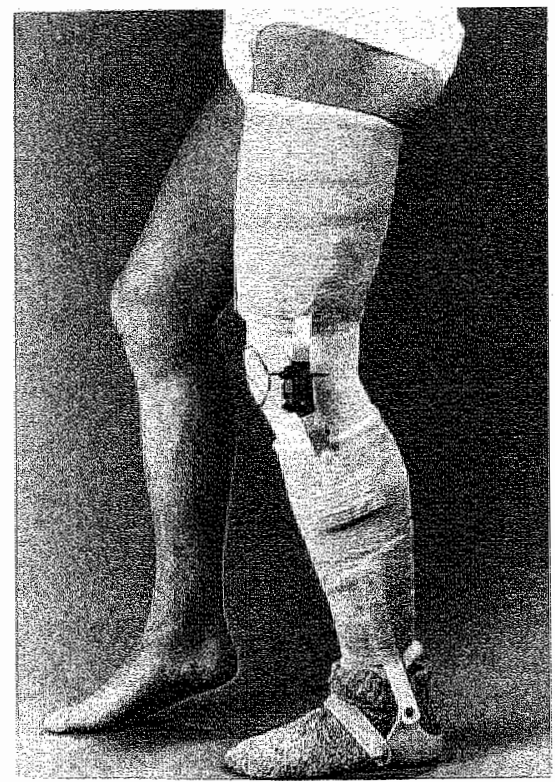

Fig. 1: Cast-brace as used in this study

Table 2: Test sequence

\begin{tabular}{|c|c|c|c|c|}
\hline & \multirow[b]{2}{*}{$\begin{array}{l}\text { test } 1 \\
\text { day }-3\end{array}$} & \multicolumn{2}{|c|}{ Application } & \multirow{2}{*}{ 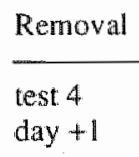 } \\
\hline & & $\begin{array}{l}\text { test } 2 \\
\text { day } 2\end{array}$ & $\begin{array}{l}\text { test } 3 \\
\text { day } 28\end{array}$ & \\
\hline peak torque & + & - & - & + \\
\hline $60 \mathrm{~m}$ dash & + & - & - & + \\
\hline jump height & + & - & - & + \\
\hline ireadmill level running & + & - & - & + \\
\hline treadmill uphill walking & + & + & + & + \\
\hline
\end{tabular}

dash, an incremental level running treadmill test and an uphill walk treadmill test. Test 2 and test 3 were restricted to the progressive uphill walk test because of movement limitations determined by the cast-brace (Table 2). Strength of knee flexion and extension was measured as maximal torque output using a Cybex II isokinetic dynamometer (Lumex, N.Y). Peak torque was registered at angular velocities of $60,120,180,240$, and $300 \mathrm{deg} . \mathrm{s}^{-1}$ from two series of five movements with maximal effort. Dynamometry was followed by a vertical jump height test and a manually clocked outdoor 60 meter dash. After a 30 minutes rest period the subjects performed a level running treadmill test (Quinton 18-50, Seattle, USA). This test 
consisted of a warm-up of five minutes at a speed of $10 \mathrm{~km} \cdot \mathrm{h}^{-1}$. Subsequently the running speed was increased two $\mathrm{km} \cdot \mathrm{h}^{-1}$ every three minutes until the subject could not keep up with the imposed speed due to exhaustion $\left(\mathrm{Vmax} ; \mathrm{km}^{-1} \mathrm{~h}^{-1}\right)$. Oxygen uptake $\left(\mathrm{VO}_{2} ; 1 . \mathrm{min}^{-1}\right)$ and heart rate $\left(\mathrm{HR} ; \mathrm{b} . \mathrm{min}^{-1}\right)$ were monitored by means of an automatic pulmonary metabolic apparatus (EOS SPRINT, Jaeger, Wurzburg, Germany) and an E.C.G. recorder (Hellige, Freiburg, Germany), respectively. At the end of each stage a blood sample was drawn from a catheter in an antecubital vein for plasma lactate analysis (PLa; mmol. $\mathrm{l}^{-1}$ ). The samples were analyzed using the Lactate Analyzer 640 (Kontron, Zürich, Switzerland). After a three hours rest period the subjects performed the treadmill walk test with a constant speed of six $\mathrm{km}^{-\mathrm{h}^{-1}}$ and an increasing slope of $10,15,20$ degrees. Similar physiologic variables as in the running tests were registered.

\section{Data analysis}

Data were statistically analysed using the Wilcoxon test for non-parametric data. An analysis of variance and a postiori test were done on the results of the progressive uphill walking tests. The level of significance was set at 0.05 . Because of the limited number of participants the data are presented as medians.

\section{Results}

Immediate and late effects of cast-brace application as tested in the uphill walk test

The immediate effect (one day after application) of wearing the cast-brace is demonstrated in test 2 compared to test 1 (Fig.4). Submaximal oxygen uptake in the uphill walk test at subsequent slopes of $10^{\circ}, 15^{\circ}$ and $20^{\circ}$ showed an average rise of $9 \%$ (range $5 \%$ to $12 \% ; \mathrm{p}<0.05$ ). A similar effect was found for the heart rate (average rise $7 \%$; range $6 \%$ to $9 \%$; $<0.05$ ). Plasma lactate concentration was not affected. The late effects of wearing the cast-brace (four weeks of application) are shown in test 3 as compared to test 2 . Submaximal oxygen uptake showed a tendency to decrease (average $4 \%$; range $2 \%$ to $5 \%$; n.s.), but it remained elevated compared to the baseline test.

Anallysis of variance and a postiori test showed, that the heart rate was significantly higher during both tests wearing the brace (test 2 and test 3 ) and after removal (test 4 ).

Effects of four weeks of cast-bracing on various performance tests.

After removal of the cast-brace the subjects did not report any complaints and they were able to resume their usual gait. Peak torque of knee extension at five angular 

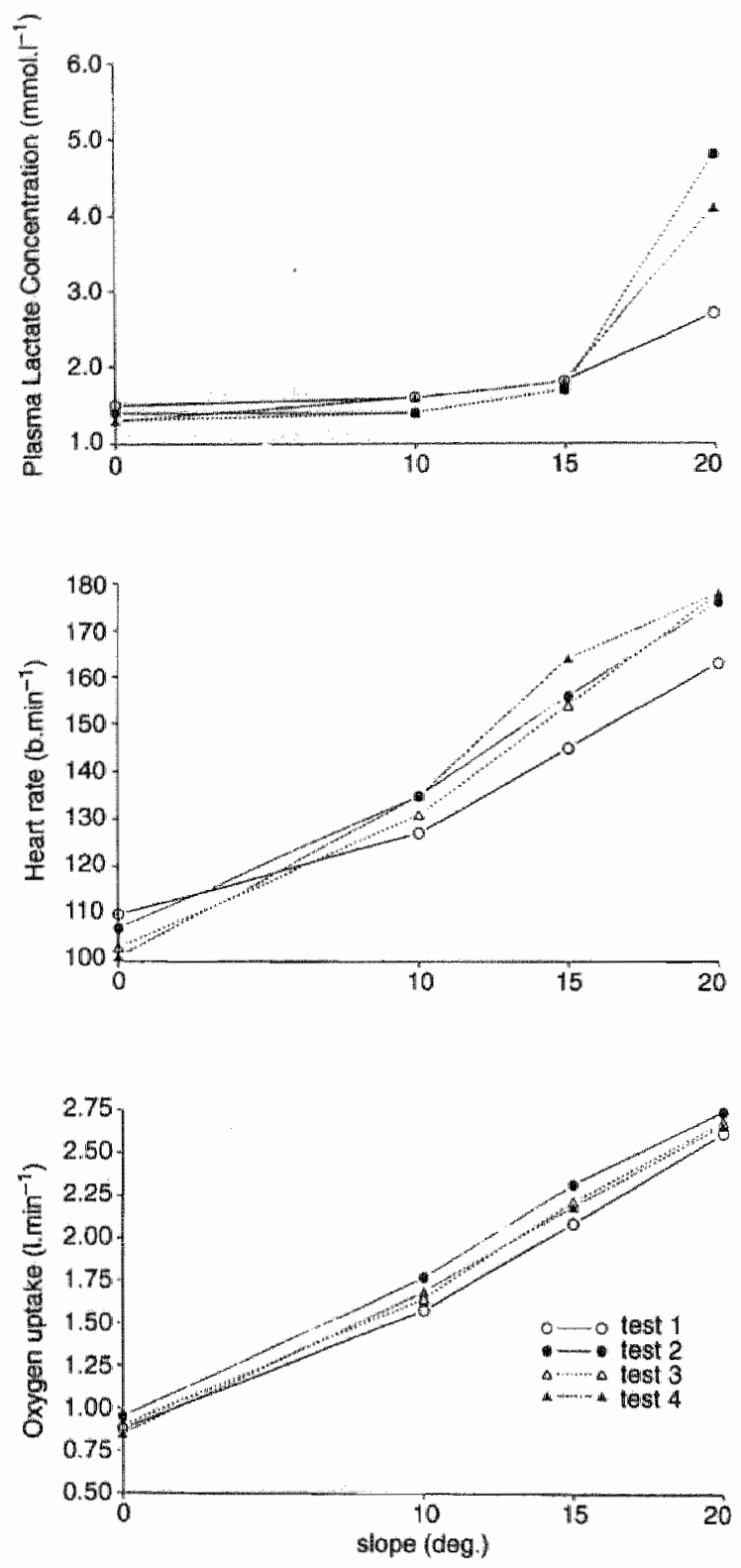

Fig. 2: Plasma lactate concentration (mmol..$^{11}$ ), heart rate (b. $\left.\mathrm{min}^{-1}\right)$ and oxygen uptake $\left(1 . \mathrm{min}^{-1}\right)$ in the progressive uphill walk test with slopes of $0^{\circ}, 10^{\circ}, 15^{\circ}$ and $20^{\circ}$. Test 1 represents the baseline values, test 2 is taken after cast-brace application, test 3 after 4 weeks of cast-brace application and lest 4 after removal of the cast-brace. Heart rate was significantly higher in test 2,3 and 4 as compared with test 1 (ANOVA; $<<0.05$ ). 
Table 3: Vertical jump height, $60 \mathrm{~m}$ dash and maximal speed achieved in graded treadmill running before application of the cast-brace and after removal. Values are medians and range.

\begin{tabular}{|c|c|c|}
\hline & $\begin{array}{l}\text { Pre-tes } \\
\text { day }-3\end{array}$ & $\begin{array}{l}\text { End-test } \\
\text { day }+1\end{array}$ \\
\hline jump height $(\mathrm{cm})$ & $49.0(34.58)$ & $49.0(35 \times 56)$ \\
\hline 60 m dash (s) & $8.88(7.74-10.12)$ & $8.29(7.56-10.54)$ \\
\hline $\operatorname{Vmax}\left(\mathrm{km} \cdot \mathrm{h}^{-1}\right)$ & $16.6(14.0-20.0)$ & $15.1(14.0-19.7)$ \\
\hline
\end{tabular}

velocities was unaffected (Fig.3). Knee flexion strength was also unaffected with the exception of an $8 \%$ rise $(\mathrm{p}<0.05)$ at $180 \mathrm{deg} . \mathrm{s}^{-1}$ (Fig.4).

The performances at $60 \mathrm{~m}$ dash, vertical jump height and the peak running speed in the progressive treadmill test were not significantly different between the pre- and post cast-brace period (Table 3). During the submaximal uphill walking none of the physiological parameters (submaximal oxygen uptake, heart rate and plasma lactate concentration) showed consistent differences between the baseline test and testing after removal of the cast-brace (Fig.2). Also no significant differences of the given parameters were observed during level treadmill running at 10,12 and $14 \mathrm{kn} . \mathrm{h}^{-1}$.

\section{Discussion}

A hinged cast-brace of the knee influences the daily use of the leg involved, although this cannot be quantified. The effect of wearing the cast-brace on energy expenditure was tested in an uphill walking test. The late effects after four weeks of application were evaluated with various performance tests. The tests were taken in a relatively small sample population of eight healthy subjects, therefore the results have to be regarded more as tendencies than as absolute values.

Immediate and late effects of cast-brace application as tested in the uphill walk test

All subjects completed the study. Apart from the mechanical hindrance of the cast-brace no complaints were reported. The uphill walk test with the cast-brace was completed by seven of the eight subjects. The oxygen uptake at submaximal exercise, as parameter for energy expenditure, was increased while wearing the cast-brace (test 2). The heart rate, as a parameter for the oxygen transport system, showed a corresponding rise. Plasma lactate concentration remained below two mmol. $\mathrm{l}^{-1}$ at the three lowest stages in both tests, indicating that the energy delivered was covered 


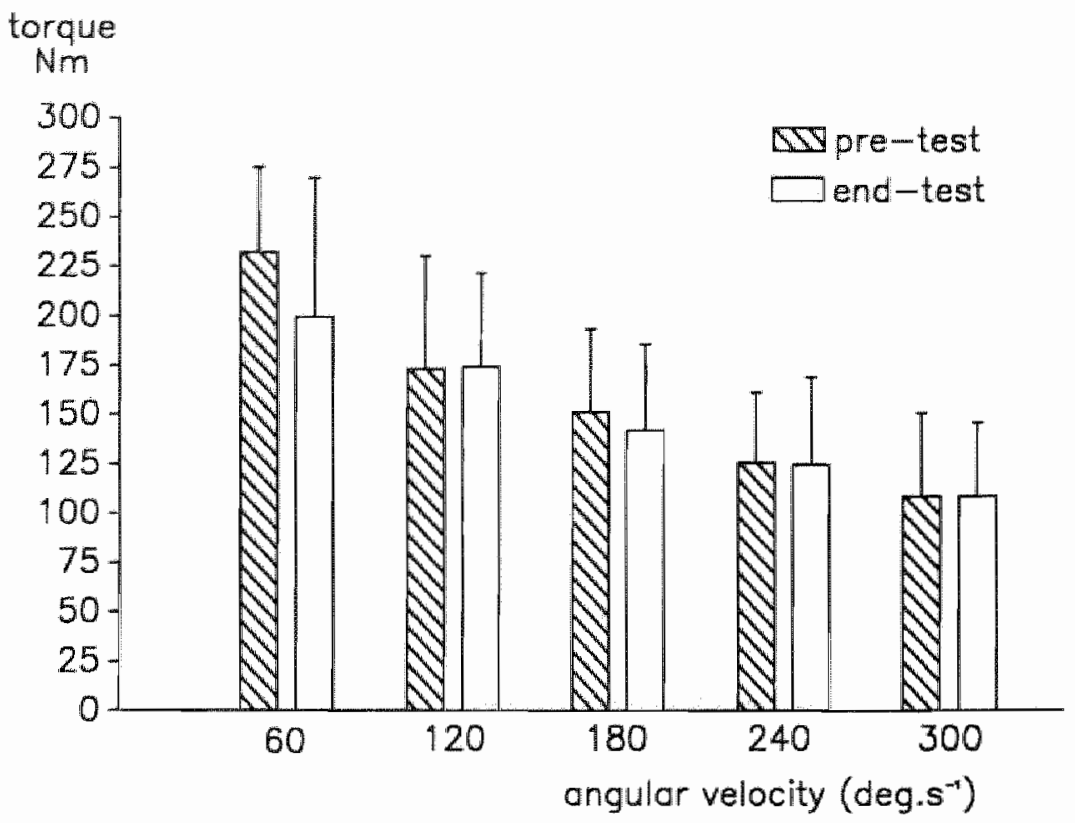

Fig. 3: Knee extension strength of the casted leg before application (test 1 ) and after removal (test 4).

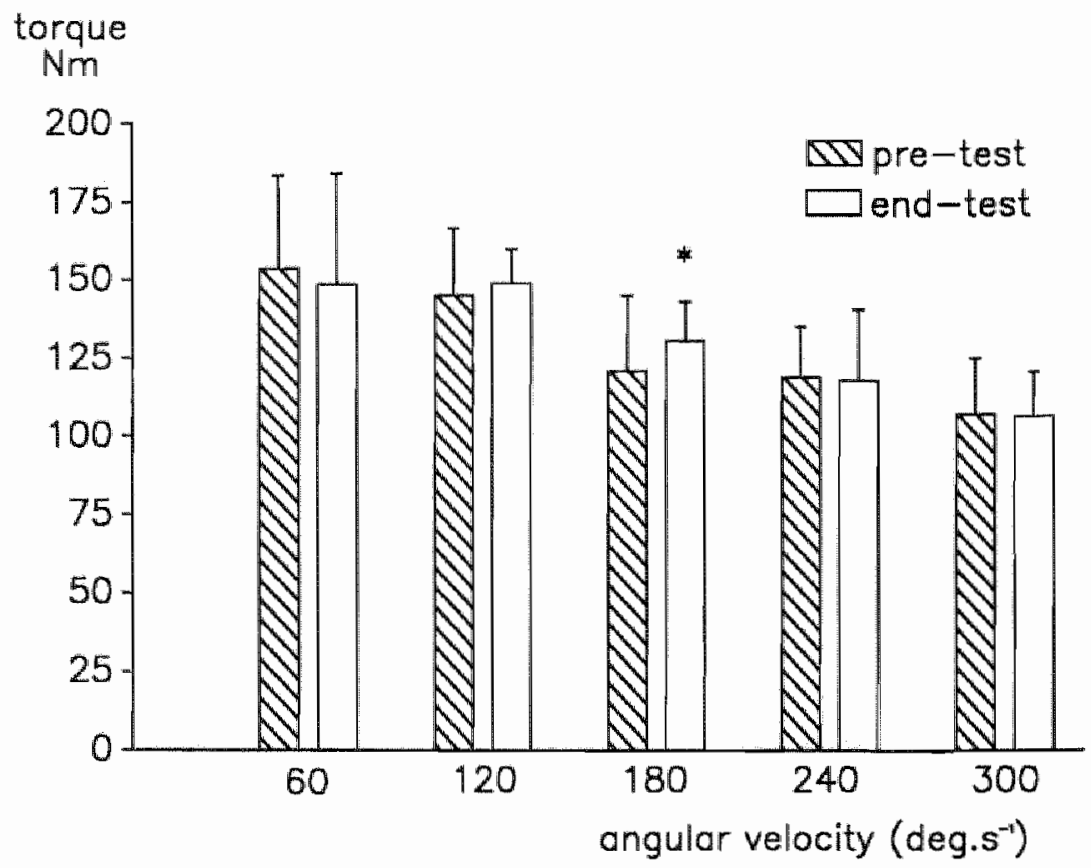

Fig. 4: Knee flexion strength of the casted leg before application (test 1) and after remowal (tesi 4$).(* 0<0.05)$ 
practically completely by aerobic processes. Only at a slope of $20^{\circ}$ was the exercise hard for several subjects, reflected in a rise in PLa (range 1.1 to $9.8 \mathrm{mmol}^{-1}$ ). In the literature no studies concerning the effects of cast-bracing on energy expenditure were found. When comparing our data with the effects of less firm functional knee braces similar increases in oxygen uptake and heart rate were reported. Zetterlund et al. revealed that patients wearing the Lennox Hill brace had a $4.6 \%$ higher $\mathrm{VO}_{2}$ and $5.1 \%$ higher HR while walking on a treadmil at a speed of $5.7 \mathrm{~km} \cdot \mathrm{h}^{-1}(20)$. Highgenboten published similar results for four different functional knee braces and reported a significant rise in energy expenditure of 3-8\% (9). The rise in oxygen uptake was dependent on the weight of the knee brace. It was demonstrated by Soule and Goldman that a weight added to a leg has a high mechanical impact with regard to the energy expenditure (17). Additionally Houston demonstrated that athletes wearing a functional knee brace had significantly less knee extension strength ( $12 \%$ to $30 \%$ ), were slower in unloaded knee extension, performed worse in a stair run and had a $41 \%$ higher plasma lactate concentration at submaximal bicycle ergometer loading (10).

\section{Effects of four weeks of cast-bracing on various performance tests}

Cast-bracing does restrict the normal use of the leg involved, but mainly for those movements that require a large flexion angle or a high angular velocity. Walking in daily life is acceptable, but running as in sports is practically impossible. It is unfeasible to monitor subjects for several weeks to estimate the difference in physical activity due to cast-brace application. However, it is reasonable to speculate that the overall physical activity has declined during cast-bracing resulting in a detraining effect. On the other hand it can be speculated that a training effect is elicted due to the mechanical hindrance by the hinges of the cast-brace and the extra weight applied to the leg. The results of various performance tests involving the thigh muscles revealed that the subjects were not significantly affected in either direction. This means that cast-bracing alone has no significant effect on the knee function of the thigh muscles.

Earlier we conducted a study with healthy subjects wearing a supportive knee brace for four weeks (18). Muscle strength of knee flexion and extension, sprint time at 60 $m$ dash and jump height were not affected by functional bracing. Running at submaximal speed revealed a slightly decreased heart rate, oxygen uptake and PLa, indicating some training effect due to mechanical hindrance by the brace. In the present study no significant differences were observed between post cast-brace tests and the baseline tests for muscle strength, sprint time at $60 \mathrm{~m}$ dash, jump height, or maximal running velocity, nor were there significant alterations at submaximal exercise. This might indicate that in the case of cast-bracing the training effect as observed in functional bracing is compensated for by a detraining effect due to decreased physical activity. 
Cast application for four weeks causes considerable loss of muscular strength and endurance capacity which can be observed in healthy subjects as well as in patients $(12,19)$. When comparing cast-brace application with casting in patients after knee ligament surgery, significantly increased muscle atrophy is observed after standard casting (7). Earlier (partial) recovery of muscle strength in patients with a cast-brace has also been reported (11). However, in patients treated with cast-bracing a considerable decrease in muscular function is observed whereas in the present study it was found that cast-brace application in healthy subjects did not result in any decline in muscular performance. Therefore, it must be concluded that the deterioration of muscular performance observed in patients after knee injury receiving surgery and cast-brace application is the result of other immobilizing factors; i.e. pain, fear of movement and joint effusion, and damage to the joint and/or muscle-tendon complex and not cast-bracing itself (5). 


\section{References}

1 Basset III FH, Beck JL: A modified cast brace: its use in non-operative and postoperative management of serious knee ligament injuries.

Am J Sports Med 1980, 8, 63-67

2 Burri $\mathrm{C}$, Henkemeyer $\mathrm{H}$, Pàssler HH: Funktionelle Behandlung nach Bandnaht und Plastik am Kniegelenk.

Langenbecks Arch Chir 1971, Suppl 112

3 Cooper RR: Alterations durng immobilization and regeneration of skeletal muscle in cats.

J Bone Joint Surg 1972, 54A, 919-953

4 Enneking WF, Horrowitz M: The intra-articular effects of immobilization on the human knee. J Bone Joint Surg 1972, 54A, 973-985

5. Eriksson E: Rehabilitation of muscle function after sport injury - major problem in sports medicine.

Int J Sports Med 1981, 2, 1-6

6 Gamble JG, Edwards CC, Max SR: Enzynatic adaptation in ligaments during immobilization. Am J Sports Med 1984, 12, 221-228

7 Häggmark T, Eriksson E: Cylinder or mobile cast brace after knee ligament surgery. A clinical analysis and morphologic and enzymatic studies of changes in the quadriceps muscle.

An J Sports Med 1979, 7, 48-56

8 Hettinger Th: Das Verhalten der Kraft eines trainierten Muskels willhrend und nach mehrtägiger Ruhigstellung.

Int Z Physial einschl Arbeitsphysiol 1961, 18, 357-360

9) Highgenboten CL, Jackson A, Meske N, Smith J: The effects of knee brace wear on perceptual and metabolic variables during horizontal treadmill running.

Am J Sports Med 1991, 19, 639-643

10 Houston ME, Goemans PH: Leg muscle performance of athletes with and withou knee support braces.

Arch Phys Med Rehabil $1981,63,431-432$

11 Indelicato PA: Non-operative treatment of complete tears of the medial collateral ligament of the knee.

I Bone Joint Surg 1983, 65A, 323-329

12 Kristensen $\mathrm{JH}_{\mathrm{H}}$ Hansen $\mathrm{TT}$ : Wasting and training of the human quadriceps muscle during treatment of knee ligament injuries.

Scand J Rehab Med 1985, Suppl 13

13 Küh J: Der Eimfluß der Immobilisation auf Zahl und Funktion der Osteoblasten.

Chinurg 1982, 53,160-164

14 Langenskiold A, Michelsson JE, Videman T: Osteoarthritis in the rabbit produced by immobilization.

Acta Orthop Scand $1979,50,1-14$ 
15 MacDougall JD, Ward GR, Sale DG, Sutton JR: Biochemical adaption of human skeletal muscle to heavy training and immobilization.

J Appl Physiol 1977, 43, 700-703

16 Sandberg R, Nilsson B, Westlin N: Hinged cast after knee ligament surgery. An J Sports Med 1987, 15, 270-274

17 Soule RG, Goldman RF: Energy cost of loads carried on the head, hands, or feet. J Appl Physiol 1969, 27, 687-690

18 Veldhuizen JW, Koene FMM, Oostwogel HJM, v. Thiel ThPH, Verstappen FT: The effects of a supportive knee brace on leg performance in healthy subjects.

Int J Sports Med 1991, 12.577-580

19 Veldhuizen JW, Verstappen FTJ, Vroemen JPAM, Kuipers H, Greep IM: Functional and morphological adaptations following four weeks of knee immobilization.

Int J Sports Med 1993, 14, 283-287

20 Zetterlund AE, Serfass RC, Hunter RE: The effect of wearing the complete Lennox Hill Derotation Brace on energy expenditure during horizontal treadmill running at 161 meters per minute.

Am J Sports Med $1986,14,73-76$ 


\title{
Chapter 5
}

\section{Functional and morphological adaptations following four weeks of knee immobilization}

\author{
J.W. Veldhuizen \\ F.T.J. Verstappen \\ J.P.A.M. Vroemen \\ H. Kuipers \\ J.M. Greep
}

Departments of Surgery, Movement Sciences and Physiology, University of Limburg,

Maastricht, The Netherlands 


\section{Summary}

Immobilization of the knee as part of the treatment in bone or joint lesions leads to atrophy and consequently loss of functionality. In patients this atrophy and loss of functionality is difficult to quanify because of interfering symptoms and missing baseline data. In the present study structural and functional changes in thigh muscles were examined in eight healthy volunteers of whom one leg was immobilized in a cast for four weeks. Quadriceps cross-sectional area determined with computed tomography was $21 \% \pm 7 \%$ diminshed after four weeks immobilization $(p<0.05)$. Muscle biopsies from the musculus vastus lateralis revealed an $16 \%$ decreased fiber diameter $(p<0.05)$ and no significant shift in fiber types. Isokinetic strength measurements of knee extensors and flexors demonstrated a fall in peak tarque of $52 \% \pm 9 \%$ and $26 \% \pm 13 \%$ at an angular velocity of 60 deg. $s^{-1}(p<0.01)$. Aerobic power in one-leg-cycling exercise was not significantly affected, but isokinetic quadriceps endurance work decreased from $9.1 \mathrm{KJ}$ 10 $5.6 \mathrm{KJ}(\mathrm{p}<0.05)$. Despite the fall in quadriceps performance the subjects had only minor functional complaints for a few days. It is concluded, that immobilization of the knee is an important factor in the development of thigh muscle atrophy in patients and should therefore be diminished as much as possible.

\section{Introduction}

Thigh muscle atrophy is a major problem in the rehabilitation following knee injury and/or surgery. Several factors are thought to be responsible for the development of quadriceps atrophy such as pain, joint effusion, tourniquet application during surgery, and probably the most important factor: immobilization $(2,3,6,8,9)$. It is an empirical finding that quadriceps atrophy in knee-injured patients is difficult to restore. Therefore much effort is spent on prevention of this muscle atrophy. Non-Steroid Anti-Inflammatory Drugs (NSAID) are administered to relieve pain and diminish joint effusion. Transcutaneous Neural Stimulation (TNS) may reduce pain, while electromyostimulation can decrease muscle atrophy $(10,15,23,26)$. To avoid immobilization cast-bracing is applied whenever possible $(12,22)$. However, the effect of immobilization alone on thigh muscles in humans has not been examined yet. Several techniques are available to analyze the effects of immobilization. Muscular strength and endurance and motoric skills are functional. variables, whereas leg circumference, histology, histochemistry and Computed Tomography (CT) or Ultrasound provide information on muscle siructure. 
Functional testing is not possible immediately following immobilization in patients. therefore most data refer to passive measurement techniques or are obtatined after partial rehabilitation.

Therefore the aim of the present study is to quantify the deterioration of leg performance due to immobilization alone by functional and morphological measuring techniques in healthy subjects.

\section{Materials and Methods}

\section{Design}

Eight healthy volunteers participated in this study after giving their written informed consent. The main characteristics of the subjects are listed in Table 1.

The participants had no history of prior knee injury and all had a sedentary life style. In two preparatory training sessions they were accustomed to the isokinetic measuring techniques, and a $\mathrm{VO}_{2} \max$ test on a bicycle ergometer was performed to determine the $\mathrm{VO}_{2} \max$ workload (W/max).

A long leg cast (Scotch Cast ${ }^{\circledR}$ ) was applied to the randomly selected left or right leg for four weeks. Weight bearing on the casted leg was not allowed.

Leg performance and muscular atrophy were examined before and after immobilization.

Table 1: Characteristics of the subjects

\begin{tabular}{|c|c|c|c|c|c|c|}
\hline \multirow[t]{2}{*}{ Sex } & \multirow{2}{*}{$\begin{array}{l}\text { Age } \\
\mathrm{yr}\end{array}$} & \multirow{2}{*}{$\begin{array}{l}\text { Length } \\
\mathrm{cm}\end{array}$} & \multirow{2}{*}{$\begin{array}{l}\text { Weight } \\
\mathrm{kg}\end{array}$} & \multirow{2}{*}{$\begin{array}{l}\mathrm{VO}_{2} \max \\
\text { Inmin' }\end{array}$} & \multicolumn{2}{|c|}{$\begin{array}{l}\text { Peak torque at } 180 \text { degs } s^{-1} \\
\text { knee extension pre-immob }\end{array}$} \\
\hline & & & & & casted leg & control ( $\mathrm{Nm})$ \\
\hline $\mathrm{F}$ & 21 & 157 & 62 & 2.18 & 99 & 95 \\
\hline$M$ & 20 & 179 & 63 & 3.11 & 121 & 141 \\
\hline $\mathrm{F}$ & 21 & 163 & 56 & 2.07 & 89 & 85 \\
\hline $\mathrm{M}$ & 23 & 183 & 72 & 2.74 & 131 & 165 \\
\hline $\mathrm{M}$ & 23 & 184 & 70 & 3.18 & 155 & 165 \\
\hline$M$ & 19 & 187 & 84 & 3.89 & 137 & 171 \\
\hline M & 20 & 183 & 60 & 3.42 & 135 & 113 \\
\hline $\mathrm{M}$ & 26 & 176 & 85 & 3.46 & 165 & 173 \\
\hline median & 21 & 181 & 66.5 & 3.15 & 133 & 153 \\
\hline
\end{tabular}

Quantification of muscle atrophy

Muscle atrophy was quantified by means of computed tomography (CT) and histological parameters. Immediately before application and after removal of the cast 
the cross-sectional area of the quadriceps femoris was measured by means of CT at the mid-thigh-region. The location of the cross-sectional scanning was marked as a given distance from the medial femoral condyle.

Further a biopsy from the $m$. vastus lateralis was taken with a Bergstrøm needle, ten to fifteen cm proximally from the patella. The muscle sample was mounted on cork and quickly frozen on isopenthane, cooled to the melting point in liquid nitrogen. The samples were stored at $-80^{\circ} \mathrm{C}$ untill processing. From the frozen samples ten $\mu \mathrm{m}$ thick serial cross sections were cut in a cryostat at $-20^{\circ} \mathrm{C}$ and mounted on cover glasses for histochemical staining. The samples were stained for ATPase after pre-incubation at $\mathrm{pH} 4.2$ and 4.6 and classified as type I, IIa and IIb. The ATPase stained sections were analyzed for morphometrical characteristics (lesser fiber diameter) using a Kontron Mop Videoplan Digitizer System (Zeiss, Germany) (7).

\section{Leg performance}

Test series examining leg performance were conducted some days before application of the cast and three days after removal. Leg performance parameters were strength of the knee flexion and extension movement, and endurance of knee extension. Strength was measured as maximal torque output (PT; Nm) using a Cybex. II isokinetic dynamometer (Lumex, N.Y.). PT was recorded for both knees at angular velocities of $60,120,180,240$ and $300 \mathrm{deg} . \mathrm{s}^{-1}$ from two series of five movements with maximal effort. Data were not corrected for gravity.

Endurance was tested with one-leg-cycling and an isokinetic knee extension protocol. One-leg-cycling was performed on an electromagnetically braked bicycle ergometer (Lode, Germany) at workloads of $30 \%, 40 \%, 50 \%$ and $60 \%$ of the previously determined maximal aerobic power (Wmax; Watt) with two-leg-cycling. Every three minutes the workload was increased stepwise and heart rate (HR; b. $\left.\mathrm{min}^{-1}\right)$ and oxygen uptake $\left(\mathrm{VO}_{2} ; 1 . \mathrm{min}^{-1}\right)$ were monitored continuously by means of an ECG recorder (Hellige, Freiburg, Germany) and an automatic pulmonary metabolic apparatus (EOS Sprint, Jaeger, Würzburg, Germany), respectively. At the end of each workload a blood sample was drawn from a catheter in an antecubital vein for plasma lactate analysis (PLa; mmol..$^{-1}$ ).

The isokinetic endurance test consisted of bouts of 200 knee extensions. The subjects were instructed to perform extension movements at an angular velocity of $180 \mathrm{deg} . \mathrm{s}^{-1}$ at a given torque level of $20 \% \mathrm{PT}$, alternated with passive knee flexion. Range of motion was set from full extension to maximal flexion $(100 \mathrm{deg}$.). Torque level was indicated on an oscilloscope placed in front of the subject for visual feedback. After completing this step the torque level was increased with $20 \% \mathrm{PT}$ to $40 \% \mathrm{PT}$ and so on , untill exhaustion. The test ended when the subject could not meet the demanded torque level or when the cumulative work was less than the previous step. Torque of knee flexion and extension were registered by means of an Apple II computer with an AD-chart sampling at $50 \mathrm{~Hz}$. Custom made software provided total work of each 
step of 200 movements. $\mathrm{HR}, \mathrm{VO}_{2}$, PLa and cumulative work (J) were measured during the test.

All leg performance tests were taken on one day. First the strength of knee flexion and extension was measured, next the endurance tests (isokinetic and one-leg-cycling) were taken in random order with $1 / 2$ to two hours rest. After this interval no fatigue was indicated by the subjects, irrespective of the test order.

\section{Statistics}

The Wilcoxon test (non-parametric) was used for statistical analysis of the pre and post casted data. The level of significance was set at $p<0.05$. Results of strength and endurance testing are presented as medians with range. Pre and postimmobilization differences are presented as means $\pm S . D$.

\section{Results}

\section{Symptoms after cast removal}

During the first and second day after removal of the cast some subjects were hindered by stiffness of knee and ankle joint, impairing normal gait. At day three full range of motion of knee and ankle joint were restored and they were able to walk normally without discomfort.

\section{Quantification of muscular atrophy}

Computed tomography of the quadriceps immediately after removal of the cast revealed a $21 \% \pm 7 \%$ decrease in quadriceps area of the casted leg compared with $\mathrm{CT}$ findings before immobilization $(\mathrm{p}<0.05)$.

The biopsy specimens of the $m$. vastus lateralis showed on average $16 \%$ decrease in fiber diameter ( $<<0.05$ ) and $8 \%$ more type II fibers (n.s.) after immobilization (Table 2). The fiber area of the type I fibers decreased from $42 \%$ to $34 \%$ (n.s.). No pathological changes in cell structure were observed.

\section{Leg performance}

After immobilization the strength of knee flexion was decreased to maximal $26 \% \pm$ $13 \%$ at 60 deg. $\mathrm{s}^{-1}(\mathrm{p}<0.01)$. The decrease of knee extension strength was much more pronounced : $52 \% \pm 7 \%$ at $60 \mathrm{deg} . \mathrm{s}^{-1}, 53 \% \pm 9 \%$ at $120 \mathrm{deg} . \mathrm{s}^{-1}, 45 \% \pm 12 \%$ at 180 deg. $\mathrm{s}^{-1}, 43 \% \pm 10 \%$ at $240 \mathrm{deg} \cdot \mathrm{s}^{-1}$ and $41 \% \pm 9 \%$ at $300 \mathrm{deg} \cdot \mathrm{s}^{-1}(\mathrm{p}<0.01)$, see Figs. 1 and 2. Muscular strength was already retumed to pre-immobilization values without specific training when the subjects were examined finally ten weeks after removal of the cast. 
Table 2: Muscle fiber characteristics in muscle biopsies taken from the m. vastus lateralis (median and range). $p<0.05$

Pre-immobilization Post-immobilization

typel

fiber diameter $(\mu \mathrm{m})$

percentage lype I fibers ( $\%$ )

relative area (\%)

\section{type Ila}

fiber diameter ( $\mu \mathrm{m})$

percentage type Ila fibers (\%)

relative area (\%)

type $\| b$

fiber diameler ( $\mu \mathrm{m})$

percentage type $I$ llb fibers (\%)

relative area (\%)

$\begin{array}{ll}63.2(55.4-90.9) & 53.8(44.5-65.1)^{*} \\ 40.0(26-67) & 35.0(22-49) \\ 34.4(16.4-99.9) & 26.7(17.9-53.9)\end{array}$

$58.9(53.7-102.9)$

$26.0(10-44)$

$20.3(7.0 .43 .3)$

$54.7(45.5-76.0)$

$33.0(20.51)$

$25.6(18.8-57.8)$

$71.0(62.0-102.5)$

$29.5(16-44)$

$40.1(15.0-66.7)$
$57.4(50.8-85.1)^{*}$

$26.0(20-46)$

$30.2(19.1 \times 55.7)$

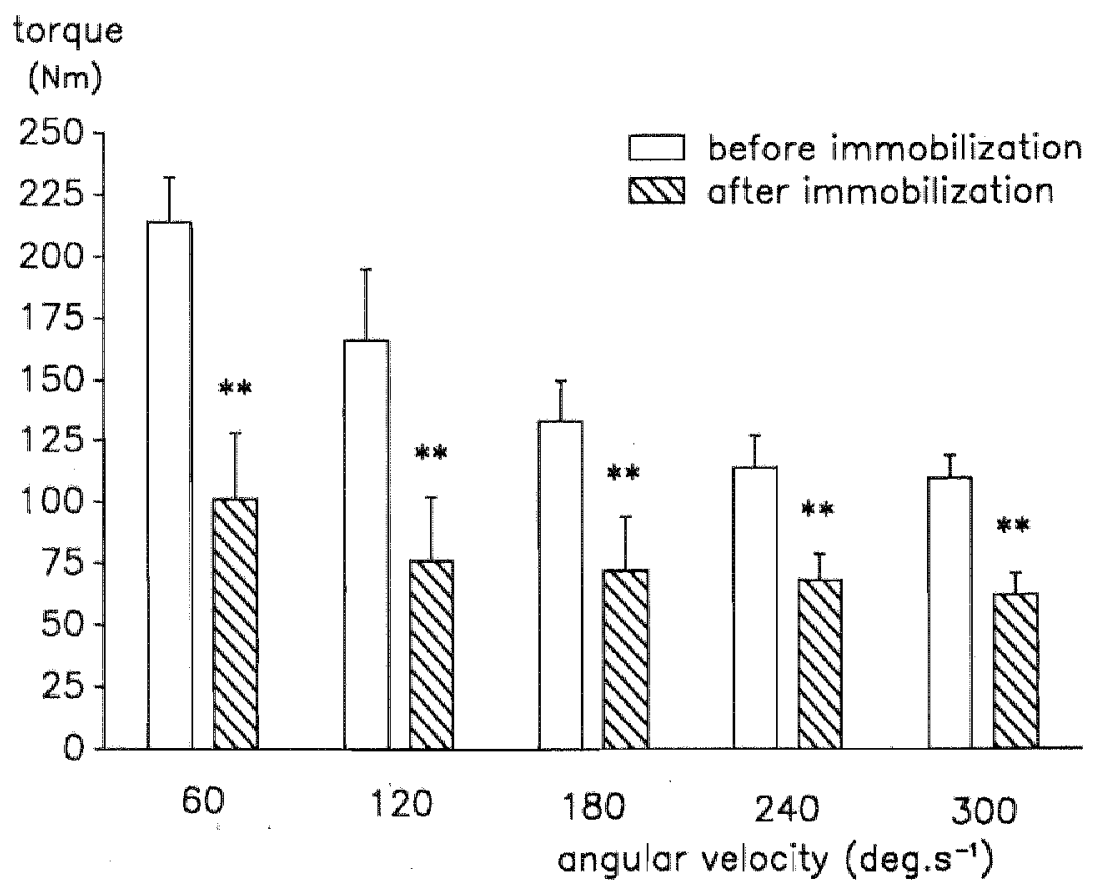

Fig. 1: Peak torque of knee extension before and after immobilization, median with $75^{\text {th }}$ percentile $(n=8)$.

$p<0.01$ 
Table 3: HR (b.min-1), VO2 (lmin-1) and PLa (mmol.1-1) at the progressive onewleg-cycling test at 30\%, $40 \%$, and $50 \%$ of the previously established two-legged Wmax (Pared samples). Duta are nedians with range.

\begin{tabular}{llll}
\hline Activitylevel (\%Wmax) & parameter & Pre-immobilization & Post-immobilization \\
\hline $30 \%$ & $\mathrm{HR}$ & $148(128-153)$ & $143(126-172)$ \\
$\mathrm{n}=8$ & $\mathrm{VO}_{2}$ & $1.28(0.84-1.64)$ & $1.25(0.80-1.64)$ \\
& $\mathrm{PLa}$ & $3.0(2.0-4.7)$ & $3.0(2.2-4.7)$ \\
& $\mathrm{HR}$ & $164(142-175)$ & $165(141-184)$ \\
$40 \%$ & $\mathrm{VO}$ & $1.75(0.98-2.01)$ & $1.75(1.19-2.12)$ \\
$\mathrm{n}=8$ & $\mathrm{PLa}$ & $4.4(3.2-6.5)$ & $5.1(3.2-6.1)$ \\
& & $177(162-183)$ & $177(168-191)$ \\
$50 \%$ & $\mathrm{HR}$ & $2.07(1.36-2.49)$ & $2.09(1.65-2.66)$ \\
$\mathrm{n}=6$ & $\mathrm{VO}_{2}$ & $6.05(4.0-9.1)$ & $6.8(4.6-9.1)$ \\
& $\mathrm{PLa}^{2}$ & & \\
\hline
\end{tabular}

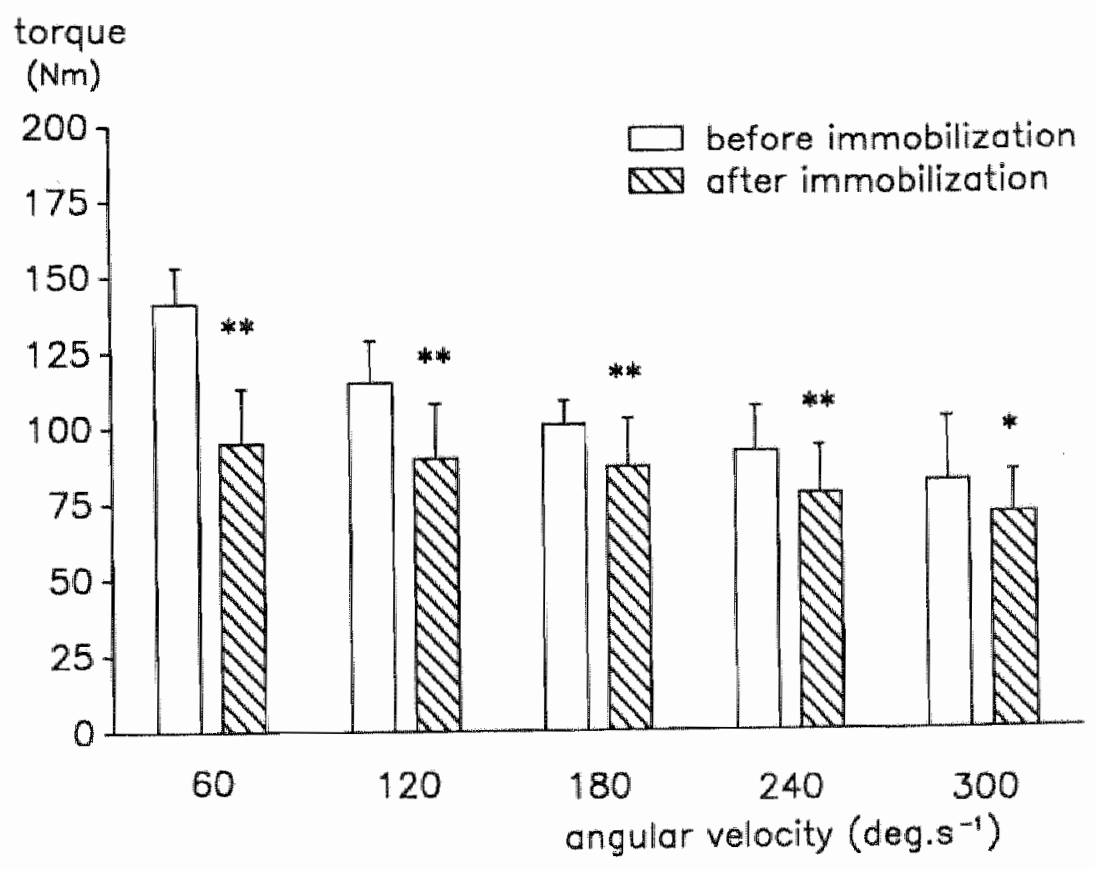

Fig. 2: Peak torque of knee flexion before and after immobilization, median with $75^{\text {th }}$ percentile $(n=8)$.

$* \mathrm{p}<0.01, \mathrm{p}<0.05$ 


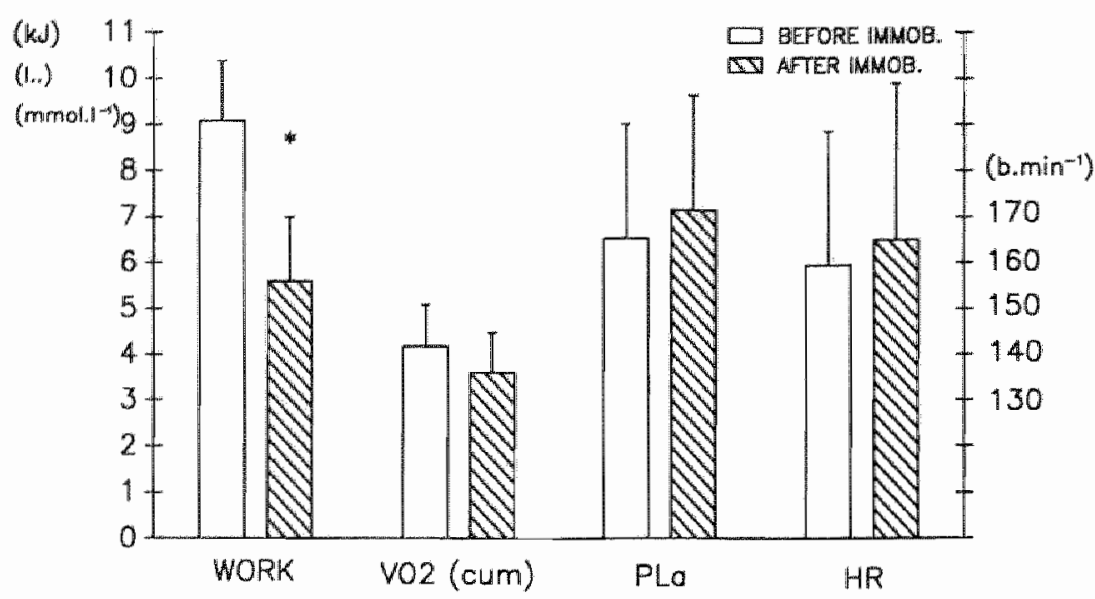

Fig. 3: Cunulative work, Oxygen uptake, Plasme Lactate Concentration and Heart Rate al an isokinetic quadriceps endurance test consisting in 200 repetitions al $40 \%$ of quadriceps peak torque at 180 deg.s $\mathrm{s}^{-1}$, before and after immobilization, median with $75^{\text {th }}$ percentile.

$* p<0.05$

Wmax at one-leg-cycling was $58 \% \pm 4 \%$ of the two-leg-cycling Wmax before immobilization, and $51 \% \pm 8 \%$ after immobilization (n.s.). With the non-casted leg the fall was only $1 \%$ after immobilization (n.s.). Physiological variables $\mathrm{HR}, \mathrm{VO}_{2}$ and PLa showed no significantly difference in response between pre- and post-immobilization tests of the casted leg at $30 \%, 40 \%$ and $50 \%$ Wmax (Table 3 ).

At isokinetic quadriceps endurance testing all subjects had the highest mechanical output at $40 \% \mathrm{PT}$. The results showed a $27 \%$ fall in maximal work delivered in 200 knee extension movements from median $9.1 \mathrm{KJ}$ (range $2.7-12.2$ ) to $5.6 \mathrm{KJ}$ (range $1.8-9.7)(\mathrm{p}<0.05)$, and a concomitant decrease in $\mathrm{VO}_{2}$ of $9 \%$, and a rise in HR of $4 \%$ and PLa of $18 \%$ (n.s.) as shown in Fig.3.

\section{Discussion}

The aim of the present study was to quantify the effects of leg immobilization on thigh muscles in healthy subjects and to study the process of muscle atrophy in association with muscle function apart from interfering symptoms as found in patients with knee injuries. 


\section{Quantification of muscle atrophy}

After four weeks of immobilization quadriceps area was decreased $21 \%$. The muscle fiber diameter was decreased by $16 \%$, resulting in a $29 \%$ decrease in mean crosssectional fiber area. This is in accordance with the findings after immobilization in patients and healthy subjects. As reported by Ingernann-Hansen and Kristensen cast-immobilization for 5 weeks after a knee ligament injury and subsequent surgery resulted in a decrease of $26 \%$ in quadriceps area measured by the CT scanning technique (14). Davies found a $10 \%$ decrease in calf circumference after three weeks of immobilization and White reported an $8 \%$ decrease in calf circumference after two weeks of cast immobilization $(5,25)$.

In the present study no significant change in fiber type distribution was found. Kristensen studied muscle fiber size and composition before and after surgical treatment of a knee ligament lesion with a subsequent cast immobilization of thirty-one days (17). He found a $6.1 \%$ decrease in the number of type I fibers and at $8 \%$ decrease in type I cross-sectional fiber area and a $5 \%$ increase in type II fiber area. The reported shift towards more type II fibers was even more pronounced in the present study, although not significant.

\section{Leg performance}

Isokinetic dynamometry does not mimic natural movements. In rehabilitation and sports medicine it has been generally accepted as a safe and reliable method of performance testing. Isokinetic strength is well related with functional scores in patients after knee injury/surgery (24). The results of isokinetic fatigue testing are known to be related to muscle structure (18).

Immobilization has a dramatic effect on quadriceps strength and to a lesser degree on the strength of the hamstrings, resulting in a deterioration to maximal $52 \%$ and $26 \%$, respectively, at isokinetic measurements at $60 \mathrm{deg} . \mathrm{s}^{-1}$. The somewhat lower decrease of knee extension strength at the higher angular velocities is an underestimation because the data are not corrected for gravity.

McDougall, who studied the m. triceps brachii found a decrease in strength of $35 \%$ after five weeks of immobilization and $41 \%$ after $5-6$ weeks $(19,20)$. In a further study the forearm was immobilized for the short period of one week, resulting in a $20 \%$ and $13.1 \%$ decrease in strength of the $\mathrm{m}$. triceps and $\mathrm{m}$. biceps brachii, respectively (21). Two weeks immobilization of the $m$. triceps surae resulted in a $24 \%$ decrease in strength (25). Animal studies show that atrophy is more pronounced when muscle is immobilized in a shortened position, and that the loss of tissue is most rapid during the first week of immobilization $(1,4)$. Animal studies have also shown that muscles rich in type I fibers are more affected than muscles with mixed fiber typing. These findings seem to contradict the empirical finding that knee extensors are far more susceptible to atrophy than knee flexors, rich of type I fibers 
(16). However, three of the four heads of the m. quadriceps femoris are mono-articular, while the hamstrings are bi-articular and thus not completely immobilized in a leg cast.

Maximal power at one-leg-cycling was $7 \%$ lower after four weeks of immobilization. Maximal work of the $\mathrm{m}$. quadriceps at 200 knee extensions in isokinetic endurance testing was $27 \%$ lower. Endurance has seldomly been tested after a period of immobilization. In general, endurance is tested as aerobic power with progressive exercise testing on a bicycle ergometer or treadmill. Such a protocol is appropriate in evaluation of systemic variables, but not really for regional muscle exercise. Surprisingly, the 7\% decrease in Wmax with sedentary subjects at one-leg-cycling seems to correlate well with data of well trained subjects in whom a $4 \%$ decrease in $\mathrm{VO}_{2} \max$ was observed at treadmill running after one week of immobilization and one week of detraining. However recovery of $\mathrm{VO}_{2}$ max to pre-immobilization/detraining values seems to be slow in athletes (13).

One-leg-cycling is thought to be a more specific test for leg performance enabling pre to post and left to right comparisons. In the present study the findings in one-leg-cycling were non-conclusive. The relatively high workloads established in these tests indeed suggest that a vast muscle volume is active during one-leg-cycling. Thigh muscle activity only accounts for a small portion of the work capacity. This test should therefore be considered to be a variety of bicycle ergometry instead of a specific thigh muscle endurance test. Isokinetic quadriceps testing using a stepwise loading protocol has not been used so far. The endurance testing of an isolated movement as used in the present study enables us to quantify deterioration of muscle aerobic capacity next to muscle strength and to make left to right comparisons. It is known that oxidative enzyme activity decreases in patients suffering a knee injury. As reported by Häggmark the quadriceps succinate dehydrogenase activity (SDH) correlates well with endurance and is decreased $21 \%$ after knee surgery and five weeks of immobilization (11). The decreased maximal work capacity of the $\mathrm{m}$. quadriceps at isokinetic testing in this study after immobilization correlates well with the decreased enzyme activity as reported in patients after knee surgery and immobilization.

\section{Clinical relevance}

The development of muscle atrophy in patients after knee injury or surgery is considered to be multi-causal. In the present study the effect of immobilization is isolated and studied in a realistic model. Next to atrophy the deterioration of muscle function is also studied. The morphological changes in the present study correlate well with the findings in comparable studies in patients. There are no comparable studies in patients concerning the deterioration of muscle function. It is known that under physiologic conditions strength is linearly correlated with cross-sectional muscle area. However in the present study a $21 \%$ decrease in cross-sectional area 
was accompanied by a $53 \%$ decrease in strength. Apparently, immobilization has not only caused a decrease in cross-sectional area (atrophy), but also the performance of the remaining muscle is decreased. Temporary loss of coordination, an important feature in isokinetic testing, might partly be responsible for this observation.

\section{Conclusions}

Four weeks of non-weight-bearing immobilization results in serious deterioration of the $\mathrm{m}$. quadriceps femoris as demonstrated by measurements of strength, endurance, muscle cross sectional area and muscle fiber diameter.

The atrophy observed in the present study after immobilization in healthy subjects is comparablle with the atrophy found in patients after injury and/or surgery followed by immobilization. It can therefore be concluded that the effect of immobilization overshadows all other factors known to inflict muscle atrophy. 


\section{References}

1 Appell $\mathrm{H}$ : Morphology of immobilized skeletal muscle and the effects of a pre- and postinmobilization training program.

Int J Sports Med 1986, 7,6-12

2 Appell HU: Skeletal muscle atrophy during immobilization. Int I Sponts Med $1986,7,1-5$

3 Arvidson I, Eriksson E, Knutsson $\mathrm{E}$, Arner $\mathrm{S}$ : Reduction of pain inhibition on voluntary muscle activation by epidural anaigesiz. Orthopedics 1986, 9, 1415-1419

4 Cooper RR: Alterations during immobilization and regeneration of skeletal muscle in cats. J Bone Joint Surg 1972, 54, 919.953

5 Davies CT, Rutherford IC, Thomas DO: Electrically evoked contractions of the triceps surae during and following 21 days of woluntary leg immobilization.

Eur J Appl Physiol 1987, 56, 306-312

6 deAnrade J, Grant C. Dixon A: Joint distension and reflex muscle inhibition in the knee. J Bone Joint Surgery $1965,47 \mathrm{~A}, 313-322$

7 Dubowitz V: Muscle biopsy a practical approach. $2^{\text {nd }}$ edition, London, Philadelphia, Toronto, Bailliere Tindal, 1985

8 Eriksson E: Rehabilitation of muscle function after sport injury -Major problem in sports medicine.

Int J Sports Med 1981, 2, 1-6

9 Gersoff W, Ruwe P, Joki P, Panjabi M: The effect of tourniquet pressure on muscle function. Am J Sports Med 1989, 17, 123-127

10 Gipson JNA, Smith K, Rennie MJ: Prevention of disuse muscle atrophy by means of electrical stimulation: Maintenance of protein synthesis.

Lancer 1988, 88, 767-769

11 Haggmark T, Jansson E, Eriksson E: Fiber type area and metabolic potential of the thigh muscle in man after knee surgery and immobilization.

Int J Sports Med 1981, 2, 12-17

12 Haggmark T, Eriksson E: Cylinder or mobile cast brace after knee ligament surgery.

Am J Sports Med 1979, 7, 48-56

13 Houston ME, Bentzen H, Larsen H: Interrelationships between skeletal muscle adaptions and performance as studied by detraining and retraining.

Acta Physiol Scand 1979, 105, 163-170

14 Ingemann-Hansen T, Kristensen JH: Computerized tomographic determination of human thigh components.

Scand J Rehabil Med 1980, 12, 27-31 
15 Jensen $J$, Conn $R$, Hazelrigg $G$, Hewett $J$ : The urse of transcutaneous neural stimulation and isokinetic testing in arthroscopic knee surgery.

Am J Sports Med 1985, 13,27-33

16 Johnson MA, Polgar J, Weightman D, Appleton A: Data on the distribution of fibre types in thirty-six human inuscles. An autopsy siudy.

J Neurol Sci 1973, 18, 111-129

17 Kristensen JH. Ingemann-Hansen T: Wasting of the human quadriceps muscle after knee ligament injuries. Ill muscle fibre morphology.

Scand J Rehabil Med 1985, Suppl 13, 12-20

18 Lorentzon R, Johansson C, Sjöström M, Fagerlund M, Fugl-Meyer AR: Fatigue during dynamic muscle contractions in male sprinter and marathon rumners: relationships between performance. electromyographic activity muscle cross-sectional area and morphology.

Acta Physiol Scand 1988, 132,531-536

19 MacDougall JD, Elder GCB, Sale DG, Moroz JR, Sutton JR: Effect of strength training and immobilization on human muscle fibres.

Eur J Appl Physiol 1980, 43, 25-34

20 MacDougall JD, Ward GR, Sale DG, Sutton JR: Biochenical adaption of human skeletal muscle to heavy resistance training and immobilization.

J.Appl Physiol 1977, 43, 700-703

21 Müller EA, Hettinger Th: Uber Unterschiede der Trainingsgeschwindigkeit atrophierter und normaler Muskeln.

Arbeitsphysiol $1950,15 \mathrm{~S}, 223-230$

22 Sandberg R, Nilsson B, Westlin N: Hinged cast after knee ligament surgery.

Arn J Sports Med 1987, 15, 270-274

23 Snyder-Mackler L, Ladin Z, Schepsis AA, Young JC: Electrical stimulation of the thigl muscles after reconstruction of the anterior cruciate ligament.

J Bone Joint Surg 1991, 73A, 1025-1036

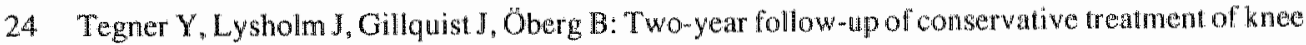
ligament injuries.

Acta Orthop Scand 1984, 55, 176-180

25 White MJ, Davies CT, Brooksby P: The effects of shortterm immobilization on the contractile properties of human triceps surae.

J Exp Physiol 1984, 69, 685-691

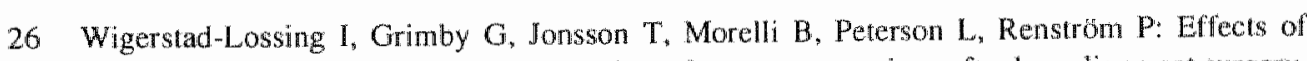
electrical muscle stimulation combined with voluntary contractions after knee ligament surgery. Med Sci Sports Exerc 1988, 20,93-98 



\section{Chapter 6}

\section{Transposition of the semitendinosus tendon for early repair of medial and anteromedial laxity of the knee}

J.W. Veldhuizen

J.W.J.L. Stapert

H.J.M. Oostvogel

F.M.M. Koene

Departments of Surgery and Movement Sciences, University of Limburg,

Maastricht, The Netherlands 


\section{Summary}

In 15 patients with acute medial $(n=8)$ or anteromedial $(n=7)$ laxity of the knee, reconstruction of the torn ligaments was combined with the use of the semitendinosus tendon as a dynamic extra-articular stabilizer. The postoperative regimen consisted of early mobilization in a cast-brace with full weight bearing. An evaluation 1 to 3 years after surgery revealed good results in 14 cases, and one fair result as graded using the Marshall score (mean score 45.3, S.D. 2.9). Isokinetic measurements of knee flexion and extension showed no loss of strength.

Equally good results have been reported in conservatively treated isolated $M C L$ lesions. The operative treatment cannot be considered anything but an alternative in these cases. In case of a combination of a MCL lesion and an ACL lesion the results reported are usually worse. This treatment regimen with emphasis on functional rehabilitation seems to be a good concept in acute anteromedial laxity of the knee.

\section{Introduction}

The treatment of complete tears of the medial collateral ligament (MCL) of the knee, isolated or with concomitant ligament damage, has been debated since 1930 (7) and no consensus of opinion exists as how to these lesions should be treated. Initial treatment can be either conservative or operative, and rehabilitation is functional, i.e. short immobilisation with functional early training, or defensive with prolonged immobilisation in a cylinder cast. In 1984 and 1985 we have treated these lesions operatively with a primary repair of the torn ligament, reinforcing it by means of a transposition of the semitendinosus tendon. The overlying tendon is thought to provide an active support to the injured M.C.L. (dynamic stablisation). This reinforcement allows early mobilization with functional training. The aim of this follow-up study is to compare our results with other series in order to evaluate this treatment.

\section{Materials and methods}

In 1984 and 1985 all patients presenting with a fresh rupture of the MCL underwent operative treatment. A total of 15 patients were treated this way. All patients showed complete MCL lesion during operation. Eight patients with a mean age of 33.5 years (range 16-72 years) with isolated MCL lesions were treated by means of repair of the MCL and semitendinosus transfer only. Seven patients with a mean age of 34.8 
years (range 22-65 years) suffered concomitant damage, all of which were total anterior cruciate ligament $(\mathrm{ACL})$ lesions, one combined with a small eminentia fracture, which was reinserted with the ACL sutures, and one with a minor tibia condyle fracture treated with internal fixation. After operation all patients were immobilised in a splint for 2 weeks, after which period the stitches were removed and a cast-brace was applied. Full weightbearing was allowed, and in the next weeks the flexion range of the hinges was extended stepwise to the maximum of $100^{\circ}$, the extension range remained limited to $20^{\circ}$ throughout this period

This follow-up study includes all 15 patients treated by this method. The results were scored using both the anamnestic scale of the Lysholm score, and the combined anamnestic and physical examination scale as advocated by Marshall $(5,6)$. Marshall classed the results in four groups i.e. 41-50 good-excellent, 36-40 fair, 31-35 moderate, and less than 30 as poor. Scoring was done by 2 independent physicians. In the final score only the lowest result was used. Maximum dynamic strength of knee extension and flexion were measured in $\mathbb{1 3}$ patients using an isokinetic dynamometer (Cybex II, Lumex, N.Y.). The angular velocities studied were 60, 120, 180 , 240 , and $300^{\circ} \cdot \mathrm{s}^{-1}$.

\section{Operative technique}

Before the operation started all knees were tested under general anesthesia for concomitant ligament lesions. In the case of a concomitant ACL lesion the operation started with arthrotomy, and continuity of the ACL was restored by suturing. For repair of the MCL a medial Payr incision was used to expose the medial retinaculum. The medial retinaculum was dissected. The tear in the MCL was inspected, and the fibers were approximated. the tendon of the semitendinosus was idlentified, transposed ventrally, and brought outside the retinaculum, without interrupting its continuity (Fig. 1). The retinaculum was then closed underneath, in sucl a way that the tendon was positioned over the MCL (Figs 2 and 3). After wound closure a well-padded splint was applied in $20^{\circ}$ flexion.

A similar technique for MCL repair was previously described by Bosworth for chronical medial instability (1).

\section{Results}

Al treated patients were seen for evaluation. Follow-up time was 10 to 33 months (mean 18.5 months). None of the patients experienced a complication of surgery. The mean time between injury and operation was 5.1 days (range 2-11 days). Mean hospitalization was 12.1 days (range 5-23 days). A total of 4 weeks of partial immobilization was used in isolated MCL lesions, and 4-12 weeks (mean 8.7 weeks) 

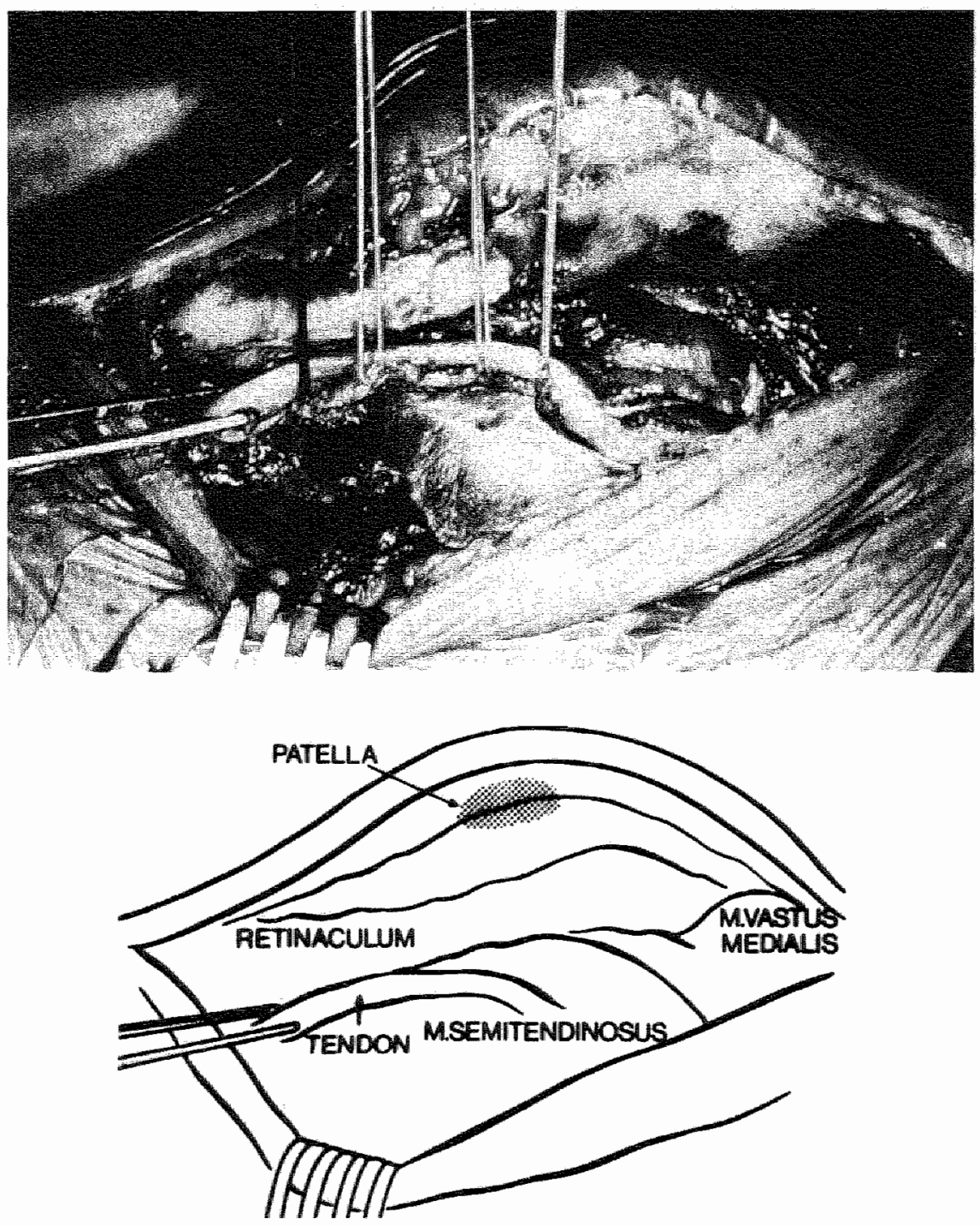

Fig. 1: Identification and transportation of the tendon of the semitendinosus.

in mixed lesions, based on the individual demands of the patient. Subjective results as measured with the Lysholm score were very good ; mean score 94.4, S.D. 8.3 points (max.100); in isolated lesions 96 (range 83-100); in mixed lesions 92.4 (range 75-100). The combined objective and subjective scoring using the Marshall score was 45.3, S.D. 2.9 (max.50), 14 patients good-excellent, and one fair. The lowest score optained was 39 in an elderly woman, age 72 , who had suffered an isolated 


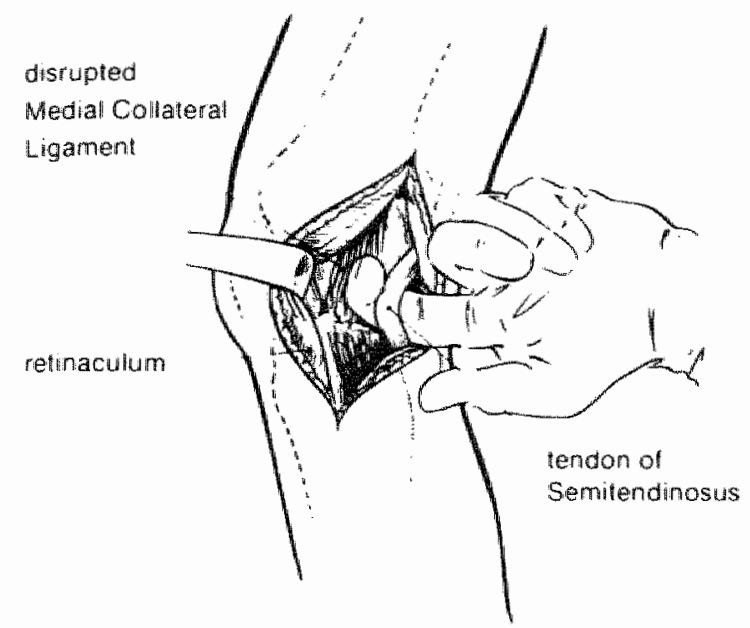

Fig. 2: MCL fibers are approximated. Subsequently the retinaculum is sutured underneath the transposed tendon of the semitendinosus.

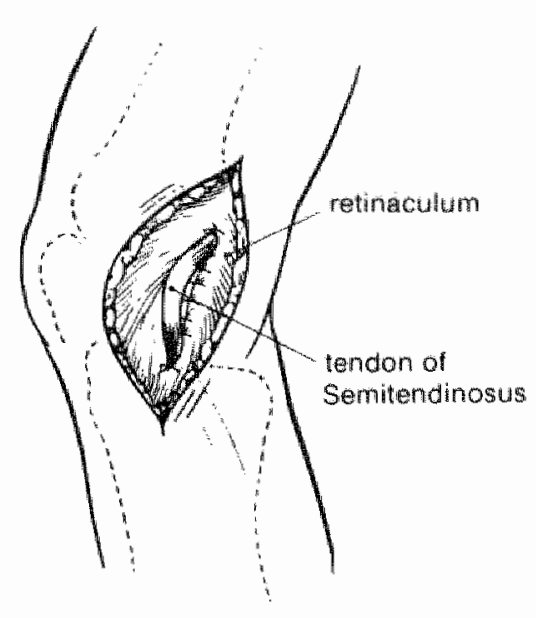

Fig. 3: Tendon of the semitendinosus ly. ing subcutaneously.

Table 1: MCL Scores (Marshall) in mixed, and isolated lesions

\begin{tabular}{lll}
\hline & $\begin{array}{l}\text { Isolated } \\
(\mathrm{n}=8)\end{array}$ & $\begin{array}{l}\text { Mixed } \\
(\mathrm{n}=7)\end{array}$ \\
\hline 5 (equal to opposite knee) & 2 & 1 \\
4 (mild instability in flexion) & 3 & 6 \\
$3 .($ moderate instability in flexion) & 2 & - \\
2 (instability in flexion and extension) & 1 & - \\
1 (gross instability) & - & - \\
\hline
\end{tabular}

M.C.L. lesion. At follow-up examination there was laxity of the restored M.C.L. in flexion as wel as in extension (rated in the score as $2 \mathrm{~B}$ ). She had, however, suprisingly few complains, and therefore she found the end result good. The MCL and ACL stability scores for the two groups (isolated, and mixed) are given in Table 1 and Table 2. Stability scores for ACL are not significantly better for identified 'isolated MCL lesions' compared with the mixed lesions.

All patients but one were able to return to their normal work in 3.8 months (range 1-12 months) after operation. Eleven patients participated in sports at the time of injury, six of them regained full activities, three limited or altered, and two had not regained full activities at the time of follow-up. No difference in strength was found between the affected leg as compared with its control. The results of the strength measurements are given in Table 3 . 
Table 2: ACL Scores (Marshall) in mixed, and isolated lesions

\begin{tabular}{lll}
\hline & $\begin{array}{l}\text { Isolated } \\
(n=8)\end{array}$ & $\begin{array}{l}\text { Mixed } \\
(n=7)\end{array}$ \\
\hline 5 (equal to opposite knee) & 1 & 1 \\
4 (slight jog when tested) & 5 & 5 \\
3 (moderato jog when tested) & 2 & 1 \\
2 (severe instability in reutral) & - & - \\
0 (severe in neutral and rotation) & - & - \\
\hline
\end{tabular}

Table 3: Maximum isokinetic strength of knee extension and flexion at different angular welocities $(\mathrm{n}=13)$. Values are means \pm S.D.

\begin{tabular}{rrr}
\hline Angular velocity & Affected leg & Controlleg \\
\hline Extension & & \\
$60^{\circ} \cdot \mathrm{s}^{-1}$ & $186.9 \pm 64.2$ & $187.9 \pm 61.7$ \\
$120^{\circ} \cdot \mathrm{s}^{-1}$ & $144.2 \pm 53.7$ & $142.8 \pm 50.8$ \\
$180^{\circ} \cdot \mathrm{s}^{-1}$ & $112.3 \pm 44.1$ & $115.7 \pm 44.4$ \\
$240^{\circ} \cdot \mathrm{s}^{-1}$ & $85.9 \pm 36.5$ & $89.7 \pm 34.0$ \\
$300^{\circ} \cdot \mathrm{s}^{-1}$ & $70.5 \pm 31.9$ & $72.3 \pm 28.1$ \\
& & \\
Fiexion & & \\
$60^{\circ} \cdot \mathrm{s}^{-1}$ & $137.2 \pm 61.6$ & $122.5 \pm 43.7$ \\
$120^{\circ} \cdot \mathrm{s}^{-1}$ & $114.9 \pm 49.1$ & $103.8 \pm 38.7$ \\
$180^{\circ} \cdot \mathrm{s}^{-1}$ & $99.5 \pm 41.2$ & $94.6 \pm 39.2$ \\
$240^{\circ} \cdot \mathrm{s}^{-1}$ & $84.3 \pm 37.9$ & $76.3 \pm 27.2$ \\
$300^{\circ} \cdot \mathrm{s}^{-1}$ & $71.9 \pm 33.0$ & $66.0 \pm 21.6$ \\
\hline
\end{tabular}

\section{Discussion}

In our series using the Marshall score, seven patients were graded good-excellent, and one one fair in the group with isolated lesions. These results are in accordance with the study of Indelicato, who had a $88 \%$ good-excellent result in operatively treated patients, and a $90 \%$ good-excellent result in conservatively treated patients in a population consisting merely of young students (3). For the isolated lesions our results equal those of his concervative treatment, so an operation cannot be considered anything but an alternative to concervative treatment (8). The combination of $\mathrm{MCL}$ and $\mathrm{ACL}$ lesions forms a generally accepted indication for operative treatment. Even with reconstruction the results are poor, only $39.7 \%$ good-excellent (2). The results using this rellatively simple technique for the combined MCL and $\mathrm{ACL}$ lesions in combination with primary suturing of the ACL, and early functional training seem to be hopeful, with all 7 patients rated as good. 
The mild to moderate laxity seems to be of little or no significance to the function of the joint. The good results of the isokinetic strength measurements might be credited for this finding. It supports the concept of knee joint stability as an interaction of both the passive (bone, ligaments, and capsule), and the active stabilizers (thigh musculature). We think that this stresses the importance of a functional rehabilitation, where preservation of muscle strength is the key. This agrees with Tegner in studies of chronic knee instability, who showed that muscular strenght has a close relationship with complains, and rehabilitated muscular stability will stay intact even in the presence of passive instability $(9,10)$. Using part of the hamstrings did not decrease its flexion strength (4).

We conclude that non-operative treatment provides good to excellent results in isolated MCL lesions, and with a concomitant ACL lesion the semitendinosus transposition is a relatively simple operation without complications. Laxity after this operation was mild, and not related to dysfunction. 


\section{References}

1 Bosworth DM: Transplantation of the semitendinosus for repair of laceration of medial collateral Higament of the knee.

I Bone Joint Surg 1952, 34A, 196-202

2 Fetto JF, Marshall JL: Medial collateral ligament injuries of the knee : a rationale for treatment. Clin Orthop 1978, 132, 206-218

3 Indelicato PA: Non operative treatment of complete tears of the medial collateral ligament of the knee.

J Bone Joint Surg 1983, 65 A, 323-329

4 Lipscomb AB, Johnston RK, Snyder RB, Warburton MJ, Gilbert PP: Evaluation of hamstring strength following use of semitendinosus and gracilis tendons to reconstruct the anterior cruciate ligament.

Am I Sports Med 1982, 10, 340-342

5 Lysholm J, Gillquist J: Evaluation of knee ligament surgery results with special emphasis on use of a scoring scalle.

Am J Sports Med 1982, 10, 150 154

6 Marshall IL, Fetto JF, Botero PM: Knee ligament injuries. A standardized evaluation method. Clin Orthop 1977, 123,115-129

7 Palmer l: On the injuries to the ligaments of the knee joint. A clinical study.

Acta Chir Scand, 1938, suppl 53

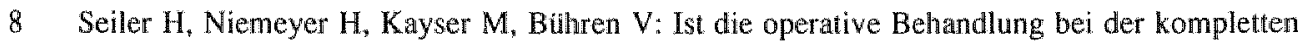
Innenbandruptur des Kniegelenkes notwendig?

Unfallchirurg $1987,90,180-185$

9 Tegner Y, Lysholm J, Gillquist J, Oberg B: Two-year follow-up of conservative treatment of knee ligament injuries.

Acta Orthop Scand 1984, 55, 176-180

10 Tegner $Y$, Lysholm J, Lysholm M, Gillquist J: Strengthening exercises for old cruciate ligament tears.

Acta Orthop Scand $1986,57,130-134$ 


\section{Chapter 7}

\section{General discussion}

The integration of therapeutic immobilization and functional treatment in the recovery after a knee injury is complex. On the one hand rest is advised to create optimal circumstances for molecular repair processes, and to protect the joint against reinjury due to poor control. The recovering tissues, on the other hand, need functional stimuli to adjust the molecular repair processes to the right mechanical structure (4). Protection of the joint by immobilization will oblige the surrounding intact structures like muscles, tendons, cartilage, and bone to inactivity, resulting in atrophy and functional deterioration. Both the initial treatment and the rehabilitation program should deal with this dualism of immobilization and functionality. This has led to the development of several partial immobilization and stabilization techniques. The evolution in surgical techniques (arthroscopic reconstructive surgery) towards firmer reconstruction and less surgical damage has led to a more aggressive early functional training after reconstructive surgery. The functional results are promising. The reduction of atrophy seems to play a major role in this success. However, the effects of complete and partial immobilization or stabilization on the functional properties of the leg have not been evaluated properly.

It is impossible to study the various elements of the rehabilitation process separately in patients. The use of the recovering knee joint depends on the severity of the injury, the type and duration of immobilization or stabilization, and also to a great extent on prescribed excercises, psychogenic factors, motivation, pain, or fear. The interference of these complex factors in the rehabilitation process are excluded in healthy subjects (5). Because the functional condition of the right and the left leg is similar, the effect of immobilization or stabilization can be studied by comparing the supported leg with the control leg. In this thesis the effects of three different commonly applied immobilization and stabilization techniques on thigh muscle performance were studied in healthy subjects with functional tests. These tests include walking, running, and jumping, but also isokinetic muscle strength testing. Another aspect in knee rehabilitation, that has got poor attention sofar, is the 
endurance capacity of the quadriceps muscle. In this thesis a new protocol is introduced to measure the aerobic power of the quadriceps muscle as a parameter for endurance. The last chapter of the thesis deals with the treatment of knee injuries and the results of a functional treatment schedule.

The first study (chapter 2) deals with functional testing in the rehabilitation phase after a knee injury. The isokinetic strength testing has proved to be a safe and reliable method in the rehabilitation after a knee injury. Surprisingly only little attention is given to endurance testing, leading to an underestimation of the problem of deterioration of the endurance capacity (2). The tests described in the literature that deal with endurance are all based on anaerobic exercise. However, the aerobic power is felt to be a better parameter for endurance. The test protocol we describe to measure the maximal aerobic power of the quadriceps (Pmax) is reproducible (test- retest correlation $r=0.82$ ) and relatively simple, and can be performed on standard isokinetic equipment. The uninjured leg can be used as the controle, since there is a natural equivalence of both legs (left-right correlation $r=0.94$ ). The test results are speed and device specific, and since there is no correction for gravity acting on the leg and lever system, the results can only be used for intra-subject comparisons. The measurement of Pmax increases the insight into the rehabilitation process, and can be used to adjust the individual rehabilitation program.

In chapter 3 the effect of a functional knee brace on the performance of the thigh muscles is evaluated. Many patients with complaints of giving-way benefit from the use of functional knee braces. The number of near-injuries, or symptoms of givingway are less. Patients feel more secure during sporting activities. Bracing may enhance performance in patients (1). Most of the symptoms of giving-way are encountered at higher levels of physiologic loading, and are therefore related to sports and less to activities of normal daily living. The main function of a knee brace is to support the knee at high physiologic loads. There is a widespread belief in sports and sportsmedicine, that supplying external mechanical support to the knee results in disuse atrophy. The results of the study presented in chapter 3 , in the contrary, show that the muscular performance is not impaired by bracing. Only on the first day of application there is a slight decline of the performance parameters. Sprinting time at $60 \mathrm{~m}$ dash is $4 \%$ slower, and $\mathrm{Vmax}$ is $6 \%$ slower. Peak torque (PT; Nm) at isokinetic strength measurements of knee flexion and knee extension are up to $9 \%$ lower. While wearing the brace for four weeks the performance parameters return to their base values. After the period of brace application the subjects are retested with similar results at maximal performance. These results contradict the persistent believe in the world of sports, that bracing will "weaken" the knee. 
In chapter 4 the effect of a hinged cast-brace on leg performance is evaluated. A cast-brace is applied in the treatment of some knee injuries as an alternative to a cylinder or long leg cast for some conditions. It provides limited immobilization and external support, limiting the normal function of the subject to some extent. Activities that require a large Range of Motion or movements at high angular velocities are virtually impossible. Wearing a cast-brace will therefore result in some disuse or detraining. The results of the study presented in chapter 4 show that wearing a hinged cast-brace gives rise to an increased energy consumption. Oxygen uptake and heart rate are slightly raised (average $9 \%$ and $7 \%$, respectively) at a submaximal uphill walk exercise, probably due to the weight of the cast-brace (approximately $1 \mathrm{~kg}$ ). After removal of the cast-brace the performance parameters return to their base values. This indicates that the expected decline in performance due to disuse/detraining was negated by the training effect due to carrying the weight of the cast-brace. It is concluded that wearing a hinged cast-brace does not result in muscular atrophy. This is a serious argument for the use of a hinged cast-brace instead of cast-immobilization.

In chapter 5 the effect of immobilization in a long leg cast on the thigh muscles is demonstrated. Cast-immobilization is often applied after knee injury or surgery. Immobilization has serious negative effects on the thigh muscles, resulting in muscle atrophy. This muscle atrophy is related to impaired functional recovery, and is hard to treat (3). The present study shows that four weeks of cast-immobilization has a dramatic negative effect on the thigh muscles; the quadriceps cross-sectional area decreases $21 \%$, the muscle fiber diameter $16 \%$, PT of knee extension $53 \%$ and of flexion $26 \%$, and $\mathrm{Pmax} 27 \%$. Immobilization is the most important factor in the development of muscle atrophy. It overshadows all other factors that induce muscle atrophy after knee injury. Reduction of immobilization time or replacing immobilization with stabilization techniques is therefore the key factor in the prevention of posttraumatic muscle atrophy.

In chapter 6 we report the results of a functionally-operative treatment of grade III $M C L$ lesions, isolated or with concomitant ACL injury. This treatment combines a simple operative technique with a functional rehabilitation, that is focused on maintaining normal function. Cast-immobilization is limited to two weeks, followed by an additional 4-12 weeks of hinged cast-bracing with full weight bearing. Surgical treatment is also limited, but it immediately provides some stability, enabling a fast return to normal function. This treatment regimen results in a successful recovery even in the serious mixed ACL-MCL ligamentous lesions. At follow-up 14 of the 15 patients revealed good or excellent results with no signs of muscle atrophy at final evaluation. This study links the findings of previous studies in healthy subjects and traumatologic practice. It shows that treatment, aimed at functional recovery instead 
of mechanical stability, can have a good functional result. The present evolution in surgical skills and materials (arthroscopic surgery) will increase the possibilities of functional rehabilitation, and thus prevent muscle atrophy, and further improve the results of treatment.

Several functional tests are used in the evaluation of the immobilization and stabilization techniques. The sensitivity of these test show a wide variation. The tests that specificly load the thigh muscles have a better sensitivity for deterioration of performance. The changes in performance capacity are best shown by the isokinetic strength measurements. The maximal aerobic power is also useful to detect the decline in endurance capacity. The one-leg-cycling test, on the other hand, shows no differences after four weeks of immobilization, and is thus useless to study this effect. The tests that rely on the performance of both legs, and crural, thigh, and gluteal muscle groups (high-jump, sprinting, treadmill running) are not useful to detect small changes in performance due to compensation by other muscle groups. Isokinetic strength and endurance parameters are therefore the best functional indicators of thigh muscle deterioration. 


\section{References}

1 Cook FF, Tibone JE, Redfern FC: A dynamic analysis of a functional knee brace for anterior cruciate ligament insufficiency.

Am J Sports Med 1989, 17, 519-524

2 Costill DL, Fink WJ, Habanski AJ: Muscle rehabilitation after knee surgery.

Physician Sportsmed 1977, 5,71-74

3 Eriksson E: Rehabilitation of muscle function after sport injury. Major problem in sports medicine.

Int J Sports Med 1981, 2, 1-6

4 Gomez MA, Woo L-Y, Inoue M. Amiel D, Harwood FL, Kitabayashi L: Medial collateral ligament healing subsequent to different treatment regimens.

J Appl Physiol 1989, 66, 245-252

5 Halkjaer-Kristensen J, Ingemann-Hansen T: Wasting and training of the human quadriceps muscle during the treatment of knee ligarnent injuries. General introduction.

Scand J Rehabil Med 1985, Suppl 13,3 



\section{Chapter 8}

\section{Summary and conclusions}

Cast-immobilization is frequently applied in the treatment of knee injuries. The indications and consequences of immobilization are discussed in chapter 1. To avoid muscle atrophy treatment schedules are adjusted towards shorter periods of immobilization. After that the joint is protected by stabilization techniques. The results of these early functional treatment regimens are promising. In the development of the early functional treatment regimens it is important to know, what the influence of immobilization and these stabilization techniques is on thigh muscle atrophy. The present study quantifies the effects of immobilization and stabilization on the thigh muscles. We used functional tests and isokinetic strength measurements to evaluate the effects on performance. A test protocol to measure the maximal aerobic power of the quadriceps is introduced for the evaluation of the endurance capacity of the quadriceps muscles. Finally the results are reported of a follow-up study of an early-functional treatment regimen in patients suffering a serious knee ligament injury.

The test protocol to measure the maximal aerobic power of the quadriceps as a parameter of the endurance capacity is introduced and evaluated in chapter 2 . The test consists of a stepwise increase in exercise on an isokinetic dynamometer until exhaustion. The reproducibility of the test is fairly good (test-retest correlation $r=0.82$ ). The test is especially suitable for use in rehabilitation settings, comparing the injured leg with the uninjured leg (left-right correlation r=0.94). Finally recommendations are made for practical application of the test. The effects on thigh muscle performance of two stabilization techniques (functional knee brace and cast-brace), and cast-immobilization are described in chapters 3-5. The tests were performed on healthy subjects in order to rule out the interfering effects of injury, and to make preand post-application comparisons. The period of application was four weeks in all three studies. The functional knee brace (Push Brace 'Heavy' (B)' impaired performance slightly on the first day of application (Table 1). This effect diminished after familiarization, and after removal of the brace all tests results returned to their base 
Table 1: Findings at the tests during and after 4 weeks of application (= no significant changes; $\downarrow$ and $\uparrow$ significan decrease, respectively increase as compared with base walues; np not performed).

\begin{tabular}{|c|c|c|}
\hline & during & after \\
\hline \multicolumn{3}{|l|}{ knee brace } \\
\hline muscle strength & $9 \% \downarrow$ & $=$ \\
\hline submax treadmill exercise ( $\mathrm{HR}, \mathrm{VO}_{2}, \mathrm{PLa}$ ) & $=$ & HR $6 \%$ \\
\hline maximal runing speed & $6 \%+$ & $=$ \\
\hline $60 \mathrm{mdash}$ & $4 \% 1$ & $=$ \\
\hline jurnp height & $=$ & $=$ \\
\hline \multicolumn{3}{|l|}{ cast-brace } \\
\hline muscle strength & np & $=$ \\
\hline submax hoilzontal treadmill running & $\mathrm{np}$ & $=$ \\
\hline maximal running speed & $n p$ & $=$ \\
\hline $60 \mathrm{~m}$ dash & np & $=$ \\
\hline jump height & np & $=$ \\
\hline \multirow[t]{2}{*}{ submax uphill walk test } & $\mathrm{VO}_{2} 9 \% \uparrow$ & $=$ \\
\hline & HR $7 \%$ & $=$ \\
\hline \multicolumn{3}{|l|}{ cast-immobilization } \\
\hline muscle strength & np & quadriceps $53 \% \downarrow$ \\
\hline & & hamstrings $27 \%$ \\
\hline maximal aerobic power & $n$ & quadriceps $21 \% \downarrow$ \\
\hline one-leg-cycling & $n p$ & $=$ \\
\hline quadriceps circumiference & np & $21 \% \downarrow$ \\
\hline muscle fiber diameter & $n$ & quadriceps $16 \% \downarrow$ \\
\hline
\end{tabular}

values. The conclusion was that the brace did not affect performance. Application of a cast-brace (weight approximately $1 \mathrm{~kg}$ ) resulted in an increased energy expenditure as determined in a progressive uphill walk test on the treadmill (Table 1). Oxygen uptake $\left(\mathrm{VO}_{2}\right)$ and heart rate (HR) rose by $9 \%$, and $7 \%$, respectively. $\mathrm{VO}_{2}$ decreased after four weeks of cast-brace application, but remained slightly elevated (4\%). After removal of the cast-brace no negative consequences of the application were observed during the exercise tests. According to expectation cast-immobilization resulted in a measurable muscle atrophy. The mean decreases in quadriceps circumference and muscle fiber diameter were $21 \%$ and $16 \%$. Muscle strength decreased considerably more than the morphological parameters (Table 1). The decline of the maximal aerobic power indicated that the endurance capacity of the quadriceps had decreased.

In chapter 6 the results of the treatment of grade III Medial Collateral Ligament (MCL) ruptures are evaluated, isolated $(n=8)$, or with concomitant Anterior Cruciate Ligament rupture $(n=7)$. The initial treatment consisted of limited surgical treatment with reconstruction of the ruptured ligaments and reinforcement of the MCL by 
means of a semitendinosus transfer. The purpose of the semitendinosus transfer was to increase stability, enabling early functional training. Postoperatively a splint was applied for two weeks, followed by 4-12 weeks of cast-brace application to protect the joint. At follow-up 14 of the 15 patients had good to excellent results as graded by the Marshall score and muscle strength testing of hamstrings and quadriceps.

\section{Conclusions}

Isokinetic muscle strength and endurance tests are the most sensitive parameters for the evaluation of the functional status of the thigh muscles after injury or immobilization. From these tests we learn that cast-immobilization gives rise to a fast and dramatic deterioration of thigh muscle performance. The extent of the observed deterioration makes it clear that immobilization is the key factor in the development of posttraumatic immobility-induced muscle atrophy. Thigh muscle performance is not impaired by stabilization of the knee allowing weight bearing and movement. This leads to the conclusion that, considering the type of injury and the individual patient, immobilization should be replaced by stabilization to enable early functional treatment. This allows an active treatment of posttraumatic immobility-induced atrophy. 



\section{Chapter 9}

\section{Samenvatting en conclusies}

Gipsimmobilisatie wordt veelvuldig toegepast bij de behandeling van knieletsels. In hoofdstuk 1 worden de indicaties en de gevolgen van immobilisatie besproken. Gezien het ontstaan van spieratrofie wordt er steeds meer overgegaan tot kortdurende immobilisatie gevolgd door toepassing van stabiliserende technieken. De resultaten van deze vroeg-functionele behandelingen zijn hoopvol. Voor de verdere ontwikkeling van dergelijke behandelingsprotocollen en voor de invulling van het nabehandelingsschema is het belangrijk te weten in hoeverre deze immobiliserende en stabiliserende technieken bijdragen tot het ontstaan van spieratrofie. Dit kwantificerend onderzoek is het onderwerp van dit proefschrift. Bij de evaluatie van de drie onderzochte immobilisatie en stabilisatie technieken hebben wij gebruik gemaakt van functionele metingen van het prestatievermogen. Dil zijn bestaande testen uit de sport en de sportmedische praktijk en een isokinetische spierkrachtmeting. Om de gevolgen voor het uithoudingsvermogen van de geimmobiliseerde spieren te kunnen meten, hebben we een protocol ontwikkeld voor de bepaling van het maximale aerobe vermogen van de quadriceps. Tenslotte wordt verslag gedaan van een follow-up onderzoek van een vroeg-functionele behandeling van patiẻnten die een ernstig knieletsel hebben doorgemaakt.

In hoofdstuk 2 wordt een protocol beschreven en geëvalueerd om het maximale aerobe vermogen van de quadriceps te meten. Het protocol bestaat uit cen stapsgewijs oplopende belasting op een isokinetische dynamometer tot opgave. De beschreven test blijkt reproduceerbaar te zijn (test- hertest correlatie $r=0,82$ ) en is vooral bruikbaar voor links-rechts vergelijking (links- rechts correlatie $r=0,94$ ). Tot slot worden er aanbevelingen gedaan voor uitvoering van de test en voor toepassing in de revalidatie.

In de hoofdstukken 3 tot en met 5 worden de effecten van een tweetal stabiliserende technieken en van volledige immobilisatie op de prestatie van de bovenbeensmusculatuur geëvalueerd. De testen zijn steeds gedaan bij gezonde proefpersonen om 
Tabel 1: Voornakmste bevindingen van metingen tijdens en na 4 weken interventie. (= geen significante veranderingen ten opzichte van uitgangswaardes, $\downarrow$ en $\uparrow$ significante daling respectievelijk stigging ten opzichte van de uitgangswaardes, nw niet verricht)

\begin{tabular}{|c|c|c|}
\hline & tijdens & na \\
\hline \multicolumn{3}{|l|}{ kniebrace } \\
\hline spierkracht & $9 \%$ & $=$ \\
\hline loopband submax (HR, VO $\left.{ }_{2}, \mathrm{PLa}\right)$ & $=$ & $\mathrm{HR} 6 \%$ \\
\hline maximale loopsnelheid & $6 \% \downarrow$ & $=$ \\
\hline 60 m sprint & $4 \% \downarrow$ & $=$ \\
\hline sprong hoogte & $=$ & $=$ \\
\hline \multicolumn{3}{|l|}{ scharniergips } \\
\hline spierkracht & nv & $=$ \\
\hline loopband horizontaal submax. & nv & $=$ \\
\hline maximale loopsneltheid & $n v$ & $=$ \\
\hline $60 \mathrm{~m}$ sprint & n. & $=$ \\
\hline sprong hoogte & nv & $=$ \\
\hline \multirow[t]{2}{*}{ loopband stijgend submax } & $\mathrm{VO}_{2} 9 \% \uparrow$ & $=$ \\
\hline & HR $7 \%$ & $=$ \\
\hline \multicolumn{3}{|l|}{ bovenbeensgips } \\
\hline spiertkracht & nv & $\begin{array}{l}\text { quadriceps } 53 \% \downarrow \\
\text { hamstrings } 27 \% \downarrow\end{array}$ \\
\hline maximat aeroob vermogen & DVy & quadriceps $21 \%$ \\
\hline one-Jeg-cycling & $\mathrm{nV}$ & $=$ \\
\hline quadricepsomvang & nv & $21 \% \downarrow$ \\
\hline spiervezel diameter & nv & quadriceps $16 \% \downarrow$ \\
\hline
\end{tabular}

voor- en nametingen te kunnen verrichten en om bias door letsel te vermijden. De interventie periode was steeds 4 weken.

De functionele kniebrace (Push Brace 'Heavy' blijkt in de cerste periode na het aanleggen een licht negatieve invloed te hebben op de prestatie (Tabel 1). $\mathrm{Na}$ gewenning is dit effect verdwenen en na afloop van de interventie periode blijkt bij metingen zonder brace, dat er geen nadelige gevolgen zijn van het dragen.

Het dragen van een scharniergips met een gewicht van $1 \mathrm{~kg}$ kost extra energie, zoals blijkt tijdens een stijgend loopband onderzoek (Tabel 1). De zuurstofopname $\left(\mathrm{VO}_{2}\right)$ en de hartslag (HR) zijn 9\% en 7\% gestegen. Na enkele weken neemt dit effect weer wat af en is de $\mathrm{VO}_{2}$ tijdens belasten nog slechts $4 \%$ gestegen. Na afname van het scharniergips zijn er geen nadelige gevolgen meer te meten.

Het dragen van een bovenbeensgips leidt geheel volgens de verwachtingen tot spieratrofie. De quadriceps omvang en spiervezel diameter nemen $21 \%$ en $16 \%$ af. De afname van de spierkracht is nog beduidend groter dan de morfologische achteruitgang (Tabel 1), Het uithoudingsvermogen van de quadriceps verslechtert ook, zoals blijkt uit de achteruitgang van het maximale aerobe vermogen van $21 \%$. 
In hoofdstuk 6 word het resultaat geëvalueerd van de behandeling van 15 patiënten met een volledige ruptuur van de mediale collaterale band $(\mathrm{MCL} ; \mathrm{n}=8)$, al dan niet in combinatie met een voorste kruisband ruptuur ( $\mathrm{ACL} ; \mathrm{n}=7$ ). De behandeling bestond uit een beperkte chirurgische ingreep met overhechting van de gelaedeerde structuren en een semitendinosusplastiek. Deze ingreep had tot doel om direct een zodanige stabiliteit te krijgen, dat een vroeg-functionele behandeling verder mogelijk was. Deze nabehandeling bestond uit 2 weken gipsimmobilisatie gevolgd door 4-12 weken bescherming met een scharniergips. Bij evaluatie hadden 14 van de 15 patiënten een goed of uitstekend resultaat volgens het Marshall scoringssysteem. De spierkracht van hamstrings en quadriceps was bij nacontrole goed vergeleken met het niet-aangedane been.

\section{Conclusies}

Voor de evaluatie van de status van de bovenbeensmusculatuur na een knieletsel of immobilisatie zijn isokinetische metingen van spierkracht en uithoudingsvermogen de meest gevoelige parameters. Hierbij blijkt, dat volledige immobilisatie leidt tot een snelle en dramatische achteruitgang van het prestatievermogen van de bovenbeenspieren. Uit de mate van deze achteruitgang blijkt, dat immobilisatie de belangrijkste factor is in de ontwikkeling van posttraumatische immobiliteitsatrofie. De beide stabiliserende technieken, die hier getest zijn (kniebrace en scharniergips), hebben geen nadelige invloeden op de bovenbeenspieren. Op grond hiervan moet gesteld worden, dat er bij de behandeling van knieletsels gestreefd moet worden naar vervanging van immobilisatie door stabiliserende technieken, dit met inachtname van het letsel en de individuele patiënt. Pas dan is een actieve bestrijding van posttraumatische immobiliteitsatrofie mogelijk. 



\section{Dankwoord}

Als ik iemand vertel dat dit proefschrift voltooid is, krijg ik direkt de vraag hoelang ik er wel niet mee bezig geweest ben. Om eerlijk te zijn weet ik het niet meer. Toen ik in 1986 in dienst trad van de vakgroep Algemene Heelkunde van het AZM was het onder andere de bedoeling om onderzoek te gaan doen met de isokinetische dynamometer van de vakgroep Bewegingswetenschappen. Dit onderzoek werd gestimuleerd door Jouwert Stapert, Cees-Rein van den Hoogenband en Frans Verstappen en mede uitgevoerd door Fred Koene. Na aan enkele andere onderzoeken te hebben deelgenomen kreeg de in dit proefschrift beschreven onderzoekslijn vanuit de praktijk van de "sportpoli" geleidelijk meer gestalte en groeide uit tot een waar promotieonderzoek. Het is daarom gelukkig niet goed meer aan te geven wanneer het onderzoek begonnen is. Duidelijk is het evenwel dat ik velen dank verschuldigd ben voor hun medewerking aan het onderzoek en de afronding ervan:

de proefpersonen die zich moeiteloos aan de vreemde en vermoeiende onderzoeken onderworpen,

Co Greep en Frans Verstappen mijn promotor en co-promotor die over een eindeloos geduld bleken te beschikken,

Fred Koene, Harry Wandler en Mascha Twellaar die enthousiast aan de experimenten hebben meegewerkt,

Harm Kuipers en Maarten Drost die hun specifieke deskundigheid met mij wilden delen,

de chirurgen, gipsmeesters en assistentes van de "sportpoli" die ook steeds bereid waren aan de onderzoeken mee te werken en met wie ik een hele fijne tijd heb gehad, Rodney Price die het engels gecorrigeerd heeft,

Victor Kaiser en John Husken die mij in de afrondingsfase in de gelegenheid hebben gesteld om de tijd ervoor vrij te maken naast de andere arbeidsbeslommeringen, Joke die mij heeft doen doorzetten in de afronding van het onderzoek, Vera en Inge die mij af en toe wel een avond lieten werken en een nacht lieten slapen. 


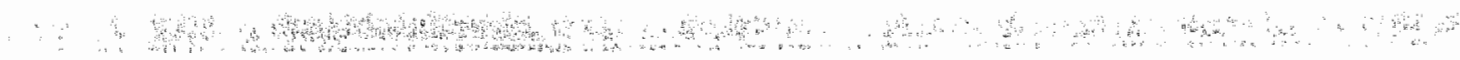




\section{Curriculum Vitae}

$1959 \quad$ Geboren 21 juli te Naaldwijk

1971-1977 VWO, Rijswijkse Openbare Scholengemeenschap

1977-1983 Studie Geneeskunde, Rijksuniversiteit Limburg, Maastricht

1983 Artsexamen, Rijksuniversiteit Limburg, Maastricht

1983-1984 Assistent Geneeskundige niet in opleiding Vakgroep Algemene Heelkunde Academisch Ziekenhuis Maastricht (hoofd Prof.dr. J.M. Greep)

1984 Onderzoeksassistent Vakgroep Inspanningsfysiologie Rijksuniversiteit Limburg, Maastricht (hoofd dr. F.T.J. Verstappen)

1985 Huisarts in opleiding Rijksuniversiteit Limburg, Maastricht

1986-1989 Onderzoeksassistent traumatologie Vakgroep Algemene Heelkunde Academisch Ziekenhuis Maastricht (hoofd Prof.dr. J.M. Greep)

1987-heden Adviseur NEA-International, Maastricht, fabrikant van Push Braces ${ }^{\circledR}$

1989-heden Huisarts te Eygelshoven in samenwerking met V. Kaiser

1991 -heden Directeur-eigenaar Medisch Expertise Buro Maastricht

1994 heden Toegevoegd onderzoeker RNH project Vakgroep Huisartsgeneeskunde Rjjksuniversiteit Limburg, Maastricht 

The publication of this thesis was financially supported by Abbott B. V. Bristol- Myers- Squibb, Christiaems B.V. Ciba- Geigy B.V., Glaxo B.V., Janssen Pharmaceutica B.V., NEA Internationa! B. V., Organon Nederland B.V. Schering Nederland B.W., Searle Nederland B.V., UCB Pharma B. V., Wellcome Pharmaceuticals B.V. and Yamanouchi Pharma B.V. 